\title{
Impact Evaluation of I am Moving, I am Learning Using the RE-AIM Framework
}

Ishonte Allar

Follow this and additional works at: https://researchrepository.wvu.edu/etd

\section{Recommended Citation}

Allar, Ishonte, "Impact Evaluation of I am Moving, I am Learning Using the RE-AIM Framework" (2015). Graduate Theses, Dissertations, and Problem Reports. 5074.

https://researchrepository.wvu.edu/etd/5074

This Dissertation is protected by copyright and/or related rights. It has been brought to you by the The Research Repository @ WVU with permission from the rights-holder(s). You are free to use this Dissertation in any way that is permitted by the copyright and related rights legislation that applies to your use. For other uses you must obtain permission from the rights-holder(s) directly, unless additional rights are indicated by a Creative Commons license in the record and/ or on the work itself. This Dissertation has been accepted for inclusion in WVU Graduate Theses, Dissertations, and Problem Reports collection by an authorized administrator of The Research Repository @ WVU.

For more information, please contact researchrepository@mail.wvu.edu. 


\title{
Impact Evaluation of I am Moving, I am Learning \\ Using the RE-AIM Framework
}

\author{
Ishonté Allar \\ Dissertation submitted to the College of Physical Activity and Sport Sciences \\ at West Virginia University \\ in partial fulfillment of the requirements \\ for the degree of \\ Doctor of Philosophy in \\ Kinesiology \\ Sean Bulger, Ed.D., Chair \\ Eloise Elliott, Ph.D. \\ Emily Jones, Ph.D. \\ Alfgeir Kristjansson, Ph.D. \\ Andrea Taliaferro, Ph.D. \\ Department of Coaching and Teaching Studies \\ Morgantown, West Virginia \\ 2015
}

Keywords Physical Activity, Nutrition, Preschool, Family Engagement, Head Start, I am Moving I am Learning

Copyright 2015 Ishonté Allar 


\section{Abstract \\ Impact Evaluation of I am Moving, I am Learning Using the RE-AIM Framework}

Ishonté Allar

Background: Presently, there are a lack of preschool physical activity and nutrition programs documented in the literature. I am moving, I am Learning (IMIL) is a preschool physical activity and nutrition program used by many Head Start programs across the nation. The purpose of this study was to determine the reach, effectiveness, adoption, implementation, and maintenance (RE-AIM) of IMIL in the state of Illinois.

Methods: Employing a QUAL+ quan simultaneous mixed-methods design, data were collected via a statewide agency administrator survey, classroom teacher survey, parent surveys, and program staff focus groups that occurred within a single program in Rock Island, Illinois.

Results: IMIL has reached $60.8 \%$ of Head Start classrooms $(n=941)$ in the state of Illinois. Teachers reported the effectiveness of IMIL in a number of areas including knowledge, behavior, and student learning. Sixty-two point two percent of Head Start agencies have classrooms that adopted IMIL exposing at least 7,867 families. Classrooms have implemented IMIL strategies in a variety of ways using its resources for classroom instruction, menu planning, lessons plans, parent engagement, music, assessment, print materials, and community collaboration to engage families and communities in Epstein's six types of involvement (parenting, communicating, decision making, volunteering, community collaboration, and learning at home). Of the administrative survey respondents, 52\% had used IMIL for 1-5 years, while another $26 \%$ had used it for 6-10 years. Administrators identified the following reasons for the sustainability of IMIL: aligns in with goals and policies, enjoyment, resources, informational, positive results, training, easy implementation, and flexibility.

Conclusion: Use of IMIL can meet the initiatives and goals of the Head Start National Center on Health and National Center on Parent, Family, and Community Engagement and has potential to meet the benchmark domains of the National Center on Quality Teaching and Learning's Classroom Assessment Scoring System (CLASS). Teachers, children, and families appreciate IMIL and the impacts it has made on their lives. 


\section{Dedication}

This work is dedicated to my grandparents the late Guy Morris and June Hidelia Johnson. I am eternally grateful for their love and support, along with the occasional spoiling that can only come from grandparents. Seeing their perseverance in obstacles that they faced in their lives helped mold and shape me into the mother, wife, friend, and person that I am today. You are deeply missed!

I also dedicate this work to my family. I am thankful to my husband Justin for his love and support, believing in me, and pretending to understand my research to make me feel better. I would also like to thank my two beautiful boys. I began the journey with an infant and end it with one, as well. To Zane and Kai, Mommy loves you and thank you for the smiles, laughs, and joy that you've brought to my life! 


\section{Acknowledgements}

Thank you to everyone who has helped me be successful and meet my goals throughout this whole process. From kind words to advice, your support and guidance have truly helped me grow.

First and foremost, I would like to thank God, with whom all things are possible. Next, I would like to thank my committee: Dr. Eloise Elliott, Dr. Emily Jones, Dr. Andrea Taliaferro, Dr. Alfgeir Kristjansson, and my chair, Dr. Sean Bulger. Dr. Elliott, thank you for your friendship, guidance (via many text messages), and becoming part of my family. Dr. Jones, thank you for providing your wisdom and expertise with qualitative analysis. To Doctors Taliaferro and Kristjansson, thank you for your insightful comments and suggestions throughout this entire process. Last but certainly not least, to Dr. Bulger, my chair, thank you so much for your time and dedication over the past few years. You have taught me to be more confident in my academic skills and have helped greatly improve my technical writing skills. You have been an amazing mentor and I have learned a lot from you that I will take with me as I move on to becoming a faculty member (most notably humor and patience).

Special acknowledgements to Doctors Sam Zizzi and Constinia Charbonnette. To Dr. Zizzi, thank you for introducing me to the RE-AIM framework and pushing me in dissertation seminar so that I could graduate sooner than I expected. To Dr. Charbonnette, thank you for your love, support, and the best advice along this journey. Thank you both for believing in me.

I would also like to thank Dr. Carson and Choosy Kids, Marilyn Arp, Sue Gaon of Lakeshore Learning, and the Division of Diversity, Equity, and Inclusion. To Dr. Carson thank you for the support from you and your staff and this opportunity. Marilyn, thank you for providing access to the teachers, children, and parents of Rock Island Head Start. You all do an amazing job! Sue Gaon for providing gift card incentives and the Division of Diversity, Equity, and Inclusion at West Virginia University for funding my research.

Special thanks to fellow doctoral students Kristi Wyant, Shanequa Smith, Aaron Goodson, Lindsay Hammond, Jun Baek, and Jamie Gilbert for helping me in areas that I was weak, proofreading my work, and being a strong support system. I'd also like to thank Dairy Queen for its amazing ice cream (especially the confetti cake blizzard) and getting me through some tough times.

Finally, I would like to thank the following people for their kind words, encouraging conversations, and smiling faces: Dr. Valerie Wayda, Dr. Krystal Frazier, Kim Mocniak, Robin McKinney, Tracy Wheeler, Carol Straight, Sherry Binion, Dr. Floyd Jones, and Dr. Brooks. 


\section{Table of Contents}

$\begin{array}{ll}\text { Introduction } & 1\end{array}$

$\begin{array}{lr}\text { Purpose Statement } & 6\end{array}$

$\begin{array}{lr}\text { Method } & 8\end{array}$

$\begin{array}{lr}\text { Research Design } & 8\end{array}$

$\begin{array}{lr}\text { Participants } & 8\end{array}$

$\begin{array}{lr}\text { Instrumentation } & 8\end{array}$

$\begin{array}{ll}\text { Administrative Procedures } & 9\end{array}$

$\begin{array}{ll}\text { Data Analysis } & 11\end{array}$

Results \& Discussion 12

$\begin{array}{ll}\text { Reach } & 12\end{array}$

$\begin{array}{ll}\text { Effectiveness } & 12\end{array}$

$\begin{array}{ll}\text { Adoption } & 14\end{array}$

$\begin{array}{ll}\text { Implementation } & 16\end{array}$

$\begin{array}{ll}\text { Maintenance } & 18\end{array}$

Limitations \& Future Directions 20

$\begin{array}{ll}\text { Conclusion } & 20\end{array}$

$\begin{array}{ll}\text { References } & 22\end{array}$

$\begin{array}{lr}\text { Tables } & 26-45\end{array}$

Appendix A Review of Literature 46-111

Appendix B Agency Administrator Survey Cover Letter 112

Appendix C Classroom Teacher Survey Cover Letter 113

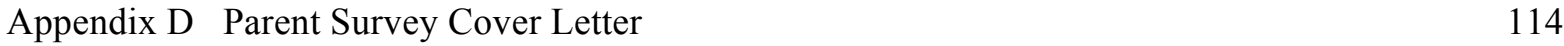

Appendix E Focus Group Protocol 115-116

$\begin{array}{lrr}\text { Appendix F Letters of Support } & 117-118\end{array}$

Appendix G Curriculum Vitae 119-120 


\section{Introduction}

Physical activity (PA) offers numerous benefits related to improved health and quality of life.

These mental, physical, and cognitive benefits include promotion of healthy growth and development, lower body fat, increased muscle and bone strength, enhanced cardiovascular and metabolic health, decreased anxiety, and higher self-esteem (Institute of Medicine, 2013). In 2008, the initial U.S. physical activity guidelines were released reiterating the promotion of PA as a public health priority (Pate \& O'Neill, 2012). This landmark report includes the following recommendations specific to school-aged children and adolescents: (a) accumulation of 60 minutes or more of moderate-to-vigorous physical activity (MVPA) each day; (b) use of aerobic, muscle strengthening, and bone strengthening activities; and (c) participation in a variety of enjoyable and developmentally appropriate alternatives (U.S. Department of Health and Human Services, 2008). Although direct relationships between childhood and adult PA are not yet well understood, the PA and exercise patterns established in childhood are thought to carry over into adulthood (Harris et al., 1997; Moore, Lombardi, White, Campbell, Oliveria, \& Ellison, 1991; Trost, Sirard, Dowda, Pfeiffer, \& Pate, 2003).

While the previously referenced guidelines exclude children under the age of six due to the limited scientific consensus linking PA and health outcomes at this developmental level, several organizations have proposed recommendations based on the best available research (Pate, Pfeiffer, Trost, Ziegler, \& Dowda, 2004). The National Association for Sport and Physical Education indicates that children between the ages of three and five require at least 60 minutes of structured and 60 minutes of unstructured PA each day (Pate \& O’Neill, 2012). The Caring for Our Children National Health and Safety Performance Standards maintain that children in this age group should receive 90-120 minutes of MVPA per every eight hours (Pate \& O’Neill, 2012). Furthermore, the Commonwealth of Australia Department of Health and Ageing asserts that toddlers and preschoolers should be active for at least three hours spread throughout the day (Pate \& O'Neill, 2012). The Institute of Medicine (IOM) recommends that childcare providers offer access to opportunities for light, moderate, and vigorous PA at least 15 minutes per hour, which is equivalent to 3 hours over a 12-hour period. Four Chief Medical Officers in 
the United Kingdom recommend the accumulation of at least 180 minutes ( 3 hours) across the day (Pate et al., 2004). Despite the existence of these guidelines for preschool-aged children, the available data support that the recommended amounts of PA are not being met (Pate et al., 2004).

Because preschool children are not meeting the recommended amounts of PA, Pate et al. (2013) identified ten important research questions regarding the study of preschool PA. Pate et al. organized the questions into three categories: effects of PA on health, patterns of PA, and effectiveness of interventions and policy modifications. The questions related to the effects of PA are necessary to better understand its influence on health outcomes among younger children. The questions regarding behavior patterns, if answered, would provide greater insight regarding the types and amounts of physical activity needed, in addition to the factors that influence participation. The final category, interventions and policies, referred to questions addressing the mechanisms by which practitioners can improve preschooler PA in an effective and efficient manner. The questions in this category included: What are the most effective strategies for promoting young children's PA in the childcare, home, and community settings? How can interventions that actually increase PA among 3-to-5-year-old children be implemented and disseminated? Also, how effective are national, state, local, and institutional policies in increasing PA of 3-to-5-year-old children?

There is a lack of PA/nutrition programs for preschool children documented in the literature. Head Start Body Start was an initiative of AAHPERD (2011) with a goal of increasing outdoor play by educating staff, children and families. The initiative began in 2008 and provided onsite physical education, game, and activity suggestions from PA consultants and play space grants. Due to these efforts, which included play space upgrades, $75 \%$ of parents and staff reported increased outdoor time for children. The Child Health Initiative for Lifelong Eating and Exercise (CHILE) obesity prevention intervention targeted rural Head Start programs in New Mexico using a socioecological approach (Davis, Sanders, FitzGerald, Keane, Canaca, \& Volker-Rector, 2013). The program utilized various people and strategies including program directors and staff, grocery store managers, and primary care providers, along with classroom observations; dietary recalls for children, food availability/pricing assessments in 
community grocery stores, staff orientation, professional development for staff, parent orientation, and family night presentations. In addition, improvements were made, as well, including training enhancements such as nutrition modules and PA training and a family component with take-home newsletters, activity cards, and family events. The researchers acknowledged the importance of linking the material to the content via recipes, shopping lists, and family PA recommendations to name a few.

Color Me Healthy (CMH), another early childhood PA/nutrition program, was implemented in 2001 in 47 North Carolina counties and a reservation (Dunn, Thomas, Pegram, Ward, \& Schmal, 2004; Dunn, Thomas, Ward, Webber, Cullitan, Pegram, \& Webber, 2006). The program, based upon the Social Cognitive Theory and Socioecological Model, was designed to increase PA and healthy eating in children ages 4-5 using color, music, and senses. Resources include a teacher's guide with activities, bulletin board and display suggestions, strategies for teachers to be role models, food and places to be healthy picture cards to be used in circle time, classroom posters, music, hand stamps, parent newsletters, and posters. Using the information-dissemination model, train-the-trainer, CMH provided training to county teams made up of public health professionals to go back to their home counties and train childcare providers in their areas. The training, which lasted either 4 hours, 1 day, or 2 days, involved visual displays, model lessons, training manual, PowerPoint, evaluation instruments, sample training agenda, marketing materials, in addition to strategies and materials for local training.

The Food Friends: Get Moving' with Mighty Moves program intended to increase gross motor skill and PA by focusing on barriers that the child may face at home (Bellows et al., 2013). Because parent education is essential for lowering obesity rates, parents were provided with handouts, an activity planner, music $\mathrm{CD}$, poster, and trading cards. Finally, Nemours and partners conducted an intervention to prevent childhood obesity called Taking Steps to Healthy Success (National Early Care and Education Learning Collaborative, 2013). The intervention, which originally started in Delaware with a focus on healthy eating, PA, and screen time in early childhood settings and a goal of increasing the number of children and programs who met the standards of several initiatives, including Let's Move Child Care. Let's Move Child Care includes access to a checklist, customized action plan, ideas/resources, recognition 
awards and success stories as a lead up to Let's Move Active Schools. The program uses five learning sessions, homework, assessment tools, and implementation action plans and is used in a variety of settings including Head Start, public, private, and faith-based child care centers.

A recent study found that overall there were no significant changes in childhood and adult obesity over a similar period, but for children ages 2-5 there was a positive change from $14 \%$ in 2003 2004 to a little over 8\% in 2011-2012 (Ogden, Carroll, Kit, \& Flegal, 2014). There were significant decreases reported for low-income preschool-aged children who participated in federal nutrition programs in at least 18 states (Ogden et al., 2014). Further research is needed to identify the types of PA and nutrition education intervention approaches, and services that preschool children were exposed to that may have contributed to this observed decrease. Head Start, the largest federally funded early childhood program in the United States (Whitaker, Gooze, Hughes, \& Finkelstein, 2009), has a National Center devoted to parent, child, and community engagement which provides resources for staff and families, as well as trainings and assistance for staff. As a context for PA intervention, early childcare centers function as relationship-based facilities and remain unique in that parents maintain direct contact with their children's teachers on a daily basis (Elliott, 2005). This frequent communication serves as an important mechanism for transferring information between home and school environments in support of student learning and well-being. This Center's framework aligns with the six types of family involvement in schools identified by Epstein (2008): parenting, learning at home, communicating, decision-making, community collaboration, and volunteering.

Head Start is unlike many other childcare facilities in that by law their programs must provide a variety of services including opportunities for MVPA, nutrition education, outreach activities, and parent education (Puma et al., 2010). Since early childhood educators are often not trained in physical education, many Head Start classrooms have adopted the educational resource titled I am Moving, I am Learning (IMIL) to increase PA time, facilitate healthy food choices, and improve the quality of teacher-guided PA (Gooze, Hughes, Finkelstein, \& Whitaker, 2010). The IMIL resources serve as a research-informed, unobtrusive means to infuse quality PA and healthy food choices into an already existent preschool 
curriculum and routines. The IMIL resources combine best practice guidelines and policies as outlined by the National Center for Education in Maternal and Child Health, American Academy of Pediatrics, National Association for Sport and Physical Education, Institute of Medicine, and Centers for Disease Control and Prevention. IMIL is meant to serve as a curriculum enhancer that includes a variety of activities, music, and props. Programs can purchase props, but it is important to note that IMIL can be implemented without any extra costs and some programs elect to construct their materials. Many of the props available for purchase bear the likeness of Choosy ${ }^{\circledR}$ (Choose Healthy Options Often and Start Young), a friendly green character around whom IMIL is branded.

The Head Start National Center on Health currently houses IMIL. The goals of IMIL are to increase MVPA to meet national guidelines, improve daily healthy food choices, and improve the quality of structured PA. There is also an oral health care component. Using the train-the-trainer model, IMIL specialists deliver a 3-day interactive workshop during which participants engage in sample activities and songs. The basic premise is that the attendees travel home and train others in their programs. The provided workshop materials include copies of all PowerPoint presentations, worksheets and handouts including those for planning and reflection, and a resource list with Angela Russ music, Choosy Kids ${ }^{\circledR}$ music, puppets, dolls, posters, and online materials such as choosemyplate.gov and kidshealth.org. Other components of IMIL include newsletters and a checklist to help teachers assess gross motor skills such as throwing, catching, kicking, and striking.

One of the purported benefits of IMIL is that it is flexible and customizable to each classroom's unique needs and aligns with Head Start Program Performance Standards. Another signature feature of IMIL is its ability to meet initiatives of various Head Start National Centers. IMIL offers opportunities for greater family and community engagement and a mechanism for achieving the benchmark domains of the Classroom Assessment Scoring System (CLASS). The CLASS is used to assess program progress in order to maintain federal funding. The CLASS System focuses on teacher-child interactions across three domains: emotional support, classroom organization, and instructional support (National Center on Quality Teaching and Learning, 2014). The dimensions of CLASS include positive climate, teacher 
sensitivity, regard for student perspectives, behavior management, productivity, instructional learning formats, concept development, quality of feedback, and language modeling.

The initial pilot of the IMIL program in 2004-2005 at 10 sites in Virginia and 7 sites in West Virginia, provided evidence of many positive outcomes including increased movement, improved body mass index (BMI) for children, increased staff involvement, and increased family and community involvement (Administration for Children and Families, 2006). In 2010, the Office of Planning, Research, and Evaluation conducted an implementation evaluation of the program (ACF, 2010). There were many strengths mentioned such as staff enthusiasm and ease of application in classes and homes, but barriers included time and support. Following this implementation evaluation, there have been improvements in the training of teachers using IMIL that helped minimize these related barriers. To date, researchers have not completed follow-up evaluation regarding the longer-term effectiveness of IMIL.

\section{Purpose Statement}

This gap in the literature is problematic in that program evaluation research of this sort provides valuable information on the effects of an intervention and practitioners can use the results to make databased decisions (Thomas, 1994). The purpose of this study was to evaluate the impact that IMIL has made on families participating in Head Start settings using the RE-AIM framework. The implementation of IMIL varies according to the unique contextual factors at each program site, and these differences were also explored. This study provides insight into the various uses of the IMIL instructional strategies and resources in schools, homes, and communities.

\section{Method}

Program evaluation can focus on the process, impact, or outcome, with impact evaluations assessing the immediate effects of a program (Mathews, Werch, Michniewicz, \& Bian, 2007). The REAIM framework enables researchers to evaluate programs across five dimensions (reach, effectiveness, adoption, implementation, and maintenance) at multiple levels (Glasgow, Vogt, \& Boles, 1999). Reach refers to the percentage of people affected by the program and often includes demographic information. Effectiveness addresses the positive and negative outcomes of the program. Adoption refers to the extent 
of use by the targeted staff, settings, or institutions while implementation describes the fidelity with which the team delivers a program as designed. Maintenance represents the degree to which a program or policy becomes institutionalized or part of the routine organizational practices.

\section{Research Design}

For this study, researchers used a QUAL+ quan simultaneous mixed-methods design within which quantitative and qualitative data were collected concurrently, analyzed separately, and then mixed during analysis and interpretation (Morse \& Niehaus, 2009; Plano Clark \& Creswell, 2008). Data sources included an agency administrator survey, classroom teacher survey, program staff focus groups, and parent survey (see Table 1). The study answered the following research questions using the RE-AIM framework: (1) Reach - How many classrooms has IMIL entered in the state of Illinois? (2) Effectiveness - How effective has IMIL been in helping programs engage families and communities? (3) Adoption How many agencies in Illinois house classrooms that have adopted IMIL? What barriers, if any, have programs faced in their use of IMIL? (4) Implementation - Which IMIL strategies and resources have been adopted to engage families and communities? How have Epstein's six types of involvement been used to engage communities and families in IMIL? (5) Maintenance - How has IMIL been sustainable since the time of its initial use?

\section{Participants}

Participants included Head Start agency administrators, classroom teachers, program staff, and parents in the state of Illinois who contributed to various components of the research process. The sampling process started with a broad focus to estimate IMIL use statewide. The agency administrator agency was delivered to all Head Start agency directors $(N=37)$ in Illinois. A total of $73 \%(n=27)$ of the agency administrators responded. Based on the data collected, sampling narrowed to focus on classroom teachers statewide who incorporate IMIL in their instruction. All of the lead teachers of IMIL classrooms identified through the agency administrator survey were invited to participate $(N=455)$. The response rate 
was $11 \%(n=52)$ of all classroom teachers representing $44 \%(n=12)$ of the agencies responding to the agency administrator survey. See Tables 2 and 3 for the related demographic information.

The sampling process then narrowed to focus on the parents and staff within an intentionally selected Head Start program. Of the 289 families (73 non-English speaking) represented, 39\% $(n=113)$ participated in the corresponding parent survey. See Table 4 for the related demographic information. The participants in the program staff focus groups included 33 teachers/teacher aides, one education manager, one health/nutrition manager, and two family service workers $(n=37)$. Dr. Linda Carson, the creator of IMIL and owner of Choosy Kids ${ }^{\circledR}$, recommended this specific program as the data collection site given their established record of family and community involvement. She made this determination based on periodic contact with program personnel following their participation in an earlier IMIL training.

\section{Instrumentation}

Pilot testing. As the target population is Head Start centers in Illinois, the agency administrator survey was Head Start centers in West Virginia, Maryland, Delaware, Pennsylvania, South Carolina, and Virginia. These states were chosen because they were part of the initial pilot and beginning years of IMIL. Fourteen directors responded, and the survey was revised based on the feedback. Researchers employed a process similar to the one described above to pilot-test the classroom teacher survey using the same directors, an e-mail was sent asking them to forward the questionnaire to their teachers. Twentynine teachers responded, and the survey was revised based on the feedback. Researchers piloted the parent survey within one childcare center in West Virginia. Based upon the feedback responses from 17 parents, researchers modified the survey. Finally, focus groups were piloted at four different centers with nine teachers who use IMIL and revisions were made based upon their feedback.

Agency administrator survey. This online survey included a combination of 18 open-ended and closed-ended questions to measure the extent to which Head Start agency administrators perceived programs were incorporating IMIL. The survey also estimated the number of programs that received training in IMIL, the extent to which it was being implemented, and the number of families impacted as key indicators of program reach. Within the instructions, the agency administrators were asked to forward 
the survey to a more appropriate person (e.g., health or education managers) if they perceived that person was better positioned to answer the questions.

Classroom teacher survey. An online survey of Head Start teachers was used to determine specific IMIL resources being employed in classrooms, the perceived impact of IMIL on children and families, and the reported barriers to implementation. A total of 49 open-ended and closed-ended questions were constructed based on the IMIL resource list, goals for both Head Start and IMIL, and contextual barriers identified through prior implementation evaluation research (ACF, 2010).

Parent survey. Researchers developed a survey to gather information from parents with respect to the impact that IMIL has made on their family and community. A combination of 13 open-ended and closed-ended questions were included to measure the extent to which IMIL was being incorporated and its related impact. Participants were given the option to take the survey online or return a paper version.

Program staff focus groups. The lead researcher conducted four program staff groups at the local program site. The focus group protocol included 14 questions with follow-up prompts based on six approaches that schools use to engage families: parenting, communicating, volunteering, learning at home, decision-making, and community collaboration (Epstein, 2008).

\section{Administrative Procedures}

After pre-testing and pilot testing of all instruments and IRB approval, data collection took place from May 2014-October 2014. The surveys were made available using the Qualtrics ${ }^{\circledR}$ online platform and took between 5 and 20 minutes to complete. If preferred, respondents were also invited to complete a paper version as an alternative. The four focus groups were completed on-site at the program's home office and lasted between 20 and 60 minutes. The initial data collection, which consisted of parent surveys and program staff focus groups, occurred within a single, preselected program in Illinois. The remaining data collection occurred statewide over time.

Program staff focus groups and parent surveys. The education manager, identified by Dr. Carson, was the point of contact for the program staff focus groups and parent surveys. The education manager recruited teachers, teacher aides, and family service workers to take part in the focus groups to 
represent all 18 classrooms in 8 buildings within the program. For their participation, the program was given a $\$ 250$ gift certificate from Choosy Kids ${ }^{\circledR}$. Prior to focus groups, classrooms were visited to provide context as to how IMIL was currently being used by teachers. Refreshments were provided for participants prior to introductions and participants were informed that the focus groups would be audiotaped before the focus groups began. At the conclusion of the focus groups, participants were thanked for their participation. Researchers solicited parent participation indirectly through the classroom teachers by sending enveloped surveys home with each child in advance of the site visit. The researchers prepared and sent these envelopes ahead of time and collected them onsite following the program staff focus groups. Parents who completed surveys were entered into a drawing to win a \$25 Target gift card.

Agency administrator and classroom teacher surveys. Members of the research team contacted all agency directors in Illinois via e-mail, reminder e-mails, postcards, and phone calls to participate in an online survey. A reminder e-mail was sent one week after initial contact to all non-respondents. The following week, a reminder postcard was sent to all non-respondents. Over the next three weeks, one phone call a week was made to any non-respondent. If there was no answer, researchers left a voice mail. If there was no voicemail available, phone calls were repeated until someone answered. The researchers encouraged each person contacted to complete the survey or forward the information to a more appropriate person, including but not limited to the education manager or health and nutrition coordinator. For their participation, respondents were entered to win a \$25 Lakeshore ${ }^{\circledR}$ Learning gift card. Researchers sent personal notes to thank all respondents and encourage their continued participation in the next phase of the study. As a follow-up, a classroom teacher survey was sent to all programs that reported using IMIL on the previous agency administrator survey. If teachers elected to participate, they were entered into a drawing to win a $\$ 25$ Lakeshore $^{\circledR}$ Learning gift card as well. Contact was made via e-mail, reminder e-mails, postcards, and phone calls using the described protocol.

\section{Data Analysis}

Data from the agency administrator, classroom teacher, and parent surveys were downloaded from Qualtrics ${ }^{\circledR}$ into Microsoft ${ }^{\circledR}$ Excel spreadsheets. Questions that were open-ended were given 
quantifiable categories and coded accordingly. The researchers used descriptive statistics to summarize data to determine trends and patterns related to the specified research questions (Teddlie \& Tashakkori, 2009; Tashakkori \& Teddlie, 2010). The focus groups were audio recorded, saved to a computer and flash drive, and professionally transcribed. Researchers used NVivo qualitative software for data storage and coding. The transcribed data were analyzed inductively to identify patterns and themes through: (a) data reduction, (b) data display, and (c) drawing and verifying conclusions (Miles \& Huberman, 1994). For data reduction, the transcripts were read and codes assigned to words, sentences, and/or paragraphs based on meaning. A codebook was developed in order to establish themes. For display purposes, researchers organized the data in tabular format with examples of relevant quotations. Finally, meaning and significance were derived from the data and presented with other results. Two researchers coded the data independently to check for interrater reliability. Interrater reliability was calculated by theme ranging from 84 to $100 \%$ agreement. A member check was also conducted with the education manager of the local program. Data from all sources were mixed for results purposes. Summary paragraphs were derived for each theme from focus group data after which these findings were supplemented with data from the parent survey, agency administrator survey, and classroom teacher survey.

\section{Results \& Discussion}

\section{Reach}

IMIL has reached $60.8 \%$ of Head Start classrooms $(n=941)$ in the state of Illinois. Of those agencies who reported having classrooms that used IMIL $(n=23), 78 \%$ reported that all of their classrooms used IMIL; 13\% reported that the majority of their classrooms used IMIL; and 9\% reported that the number of classrooms that used IMIL were in the minority. A high percentage was anticipated for reach, as IMIL is a national Head Start initiative (ACF, 2006). One way to further increase the number of classrooms that use IMIL is to provide ongoing support after training. In the 2010 implementation evaluation, teachers were also cited as desiring support after the initial 3-day training (ACF, 2010). Recently Choosy Kids ${ }^{\circledR}$ has updated their website to allow for more collaboration between teachers following training (http://choosykids.com). Further improvements could include offering an 
online training and support as a viable option for programs who are not able to attend or host a 3-day workshop.

\section{Effectiveness}

Data supported the effectiveness of IMIL in a number of areas including knowledge acquisition, health-related behaviors, community outreach, and supportive environments (see Table 5). Program staff reported gains in knowledge not only for children and their parents, but for themselves as well in terms of nutrition and assessment. Furthermore, IMIL helped program staff learn what to assess and allowed them to see student progress in skill level.

Eighty-five percent of parents $(\mathrm{n}=96)$ believed that their child's classroom had made a positive impact on their nutritional habits and also stated that their child's classroom helped in the following ways: educational print materials such as recipes and newsletters (32\%), new eating habits for the child and family (30\%), classroom messages that the child brought home verbally (14\%), increased knowledge (19\%), and non-print support such as cooking classes (6\%). This is similar to a study conducted with the Food Friends: Get Movin' with Mighty Moves program where parents reported higher activity levels for their child and family through use of many materials including handouts and music (Bellows et al., 2013).

While program staff presented evidence of behavior change in nutrition, they were not quite sure about changes in physical activity outside of school as a result of IMIL, but did report that children talked about different sports and activities that they were participating in. Contrary to the belief of program staff, $83 \%$ of parents believed that their child's classroom had helped their family become more active. Parents indicated that they were more active because of print materials being sent home (18\%) and reported being more knowledgeable about physical activity (45\%), in addition to participating in new activities such as gardening. Although program staff were unsure of their impact on physical activity outside of school, they did see change in physical activity levels within their classrooms, reporting that children were more active in their classrooms after being hesitant or non-participants in the beginning of the school year. Table 10 provides the perception of classroom teachers of the effect of IMIL on physical activity. 
Program staff also reported impacts made on families and the community and shared their experiences with IMIL building children's vocabulary through conversation as well their ability to make connections. As reported in the 2010 implementation evaluation, programs do not typically target the behaviors of the community (ACF, 2010). However, it was through families of the program that community members were being affected via translation of school materials, recipe sharing, and attendance to events with those targeted Head Start families. Program staff also reported that children were making an impact on their parents' nutrition, as well, thus the biggest impact appeared to be made in nutrition (See Table 9 for supplemental data from classroom teacher survey). This would be consistent with findings that most childcare facilities devote more time to nutrition than physical activity (Gooze et al., 2010).

Children were also being used as vehicles to change the behaviors of their parents and parents have communicated these changes to program staff. Seventy-five percent of parents reported that their child's classroom had helped them be a healthier role model. For example, $39 \%$ of parents said the classroom helped them eat better, $15 \%$ said they were more active, $13 \%$ said they were more knowledgeable, and $11 \%$ spoke about the impact of their child as a result of the classroom. This finding may be particular to this program, as classroom teachers on the survey reported that parent support and buy-in for IMIL was a challenge (54\%).

The character Choosy was a critical component in this program's use of IMIL. Teachers would use Choosy to get children to engage in desired behaviors with success ("Yeah, they don't do it if I say it, but if Choosy says it“). Also, parents were familiar with the character and reported seeing Choosy in various locations in the community including school, family events, the library, the local news, and parades. In addition to the use of the Choosy character, music was another critical component to success. Through music associated with IMIL, students were learning self-control and taking the lead becoming active participants in their learning.

In order to improve effectiveness, programs should survey their parents to find out which strategies and materials are making an impact, especially those concerning physical activity. Other 
preschool and physical activity programs have obtained information from parents in order to improve effectiveness (Bellows et al., 2013; Davis et al., 2013). Of those suggestions offered by the parents themselves, they would like more family wellness activities held indoors at various locations as well as activities during the summer. While parents wanted consistency for the nutrition aspect, like recipes and classes, they desired more support in terms of physical activity. Additionally, just as The Child Health Initiative for Lifelong Eating and Exercise (CHILE) obesity prevention intervention program provided bilingual materials as an improvement to program effectiveness (Davis et al., 2013), this local program could provide print materials in all of the different languages represented within their program.

\section{Adoption}

Of Head start agencies in the state of Illinois, $62.2 \%$ of classrooms that have adopted IMIL exposing at least 7,867 families. Many of the program staff found the use of IMIL to be without barriers as they commented, “I don't see a barrier" and "I don’t see any negative." Of those barriers reported (see Table 6), programs felt that while the newsletters were helpful for the parents that did read them, they were aware that the majority of parents did not. They believed that this was likely due to the high amount of papers being sent home and the language barrier. For this reason, program staff reported sending home verbal messages with children instead. This may be an effective strategy as parents reported different areas their child talked about at home.

Program staff reported language as a large barrier, as a high number of languages and dialects were spoken. While there were translators available for home visits and conferences, written materials were only sent home in English. As stated previously, translation of written materials in all languages represented is a suggested improvement. Furthermore, program staff reported being overwhelmed trying to fit in all related assessments and felt that sometimes it was a duplication of other assessments. The researcher suggest that programs revises their assessment policy and only include those that most closely matches their needs.

Barriers reported by program staff varied by classroom but included space and time. Program staff were unanimous in that they felt that students had nowhere to progress to after they reached the 
highest level on the checklist. Classroom teachers reported that time (62\%) and space (64\%) were not barriers. Other barriers from the 2010 implementation evaluation (ACF, 2010) besides space and time were funding and the health of the staff. Classroom teachers reported that funding (55\%) and staff health $(83 \%)$ were not barriers. Because time and space are contextual barriers that vary by classroom, some suggestions are to utilize outdoor space, hallways, or rearrange one's classroom since gymnasiums or gross motor rooms are not always readily available. Head Start Body Start was an initiative of the American Alliance for Health Physical Education Recreation and Dance (AAHPERD), with a goal of increasing outdoor play by educating staff, children, and families (2011), but did consider indoor space. Furthermore, because many teachers reported the checklist did not accommodate returning students who had already met the highest level, it is suggested that additional checklists be provided for students who are performing at higher levels or a list of ideas for teachers to make the task more challenging for those students who are advanced.

It should also be noted that barriers to child behavior change may include parents, as demonstrated in this quote, "So when they come here and they try them and you know they like them, and the mom's well I'm still not going to make peas cause I don't like them. But that child is loving the peas at school, so." This is similar to the study of healthy activity and eating practices and environments in Head Start (SHAPES) survey, where teachers felt that parents had a hard time encouraging healthy foods at home (Gooze et al., 2010). As for PA, it has been shown that parents influence the PA levels of their children (Freedson \& Evenson, 1991), thus the Food Friends: Get Movin’ with Mighty Moves program were developed to address barriers to physical activity that a child may face at home including lack of access and poverty (Bellows et al., 2013). These barriers are not much different than those faced by children in Head Start, however barriers to nutrition need to be discovered in order to develop materials to overcome them.

\section{Implementation}

IMIL was implemented in numerous ways (see Table 7). Administrators reported use of the following to meet the three goals of IMIL: classroom instruction (67\%), lessons plans (30\%), menu 
planning (30\%), community collaboration (19\%), parent engagement $(22 \%)$, music $(22 \%)$, print materials (19\%), assessment (7\%). Furthermore, on the questionnaire, 51\% of classroom teachers agreed and $43 \%$ strongly agreed that IMIL strategies helped the program meet Head Start Physical Health and Development domain elements according to the early learning framework (see Tables 8,9 , and 10 for more detailed responses). While classroom teachers and program staff reported the use of a variety of resources including the Lakeshore Choosy guide, MyPlate, Choosy cutouts, Choosy music, activity cards, scarves, bean bags, Choosy posters, and Choosy growth charts (see Table 11), other classroom activities included food projects, a class garden, letter writing to Choosy, and taste testing.

Program staff used IMIL to give students roles and responsibilities within the classroom such as song selector and line leader and much like a physical educator would, teachers model skills for students ("We show them, we more model it. We model how to do it and see if they hand model after it"). Program staff and administrators also reported using other resources, such as, Color Me Healthy and Colgate Bright Smiles, Bright Futures, thus using IMIL as an enhancement to their already existing curriculum.

Epstein's six types of family involvement were implemented in a variety of ways. Like programs in the implementation evaluation (ACF, 2010), in the focus groups, program staff reported many community partners that aligned with the physical activity and nutrition goals of IMIL. These partners included the local newspaper, Hy-Vee grocery store, Illinois Extension, Americorps, Blackhawk College, Augustana College, the local health department, True Value, community healthcare, Western Illinois University, Rock Island Public Library, Riverbend Food Bank, the local news station, fitness center, and bikes for brains. Many of these partners came to the parent events, while others made their presence known within the classroom such as college students and Snap Ed. The Choosy event has been in the newspaper and one classroom was showcased on the local news, thus exposing the community to IMIL.

In terms of decision-making, there is a health advisory board. While in the past, parents have often been excluded from serving on such boards at the school level (Kann, Brener, \& Wechsler, 2007); 
this particular program has a board of 35-40 parents and community partners. At the meetings, informational updates are given on anything new going on in the nutrition curriculum and IMIL updates.

Program staff reported several ways that learning occurred at home, but said that the children bringing information home verbally was the best way for this to occur. Generally, the teachers believed that "What they're learning and it's just carrying it over" and "They're the ones that are pushing it when they get home". This is consistent with findings from the parent survey, as parents reported their children talking about Choosy at home and sharing what they learned with both parents and younger siblings.

Program staff reported that volunteering varied by school and classroom, but there was an open door policy and volunteering was encouraged. Suggested barriers for classrooms with a low volunteer rate were work, lack of transportation and childcare for younger siblings as also noted as a barrier to involvement by the CDC (2012). Other than parent volunteers, there were students from two different colleges, community volunteers, Americorps volunteers, and various family members such as aunts, uncles, and grandparents.

In terms of communicating, the most common strategy was the use of newsletters, similar to what teachers who used Color Me Healthy reported (Dunn, Thomas, Pegram, Ward, \& Schmal, 2004; Dunn, Thomas, Ward, Webber, Cullitan, Pegram, \& Webber, 2006). This continues to be a strategy in use for programs today, however materials should reflect diversity and be translated in other languages, as well. In 2010, programs reported providing families with an introduction to IMIL, education and information about healthy eating and PA, examples of PA to do as a family, and education and guidance about healthy food preparation and techniques (ACF, 2010). It was reported in focus groups that parent education occurred in a number of ways including home visits, assessments, nutrition classes, and newsletters. Home visits allowed parents to receive lots of information and parents were offered various opportunities to improve health and physical activity behaviors. Through a community collaboration with the local grocery store, parents had the opportunity to take classes on healthy shopping and cooking. Family service workers are also supporting what the teachers are doing with physical activity and nutrition in the classroom. As with parenting, information such as assessments, special events, recipes, 
and menus was communicated to parents in a number of ways including home visits/conferences and newsletters. It has been suggested that both the home environment and parent education are consistent and significant determinants in the long-term outcomes of the program (Joo, 2010), thus one suggestion for improvement besides additional translation as stated previously, is that the program provide additional spots for families in the healthy shopping and cooking classes, as well as provide more scholarships to local fitness centers to meet the needs indicated by parents on the survey.

\section{Maintenance}

Similar to the previous implementation evaluation (ACF 2010), programs reported policies related to IMIL. Of the agency administrator survey respondents, $52 \%$ had used IMIL for 1-5 years, while another $26 \%$ had used it for 6-10 years. Seventy percent of classroom teachers have used IMIL for 1-5 years, while another $21 \%$ have used it for 6-10 years. Administrators identified the following reasons for the sustainability of IMIL: enjoyment (26\%), flexibility (7\%), informational (15\%), positive results $(15 \%)$, training $(15 \%)$, resources $(22 \%)$, aligns in with goals and policies $(33 \%)$, and easy implementation $(11 \%)$.

There are many facilitators to continued use of IMIL (see Table 12). Some facilitators such as flexibility and fun are consistent with findings of the prior implementation evaluation (ACF, 2010). Furthermore, IMIL doesn't require lots of equipment as demonstrated by the following quote: "Cause it's not like you have to go out and buy that Lakeshore kit for 500 -and-some dollars per classroom to implement...you don't necessarily need a whole lot of stuff." Fifty-six percent of questionnaire respondents agreed that sustainability is not an issue with IMIL.

Although IMIL as a program is sustainable, it was noted that continued training was critical to that sustainability. Administrators reported that for staff who did not attend the 3-day training, they received in-house training by someone who attended the 3-day training (48\%), in-service training (11\%), training by outside trainers (7\%), and IMIL workshops (7\%). For new staff, training is received in orientation (33\%), in-service (26\%), and in annual training for all staff (7\%). Color Me Healthy also realized the importance of training and employed the Train-the-Trainer model (Dunn et al., 2004; Dunn et 
al., 2006), which is evidenced in how programs reported preparing their teachers in IMIL. In 2010, programs reported training for lead teachers and new teachers (ACF, 2010). Only 17\% of classroom teachers attended the 3-day training, but disagreed that staff felt inadequately trained (74\%). Respondents did believe that staff support/buy in was challenging (51\%) contrary to the findings of the 2010 implementation evaluation of IMIL (ACF, 2010). Furthermore, $56 \%$ believed that staff turnover was an issue. Similarly, Taking Steps to Healthy Success also faced this challenge in implementation of its program (National Early Care and Education Learning Collaborative, 2014).

Administrators reported using IMIL concepts and strategies for family events (see Table 13). Teachers in the focus groups reported that of all of the events held throughout the year, "It's the best attendance the Choosy" with "close to 500 every time we've done it." One reason for the high attendance is the appearance of Choosy, the collaboration with the Rock Island Fitness Center, access to opportunities, and whole family participation. Also, older children, including teens still like to attend the event. At the event teachers and community partners lead stations, including one where the parent must dance to Choosy music with their child for 15 minutes and are given a Choosy CD afterwards. In 2010, programs also reported providing incentives for families that participated in IMIL activities (ACF, 2010). Other preschool physical activity and nutrition programs have also realized the importance of family events, such as the Child Health Initiative for Lifelong Eating and Exercise (CHILE) obesity prevention intervention, which added a family component including events, after its first year (Davis et al., 2013).

\section{Limitations and Future Directions}

As the evaluation only focused on one program within the state of Illinois, results also may be less generalizable to other Head Start programs in other states and cities. Furthermore, the language barrier reported by teachers was another issue, as survey materials were only administered in English. Another limitation was the time of administration of materials. Data collection began at the end of one school year and completed at the beginning of the following school year. Because teachers had other responsibilities in regard to program and classroom maintenance, another time would have been more optimal. 
While this study showed how IMIL can meet the initiatives of the Head Start National Center on Health and National Center on Parent, Family, and Community Engagement. Its potential to meet the benchmark domains of the National Center on Quality Teaching and Learning's Classroom Assessment Scoring System (CLASS), needs to be investigated further. It is important to note that the choosy character was often mentioned in association with IMIL, thus suggesting the influence of characters for further study. Furthermore, while this research contributes to Pate's identified areas of research focus related to physical activity in preschool children in terms of the effectiveness of interventions and policy modifications to promote PA, future studies should also address the other areas he identified to determine the effects of using IMIL on health and patterns of physical activity. Because of the reliance of selfreport in this particular study, further research using more objective measures of health-related behaviors and outcomes associated with use of IMIL are also warranted, including site visits and systematic classroom observations.

\section{Conclusion}

In summary, many classrooms in Illinois have been exposed to IMIL and have adopted its strategies. Generally, program staff feel that the barriers are few to none and IMIL has helped improve their classroom environment in a number of ways including but not limited to vocabulary and nutritional knowledge. Parents report that their classrooms have helped their families become healthier by improving their physical activity and nutrition habits. Further, IMIL has allowed classrooms to communicate effectively, provide parent education opportunities, learn at home, and collaborate with various persons and organizations in the community. Of the employed resources, music and the use of Choosy were what teachers most directly attributed to IMIL's success within their programs. Although, there is a lack of evidence-based preschool physical activity and nutrition programs, IMIL is a program that can impact both families and the surrounding community. 


\section{References}

American Alliance for Health, Physical Education, Recreation and Dance. (2011, November 15). Head start body start intervention has increased physical activity levels for more than 28,000 children. [Press Release].

Bellows, L., Silvernail, S., Caldwell, L., Bryant, A., Kennedy, C., Davies, P., \& Anderson, J. (2011). Parental perception on the efficacy of a physical activity program for preschoolers. Journal of Community Health, 36(2), 231-237. doi:10.1007/s10900-010-9302-1

Davis, S. M., Sanders, S. G., FitzGerald, C. A., Keane, P. C., Canaca, G. F., \& Volker-Rector, R. (2013). CHILE: An Evidence-Based Preschool Intervention for Obesity Prevention in Head Start. Journal Of School Health, 83(3), 223-229. doi:10.1111/josh.12018

Dunn, C., Thomas, C., Pegram, L., Ward, D., \& Schmal, S. (2004). Color me healthy, preschoolers moving and eating healthfully. Journal of nutrition education and behavior, 36(6), 327-328.

Dunn, C., Thomas, C., Ward, D., Webber, K., Cullitan, C., Pegram, L., \& Webber, K. (2006). PEER REVIEWED: Design and Implementation of a Nutrition and Physical Activity Curriculum for Child Care Settings. Preventing chronic disease, 3(2).

Elliott, R. (2005). Engaging families: Building strong communication. Early Childhood Australia, 12(2). Australia: Early Childhood Australia.

Epstein, J. L. (2008). Improving family and community involvement in secondary schools. Education Digest, 73(6), 9-12.

Freedson, P. S., \& Evenson, S. (1991). Familial aggregation in physical activity. Research Quarterly for Exercise \& Sport, 62(4), 384-389.

Glasgow, R. E., Vogt, T. M., \& Boles, S. M. (1999). Evaluating the public health impact of health promotion interventions: The RE-AIM framework. American Journal of Public Health, 89(9), $1322-1327$. 
Gooze, R. A., Hughes, C. C., Finkelstein, D. M., \& Whitaker, R. C. (2010). Reaching staff, parents, and community partners to prevent childhood obesity in head start, 2008. Preventing Chronic Disease, 7(3), A54-A54.

Harris, K. J., James, V., Henke, L., Fawcett, S. B., Johnston, J. A., Richter, K. P., . . Lewis, R. K. (1997). Community partnerships: Review of selected models and evaluation of two case studies. Journal of Nutrition Education, 29(4), 189-195.

Institute of Medicine. (2013). Educating the student body: Taking physical activity and physical education to school: Report brief. Washington, DC: The national academies press.

Joo, M. (2010). Long-term effects of head start on academic and school outcomes of children in persistent poverty: Girls vs. boys. Children and Youth Services Review, 32(6), 807-814.

Kann, L., Brener, N. D., \& Wechsler, H. (2007). Overview and summary: School health policies and programs study 2006. Journal of School Health, 77(8), 385-397.

Mathews, A. E., Werch, C., Michniewicz, M., \& Bian, H. (2007). An impact evaluation of two versions of a brief intervention targeting alcohol use and physical activity among adolescents. Journal of Drug Education, 37(4), 401-416.

Miles, M. B., \& Huberman, A. M. (1994). Qualitative data analysis: An expanded sourcebook. Sage. Moore, L. L., Lombardi, D. A., White, M. J., Campbell, J. L., Oliveria, S. A., \& Ellison, R. C. (1991). Influence of parents' physical activity levels on activity levels of young children. Journal of Pediatrics, 118, 215-219.

Morse, J. M., \& Niehaus, L. (2009). Mixed method design: Principles and procedures (Vol. 4). Left Coast Pr.

National Center on Quality Teaching and Learning. (2014). Use of Classroom Assessment Scoring System (CLASS) in Head Start. Retrieved from http://eclkc.ohs.acf.hhs.gov/hslc/sr/quality/class

National Early Care and Education Learning Collaborative. Learning session one: why should we change? Taking steps to Healthy Success: ECELC [Powerpoint]. Retrieved from National Early Care and Education Learning Collaborative, 2014 
Ogden, C. L., Carroll, M. D., Kit, B. K., \& Flegal, K. M. (2014). Prevalence of Childhood and Adult Obesity in the United States, 2011-2012. JAMA, 311(8), 806-814.

Pate, R. R., O'Neill, J. R., Brown, W. H., McIver, K. L., Howie, E. K., \& Dowda, M. (2013). Top 10 Research Questions Related to Physical Activity in Preschool Children. Research Quarterly for Exercise and Sport, 84(4), 448-455.

Pate, R. R., \& O'Neill, J.,R. (2012). Physical activity guidelines for young children: An emerging consensus. Archives of Pediatrics \& Adolescent Medicine, 166(12), 1095-1096. doi:10.1001/archpediatrics.2012.1458

Pate, R. R., Pfeiffer, K. A., Trost, S. G., Ziegler, P., \& Dowda, M. (2004). Physical activity among children attending preschools. Pediatrics, 114(5), 1258-1263. doi:10.1542/peds.2003-1088-L

Plano Clark, V. L., \& Creswell, J. W. (2008). The mixed methods reader. Thousand Oaks et al.: Sage.

Puma, M., Bell, S., Cook, R., Heid, C., Shapiro, G., Broene, P., ... \& Spier, E. (2010). Head Start Impact Study. Final Report. Administration for Children \& Families.

Tashakkori, A., \& Teddlie, C. (Eds.). (2010). Sage handbook of mixed methods in social \& behavioral research. Sage.

Teddlie, C., \& Tashakkori, A. (Eds.). (2009). Foundations of mixed methods research: Integrating quantitative and qualitative approaches in the social and behavioral sciences. Sage Publications Inc.

Thomas, J. C. (1994). Program evaluation and program development. Herman, R. The Jossey-Bass Handbook of Nonprofit Leadership and Management, San Francisco: Jossey-Bass Publishers, 342-366.

Trost, S. G., Sirard, J. R., Dowda, M., Pfeiffer, K. A., \& Pate, R. R. (2003). Physical activity in overweight and nonoverweight preschool children. International Journal of Obesity \& Related Metabolic Disorders, 27(7), 834. 
U.S. Department of Health and Human Services, Administration for Children and Families. (2006). I am moving, I am learning: a proactive approach for addressing childhood obesity in Head Start Children

U.S. Department of Health and Human Services, Administration for Children and Families (2010). Efforts to meet children's physical activity and nutritional needs: findings for the I am moving, I am learning implementation evaluation.

U.S. Department of Health and Human Services, Administration for Children and Families (2009). Report to congress on head start efforts to prevent and reduce obesity in children.

U.S. Department of Health and Human Services, Centers for Disease Control and Prevention. (2012). Parent engagement: Strategies for involving parents in school health. Atlanta, GA.

U.S. Department of Health and Human Services. (2008). Physical activity guidelines for Americans. Washington DC.

Whitaker, R. C., Gooze, R. A., Hughes, C. C., \& Finkelstein, D. M. (2009). A national survey of obesity prevention practices in head start. Archives of Pediatrics \& Adolescent Medicine, 163(12), 11441150. doi:10.1001/archpediatrics.2009.209 
Table 1

Research questions and data sources

\begin{tabular}{|c|c|c|}
\hline Component & Question(s) & Data Source(s) \\
\hline Reach & $\begin{array}{l}\text { How many classrooms has } \\
\text { IMIL entered in the state } \\
\text { of Illinois? }\end{array}$ & Agency Administrator Survey \\
\hline Effectiveness & $\begin{array}{l}\text { How effective has IMIL } \\
\text { been in helping programs } \\
\text { engage families and } \\
\text { communities? }\end{array}$ & $\begin{array}{l}\text { Classroom Teacher Survey, Parent Survey, and } \\
\text { Program Staff Focus Groups }\end{array}$ \\
\hline Adoption & $\begin{array}{l}\text { How many agencies in } \\
\text { Illinois house classrooms } \\
\text { that have adopted IMIL? } \\
\text { What barriers, if any, have } \\
\text { programs faced in their } \\
\text { use of IMIL? }\end{array}$ & $\begin{array}{l}\text { Classroom Teacher Survey and Program Staff Focus } \\
\text { Groups }\end{array}$ \\
\hline \multirow[t]{2}{*}{ Implementation } & $\begin{array}{l}\text { Which IMIL strategies and } \\
\text { resources have been } \\
\text { adopted to engage families } \\
\text { and communities? }\end{array}$ & $\begin{array}{l}\text { Agency Administrative Survey, Classroom Teacher } \\
\text { Survey, Program Staff Focus Groups, Parent Survey }\end{array}$ \\
\hline & $\begin{array}{l}\text { How have Epstein's six } \\
\text { types of involvement been } \\
\text { used to engage } \\
\text { communities and families } \\
\text { in IMIL? }\end{array}$ & \\
\hline Maintenance & $\begin{array}{l}\text { How has IMIL been } \\
\text { sustainable since the time } \\
\text { of its initial use? }\end{array}$ & $\begin{array}{l}\text { Agency Administrator Survey, Parent Survey, and } \\
\text { Program Staff Focus Groups }\end{array}$ \\
\hline
\end{tabular}


Table 2

Demographic Information for Agency Administrator Survey Respondents

\begin{tabular}{|c|c|}
\hline Demographic Category & Percentage $(\%)$ \\
\hline \multicolumn{2}{|l|}{ Age } \\
\hline No response & 4 \\
\hline $18-24$ & 4 \\
\hline $25-34$ & 15 \\
\hline $35-44$ & 19 \\
\hline $45-54$ & 19 \\
\hline $55-64$ & 30 \\
\hline $65-74$ & 7 \\
\hline $75+$ & 4 \\
\hline \multicolumn{2}{|l|}{ Gender } \\
\hline No response & 4 \\
\hline Female & 96 \\
\hline Male & 0 \\
\hline \multicolumn{2}{|l|}{ Years Working in Childcare } \\
\hline No response & 4 \\
\hline $0-10$ & 19 \\
\hline $11-19$ & 11 \\
\hline $20-29$ & 52 \\
\hline $30-39$ & 7 \\
\hline $40-49$ & 7 \\
\hline \multicolumn{2}{|l|}{ Race } \\
\hline No response & 8 \\
\hline White/Caucasian & 81 \\
\hline Black/African-American & 7 \\
\hline Hispanic/Latino & 4 \\
\hline Native American/American Indian & 0 \\
\hline Asian or Pacific Islander & 0 \\
\hline
\end{tabular}


Table 3

Demographic Information for Classroom Teacher Survey Respondents

\begin{tabular}{lr}
\hline Demographic Category & Percent \\
\hline Age & 2 \\
No response & 2 \\
$18-24$ & 2 \\
$25-34$ & 36 \\
$35-44$ & 38 \\
$45-54$ & 14 \\
$55-64$ & 6 \\
$65-74$ &
\end{tabular}

Gender

No response 4

Female $\quad 94$

Male 2

Years Working in Childcare

$0-10$

11-19

43

20-29

26

30-39

17

40-49

4

Race

No response 4

White/Caucasian 91

Black/African-American 6

Hispanic/Latino 2

Native American/American Indian 0

Asian or Pacific Islander $\quad 0$ 
Table 4

Demographic Information for Parent Survey Respondents

\begin{tabular}{lc}
\hline Demographic Category & Percentage (\%) \\
\hline & \\
Age & 2 \\
No response & 21 \\
$18-24$ & 49 \\
$25-34$ & 18 \\
$35-44$ & 5 \\
$45-54$ & 3 \\
$55-64$ & 2 \\
65-74 & \\
& \\
Race & 3 \\
No response & 35 \\
White/Caucasian & 30 \\
Black/African-American & 16 \\
Hispanic/Latino & 3 \\
Native American/American Indian & 9 \\
Asian or Pacific Islander & 4 \\
Other & \\
Highest Level of Education Completed & \\
Some high school & 20 \\
Some college & 21 \\
Vocational/Trade/Technical & 31 \\
Bachelor's degree & 4 \\
Master's degree & 3 \\
Doctoral degree & \\
GED & \\
Associate degree & \\
None & \\
Less than high school & \\
Other & \\
& \\
\hline
\end{tabular}


Table 5

\section{RE-AIM Component Effectiveness}

\begin{tabular}{|c|c|c|}
\hline Key Finding & Representative Quotes & Data Source \\
\hline \multirow[t]{2}{*}{$\begin{array}{l}\text { Knowledge } \\
\text { acquisition }\end{array}$} & $\begin{array}{l}\text { "And the fact that it explains to them what a gallop is and what a hop is 'cause some of those kids } \\
\text { don't know, you know. And the teachers don't know." }\end{array}$ & $\begin{array}{l}\text { Program staff focus } \\
\text { groups }\end{array}$ \\
\hline & $\begin{array}{l}\text { "When she talks to 'em, I notice like kids will refer to the poster as she asks for vegetables they'll } \\
\text { look at the Choosy poster. They'll start naming the vegetables off the Choosy poster the fruits off } \\
\text { it, so they know by looking at it." }\end{array}$ & $\begin{array}{l}\text { Program staff focus } \\
\text { groups }\end{array}$ \\
\hline \multirow[t]{2}{*}{$\begin{array}{l}\text { Health-related } \\
\text { behavior-nutrition }\end{array}$} & $\begin{array}{l}\text { "Having Choosy as a role model for my son who is a picky eater helps me get him to choose better } \\
\text { foods for us. Knowing that's what Choosy would want for family." }\end{array}$ & Parent survey \\
\hline & $\begin{array}{l}\text { "My daughter Pre-K classroom has helped my family eat better in many ways. Her teacher sent } \\
\text { home a food pyramid explaining what a proper meal would look like and how many of each food } \\
\text { groups would be proper to eat for a whole meal. Her school had set up an activity play day where } \\
\text { we were given examples of good meals." }\end{array}$ & Parent survey \\
\hline $\begin{array}{l}\text { Health-related } \\
\text { behavior-physical } \\
\text { activity }\end{array}$ & $\begin{array}{l}\text { "My daughters Pre-K classroom has helped our family become more active, in many ways. For } \\
\text { example, many worksheets where brought home talking about being active as a family. My family } \\
\text { began taking walks along the river every now and then. And my daughter and her father would } \\
\text { take bike rides in the afternoon. Her school had set up an activity play day where we were able to } \\
\text { be given a chance to be active in many ways like, swimming, playground for the kids, and a gym } \\
\text { to be able to do all kinds of different activities.", }\end{array}$ & Parent survey \\
\hline $\begin{array}{l}\text { Community } \\
\text { outreach }\end{array}$ & $\begin{array}{l}\text { "But when I have gone out you know I've had several of them tell me even the ones that went to } \\
\text { cooking matters that they still use the recipes out of that and they've shared it with a couple of } \\
\text { mine that were non-English speaking that want and have shared it with others in the community. } \\
\text { And one mom was laughing because she said she told the dad, no you can't have that one because } \\
\text { this one's less sugar. So, yeah." }\end{array}$ & $\begin{array}{l}\text { Program staff focus } \\
\text { groups }\end{array}$ \\
\hline
\end{tabular}


Table 5 (continued)

\begin{tabular}{|c|c|c|}
\hline Key Finding & Representative Quotes & Data Source \\
\hline \multirow[t]{2}{*}{$\begin{array}{l}\text { Supportive } \\
\text { environment- } \\
\text { classroom }\end{array}$} & $\begin{array}{l}\text { "But I've noticed in my classroom I have a couple, well little ones in there and they're moving } \\
\text { now. They just get up and go. The first part of the year they're like forget you, I'm not going. But } \\
\text { now they're up and doing. So I think Choosy helped with that with him being just a mascot." }\end{array}$ & $\begin{array}{l}\text { Program staff focus } \\
\text { groups }\end{array}$ \\
\hline & $\begin{array}{l}\text { "Yeah I was going to say IMIL for the children's needs. That way we know which child needs to } \\
\text { improve on you know the throwing or the jumping." }\end{array}$ & $\begin{array}{l}\text { Program staff focus } \\
\text { groups }\end{array}$ \\
\hline \multirow[t]{2}{*}{$\begin{array}{l}\text { Supportive } \\
\text { environment-home }\end{array}$} & $\begin{array}{l}\text { "They'll talk about the different changes they've made to their eating habits at home and their } \\
\text { lifestyle changes, not that it's always consistent, and they're you know pretty forward about that } \\
\text { too, but they're trying." }\end{array}$ & $\begin{array}{l}\text { Program staff focus } \\
\text { groups }\end{array}$ \\
\hline & $\begin{array}{l}\text { "I'll talk to parents they'll tell me about how their child when they're out grocery shopping will } \\
\text { talk about good choices in foods to buy, or we shouldn't do this, we should get this." }\end{array}$ & $\begin{array}{l}\text { Program staff focus } \\
\text { groups }\end{array}$ \\
\hline
\end{tabular}


Table 6

\section{RE-AIM Component Adoption}


Table 7

\section{RE-AIM Component Implementation}

\begin{tabular}{|c|c|c|}
\hline Key Findings & Representative Quotes & Source \\
\hline Student roles & $\begin{array}{l}\text { "Our song selector, whoever the song selector is they always seem to choose a Choosy song, and then } \\
\text { everybody follows whatever the song selector does choose." }\end{array}$ & $\begin{array}{l}\text { Program staff } \\
\text { focus groups }\end{array}$ \\
\hline \multirow[t]{2}{*}{$\begin{array}{l}\text { Community } \\
\text { collaboration }\end{array}$} & $\begin{array}{l}\text { "Well like community healthcare may be there and they'll give away toothbrushes or they'll have } \\
\text { some fliers on healthy eating." }\end{array}$ & $\begin{array}{l}\text { Program staff } \\
\text { focus groups }\end{array}$ \\
\hline & $\begin{array}{l}\text { "There's also a community person that started doing bike for brains every year and we're affiliated } \\
\text { with them and they get our kids bikes every year, so." }\end{array}$ & $\begin{array}{l}\text { Program staff } \\
\text { focus groups }\end{array}$ \\
\hline Decision making & $\begin{array}{l}\text { "We have a good representation of parents on that board and so they're coming and they're also } \\
\text { hearing those updates and giving their concerns and their questions about the nutrition piece, or-" }\end{array}$ & $\begin{array}{l}\text { Program staff } \\
\text { focus groups }\end{array}$ \\
\hline \multirow[t]{2}{*}{ Learning at home } & $\begin{array}{l}\text { "I think in simple conversation too. I mean the teachers talk to the children during their classroom day } \\
\text { and like when I go to visits or I'll talk to parents they'll tell me about how their child when they're } \\
\text { out grocery shopping will talk about good choices in foods to buy, or we shouldn't do this, we should } \\
\text { get this. So it comes home verbally too with their own child." }\end{array}$ & $\begin{array}{l}\text { Program staff } \\
\text { focus groups }\end{array}$ \\
\hline & $\begin{array}{l}\text { "I know that some parents have commented, that one where they take the grocery list and they go into } \\
\text { the store, and they've done that with their kids. They've talked about what they've picked out, the } \\
\text { Choosy fruits and vegetable." }\end{array}$ & $\begin{array}{l}\text { Program staff } \\
\text { focus groups }\end{array}$ \\
\hline \multirow[t]{2}{*}{ Parenting } & $\begin{array}{l}\text { "We discuss the children's progress and their physical growth and development and talk about } \\
\text { nutrition for them and talking about [go and whoa] foods and things that are healthy and things they } \\
\text { can do to improve those fine and gross motor skills at home with them." }\end{array}$ & $\begin{array}{l}\text { Program staff } \\
\text { focus groups }\end{array}$ \\
\hline & $\begin{array}{l}\text { "Well we do cooking matters, cooking matters class, and that teaches the parents about healthy meals, } \\
\text { how you can cook meals and be easy and quick but be healthy. They go over the whoa foods and the } \\
\text { go foods with their parents so that way they get educated and they know you know ooh, okay, my kid } \\
\text { needs to eat more fruits and vegetables and cut back on the white bread and use wheat bread instead" }\end{array}$ & $\begin{array}{l}\text { Program staff } \\
\text { focus groups }\end{array}$ \\
\hline
\end{tabular}


Table 7 (continued)

\begin{tabular}{|c|c|c|}
\hline Key Findings & Representative Quotes & Source \\
\hline \multirow[t]{2}{*}{ Communicating } & $\begin{array}{l}\text { "And also letting them know when we first do the home visits that we do have a mascot, healthy } \\
\text { lifestyle mascot, and his name is Choosy, and so your kid is going to come home talking about } \\
\text { Choosy, and we let them know, you know this is who Choosy is and this is what he represents" }\end{array}$ & $\begin{array}{l}\text { Program staff } \\
\text { focus groups }\end{array}$ \\
\hline & $\begin{array}{l}\text { "I have to say with parents and home visiting another piece of it is that we can also help them with } \\
\text { possible scholarships to our fitness center here locally, so they do take that information like from our } \\
\text { cooking matters, shopping matters" }\end{array}$ & $\begin{array}{l}\text { Program staff } \\
\text { focus groups }\end{array}$ \\
\hline $\begin{array}{l}\text { Classroom } \\
\text { instruction }\end{array}$ & $\begin{array}{l}\text { "1. Intentionally planning IMIL activities throughout the day. } 2 \text {. Teaching motor skills to children and } \\
\text { assessing children's skill levels. } 3 \text {. Implementing Choosy curriculum in all classrooms. } 4 . \\
\text { Implementing Color Me healthy curriculum. } 5 \text {. Monthly nutrition lessons by community partner. } 6 \text {. } \\
\text { Choosy CD's used throughout the day." }\end{array}$ & $\begin{array}{l}\text { Agency } \\
\text { Administrator } \\
\text { Survey }\end{array}$ \\
\hline
\end{tabular}


Table 8

Detailed Responses Regarding General Health Outcomes

\begin{tabular}{|c|c|c|c|c|}
\hline IMIL strategies have... & $\begin{array}{l}\text { Strongly } \\
\text { Disagree }\end{array}$ & Disagree & Agree & $\begin{array}{l}\text { Strongly } \\
\text { Agree }\end{array}$ \\
\hline not helped children possess good overall health. & $62 \%$ & $26 \%$ & $2 \%$ & $0 \%$ \\
\hline helped children get sufficient rest and exercise to support healthy development. & $0 \%$ & $4 \%$ & $66 \%$ & $28 \%$ \\
\hline $\begin{array}{l}\text { helped children maintain physical growth within the Centers for Disease Control and } \\
\text { Prevention (CDC) recommended ranges for weight by height by age. }\end{array}$ & $2 \%$ & $11 \%$ & $57 \%$ & $28 \%$ \\
\hline $\begin{array}{l}\text { not helped children communicate an understanding of the importance of health and } \\
\text { safety routines and rules. }\end{array}$ & $60 \%$ & $34 \%$ & $6 \%$ & $0 \%$ \\
\hline $\begin{array}{l}\text { helped children follow basic health and safety rules and responds appropriately to } \\
\text { harmful or unsafe situations. }\end{array}$ & $0 \%$ & $9 \%$ & $49 \%$ & $40 \%$ \\
\hline $\begin{array}{l}\text { involved families by sharing information about physical health and development and } \\
\text { suggested home activities. }\end{array}$ & $2 \%$ & $11 \%$ & $53 \%$ & $32 \%$ \\
\hline $\begin{array}{l}\text { helped staff serve as an enthusiastic role models for practices that support health and } \\
\text { physical activity. }\end{array}$ & $0 \%$ & $11 \%$ & $47 \%$ & $40 \%$ \\
\hline helped staff discuss the importance of rest and sleep balanced with quiet and active play. & $0 \%$ & $2 \%$ & $36 \%$ & $60 \%$ \\
\hline $\begin{array}{l}\text { helped staff model health and safety practices and give step-by-step explanations of } \\
\text { what and why the practices are necessary and effective. }\end{array}$ & $60 \%$ & $36 \%$ & $4 \%$ & $0 \%$ \\
\hline $\begin{array}{l}\text { not helped staff offer activities that help children learn about their bodies, how they } \\
\text { work, and what is good for their health. }\end{array}$ & $0 \%$ & $9 \%$ & $45 \%$ & $45 \%$ \\
\hline
\end{tabular}


Table 8 (continued)

\begin{tabular}{|c|c|c|c|c|}
\hline IMIL strategies have... & $\begin{array}{l}\text { Strongly } \\
\text { Disagree }\end{array}$ & Disagree & Agree & $\begin{array}{l}\text { Strongly } \\
\text { Agree }\end{array}$ \\
\hline$\underline{n o t}$ helped staff involve children in setting basic health and safety rules. & $0 \%$ & $2 \%$ & $51 \%$ & $45 \%$ \\
\hline helped staff provide play materials related to health and safety. & $0 \%$ & $2 \%$ & $49 \%$ & $47 \%$ \\
\hline $\begin{array}{l}\text { helped staff infuse the discussion of healthy foods and good nutrition into daily routines } \\
\text { as well as music and movement activities. }\end{array}$ & $0 \%$ & $11 \%$ & $45 \%$ & $45 \%$ \\
\hline
\end{tabular}


Table 9

Detailed Responses Regarding Nutrition Outcomes

\begin{tabular}{|c|c|c|c|c|}
\hline IMIL strategies have... & $\begin{array}{l}\text { Strongly } \\
\text { Disagree }\end{array}$ & Disagree & Agree & $\begin{array}{c}\text { Strongly } \\
\text { Agree }\end{array}$ \\
\hline helped children distinguish food on a continuum from most healthy to less healthy. & $0 \%$ & $6 \%$ & $47 \%$ & $45 \%$ \\
\hline not helped children eat a variety of nutritious foods. & $60 \%$ & $36 \%$ & $4 \%$ & $0 \%$ \\
\hline $\begin{array}{l}\text { Helped students distinguish between good for you anytime food, food that should } \\
\text { only be eaten sometimes and the reasons for each. }\end{array}$ & $0 \%$ & $2 \%$ & $38 \%$ & $57 \%$ \\
\hline
\end{tabular}


Table 10

Detailed Responses Regarding Physical Activity Outcomes

\begin{tabular}{|c|c|c|c|c|}
\hline IMIL strategies have... & $\begin{array}{l}\text { Strongly } \\
\text { Disagree }\end{array}$ & Disagree & Agree & $\begin{array}{l}\text { Strongly } \\
\text { Agree }\end{array}$ \\
\hline $\begin{array}{l}\text { helped children develop motor control and balance for a range of physical activities, such } \\
\text { as walking, propelling a wheelchair or mobility device, skipping, running, climbing, and } \\
\text { hopping. }\end{array}$ & $0 \%$ & $2 \%$ & $40 \%$ & $55 \%$ \\
\hline $\begin{array}{l}\text { helped children develop motor coordination and skill in using objects for a range of } \\
\text { physical activities, such as pulling, throwing, catching, kicking, bouncing or hitting balls, } \\
\text { and riding a tricycle. }\end{array}$ & $0 \%$ & $2 \%$ & $34 \%$ & $62 \%$ \\
\hline $\begin{array}{l}\text { helped children understand movement concepts, such as control of the body, how the body } \\
\text { moves (such as an awareness of space and directionality), and that the body can move } \\
\text { independently or in coordination with other objects. }\end{array}$ & $0 \%$ & $2 \%$ & $32 \%$ & $62 \%$ \\
\hline $\begin{array}{l}\text { helped staff follow a daily schedule that allows children to spend ample time each day in } \\
\text { structured and unstructured physical activity. }\end{array}$ & $0 \%$ & $6 \%$ & $49 \%$ & $43 \%$ \\
\hline $\begin{array}{l}\text { helped staff plan structured physical activities that introduce a variety of movement skills } \\
\text { individually, with a partner, and then in a small group. }\end{array}$ & $0 \%$ & $4 \%$ & $40 \%$ & $53 \%$ \\
\hline $\begin{array}{l}\text { helped provide sufficient space, toys, and equipment for child-initiated physical activities } \\
\text { outdoors. }\end{array}$ & $0 \%$ & $2 \%$ & $49 \%$ & $47 \%$ \\
\hline $\begin{array}{l}\text { helped staff offer sufficient indoor space for gross motor activities so children can move } \\
\text { without getting in each other's way. }\end{array}$ & $2 \%$ & $15 \%$ & $49 \%$ & $32 \%$ \\
\hline $\begin{array}{l}\text { helped staff plan activities that promote perceptual-motor development, such as time } \\
\text { awareness/coordination and body and visual awareness. }\end{array}$ & $0 \%$ & $4 \%$ & $49 \%$ & $45 \%$ \\
\hline
\end{tabular}


Table 10 (continued)

\begin{tabular}{|c|c|c|c|c|}
\hline IMIL strategies have. & $\begin{array}{l}\text { Strongly } \\
\text { Disagree }\end{array}$ & Disagree & Agree & $\begin{array}{c}\text { Strongly } \\
\text { Agree }\end{array}$ \\
\hline $\begin{array}{l}\text { helped staff provide opportunities for children to experience obstacle courses in order to } \\
\text { understand their bodies in space and direction. }\end{array}$ & $0 \%$ & $6 \%$ & $43 \%$ & $49 \%$ \\
\hline increased opportunities for moderate-to-vigorous physical activity at the center. & $0 \%$ & $2 \%$ & $45 \%$ & $51 \%$ \\
\hline $\begin{array}{l}\text { not increased the amount of time that children engage in moderate-to-vigorous physical } \\
\text { activity at the center. }\end{array}$ & $53 \%$ & $43 \%$ & $4 \%$ & $0 \%$ \\
\hline $\begin{array}{l}\text { increased the amount of time that children engage in moderate-to-vigorous physical } \\
\text { activity at home. }\end{array}$ & $0 \%$ & $17 \%$ & $45 \%$ & $36 \%$ \\
\hline helped children participate in structured and unstructured physical activities. & $0 \%$ & $2 \%$ & $43 \%$ & $53 \%$ \\
\hline $\begin{array}{l}\text { not helped create safe indoor and outdoor learning environments that invite children to } \\
\text { move their bodies, explore their surroundings, and practice gross motor skills. }\end{array}$ & $64 \%$ & $34 \%$ & $2 \%$ & $0 \%$ \\
\hline
\end{tabular}


Table 11

IMIL Resources Used in Classroom as Reported on Classroom Teacher Survey

\begin{tabular}{lc}
\hline Resource & Percentage (\%) of Classrooms \\
\hline & 43 \\
Choosy character & 87 \\
Choosy music & 47 \\
fruitsandveggiesmorematters.org resources & 15 \\
Produce for Kids resources & 4 \\
Angela Russ music & 34 \\
Choosy puppet & 19 \\
Choosy doll & 15 \\
Bright Futures in Practice (Physical Activity and Nutrition) & 6 \\
Fit Kids book (Nemours Foundation) & 40 \\
IMIL vocabulary framework & 19 \\
Kidshealth.org resources & 26 \\
Let's Move Childcare resources & 57 \\
Choosemyplate.gov/kids resources & 53 \\
Choosy posters & 34 \\
Choosy messages for parents & \\
\hline
\end{tabular}


Table 12

\section{RE-AIM Component Maintenance}

\begin{tabular}{|c|c|c|}
\hline Key Findings & Representative Quotes & Source \\
\hline \multirow[t]{2}{*}{ Daily routines } & $\begin{array}{l}\text { "I think most of the classrooms are really good about just incorporating it within their day } \\
\text { rather than saying okay now it's time for IMIL. I think everyone just kind of like does it like as } \\
\text { their large group or just kind of does it when it works for them." }\end{array}$ & $\begin{array}{l}\text { Program staff focus } \\
\text { groups }\end{array}$ \\
\hline & $\begin{array}{l}\text { "There are daily routines, promoting moderate-to-vigorous exercise, such as } 30 \text { minutes } \\
\text { outdoors on playgrounds, music and dance/movement, obstacle courses, parachute games, use } \\
\text { of large motor equipment outdoors and in the gym. Nutrition activities are presented in the } \\
\text { classroom and sent home. Hand-on activities reinforce lessons from songs. Staff use graphs } \\
\text { and posters, referring to them throughout the day. Different lessons during the day promote } \\
\text { good health and nutrition. Program is mindful of healthy food service every day. Family-style } \\
\text { meals are served, and food groups are discussed at meals." }\end{array}$ & $\begin{array}{l}\text { Agency administrator } \\
\text { survey }\end{array}$ \\
\hline \multirow[t]{3}{*}{ Learning at home } & $\begin{array}{l}\text { "Choosy is good role model in school and they need same at home which this makes me want } \\
\text { to follow through at home also." }\end{array}$ & Parent survey \\
\hline & $\begin{array}{l}\text { "I feel that my child has done great choosing to eat better and she has always been very active. } \\
\text { I enjoy hearing her talk about Choosy with her younger brother that's not school aged yet as he } \\
\text { this that Choosy is cool." }\end{array}$ & Parent survey \\
\hline & $\begin{array}{l}\text { "I'm just really glad that we have the Choosy curriculum because it's helped a lot. The kids } \\
\text { really love the songs and it's helped us assess them for gross motor skills too and that way it } \\
\text { helps explain to the parents you know what they can do at home with their child to develop } \\
\text { more." }\end{array}$ & $\begin{array}{l}\text { Program staff focus } \\
\text { groups }\end{array}$ \\
\hline $\begin{array}{l}\text { Effective classroom } \\
\text { instruction }\end{array}$ & $\begin{array}{l}\text { "You know there's other health curriculum out there, which I can say not so good things about, } \\
\text { but Choosy I think the kids love it and you know we like it. It's easy to follow and it's easy to } \\
\text { adapt to different days." }\end{array}$ & $\begin{array}{l}\text { Program staff focus } \\
\text { groups }\end{array}$ \\
\hline
\end{tabular}


Table 12 (continued)

\begin{tabular}{|c|c|c|}
\hline Key Findings & Representative Quotes & Source \\
\hline $\begin{array}{l}\text { Family and } \\
\text { community } \\
\text { participation }\end{array}$ & $\begin{array}{l}\text { "What's nice too about the Choosy event is they can bring friends and family from the } \\
\text { neighborhood and stuff too so you see other kids, so they're getting used to it before they even } \\
\text { get into our classroom." }\end{array}$ & $\begin{array}{l}\text { Program staff focus } \\
\text { groups }\end{array}$ \\
\hline Policy & $\begin{array}{l}\text { "Our staff were trained on the approach approximately five years ago. We purchased the } \\
\text { Choosy kits from Lakeshore Learning through a local collaboration grant. The funder's goal } \\
\text { was to promote healthy eating and increased movement. We implement a nutrition policy that } \\
\text { limits fats, sugars and salt. This policy guides all of our program activities. / Our program also } \\
\text { revised the lesson planning process several years ago. We require IMIL activities at least once } \\
\text { per week.in our classrooms. / The materials are also available to our case managers who } \\
\text { provide weekly home visits to HS \& EHS families. They include movement and nutrition } \\
\text { activities periodically on visits and at Learn \& Play (socialization)." } \\
\text { "The IMIL concepts are practiced daily within each classroom as well as provider homes. Even } \\
\text { the home visitors provide activities for the entire family to increase physical and nutritional } \\
\text { education. As stated earlier, the program has policies in place to promote physical activity and } \\
\text { healthy nutrition on a daily basis." }\end{array}$ & $\begin{array}{l}\text { Agency } \\
\text { Administrator survey }\end{array}$ \\
\hline
\end{tabular}


Table 13

Family and Community Events that use IMIL Concepts

\begin{tabular}{ll}
\hline \multicolumn{2}{l}{ Number of Events } \\
\hline 0 & $37 \%$ \\
$1-5$ & $44 \%$ \\
$6-10$ & $7 \%$ \\
Over 10 & $12 \%$ \\
\hline & \\
\hline \multicolumn{2}{l}{ Number of Children in Attendance } \\
\hline 0 & $40.7 \%$ \\
$1-199$ & $37 \%$ \\
$200-299$ & $3.7 \%$ \\
Over 400 & $18.5 \%$ \\
\hline \\
\hline Number of Adults in Attendance \\
\hline 0 & $40 \%$ \\
$1-49$ & $37 \%$ \\
$50-59$ & $4 \%$ \\
$60-69$ & $4 \%$ \\
$70-79$ & $4 \%$ \\
Over 80 & $11 \%$
\end{tabular}




\section{Appendix A}

\section{Extended Literature Review}

\section{Physical Activity from a Public Health Standpoint}

Physical inactivity is an issue in the United States (U.S.) that affects the quality of life for children (Institute of Medicine, 2013; Richardson, Richardson, \& Sacks, 2006) both directly (i.e. access, transportation, equipment, and time spent outdoors) and indirectly (i.e. socioeconomic status and culture) (Moore, Lombardi, White, Campbell, Oliveria, \& Ellison, 1991; Sallis, Alcaraz, McKenzie, Hovell, Kolody, \& Nader, 1992). The primary prevention of obesity is a public health initiative (Pate, Pfeiffer, Trost, Ziegler, \& Dowda, 2004). Research has shown that physical activity (PA) is a strong indicator of improvement in one's quality of life (Richardson et al., 2006). PA promotes growth and development, and has mental, physical, and cognitive benefits, which include lower body fat, greater muscular strength, stronger bones, better cardiovascular health, better metabolic health, less anxiety, and higher self-esteem (IOM, 2013). From an academic standpoint, children who are physically active have greater attention, faster processing speed, and higher test scores than their sedentary counterparts (IOM, 2013).

Cardiovascular disease (CVD) risks are influenced by accessibility, peer influence, media, and family practices, therefore it is necessary to provide children with environmental and social supports to establish healthy behavior patterns (Harris et al, 1997).

Exercise activity and habits established in childhood will most likely carry over into adulthood (Harris et al., 1997; Moore et al., 1996; Trost, Sirard, Dowda, Pfeiffer, \& Pate, 2003). The fact of that matter is that only half of youth are meeting the recommendation of 60 minutes of moderate-to-vigorous physical activity (MVPA) each day (IOM, 2013). Physical educators cannot be solely to blame for low fitness levels and obesity in children (Virgilio, 1990). However, most physical education (PE) classes suffer cuts in staff and financial resources and only provide 10-20 minutes of MVPA (IOM, 2013). Despite financial setbacks in PE departments, schools remain a great environment to promote healthy behaviors, as schools provide many people that reach, focus on, and influence children, including staff, administration, and service personnel (Harris et al., 1997). 


\section{Schools, Children, and Comprehensive School Physical Activity Programs}

Schools are influential (Erwin, Beighle, Carson, \& Castelli, 2013) and play a critical role in providing supportive environments where students can be healthy through policy and practice improvements (Centers for Disease Control and Prevention, 2011), considering that students spend a majority of their time here (IOM, 2013). A comprehensive or coordinated approach is one that involves schools and family and community members to maximize student learning and success (CDC, 2011; Sanders, 2001). Community involvement is a central theme for educational reform which began with Dewey's call for community schools (Sanders, 2003). In a community school, the public school is used as a hub for many different partners to bring their resources into this setting for families and community members before, during, and after school each and every day, including weekends (Krysiak, 2001). One way to look at community schools is through a comprehensive or whole-of-school approach.

A comprehensive school physical activity program (CSPAP) or whole-of-school approach (IOM, 2013), should work with parents and communities to provide opportunities on weekends and breaks to influence out of school decisions about PA and its successful implementation needs the support of everyone including schools, communities, and families (Hall, Little, \& Heidorn, 2011). There are five components of such an approach focused on helping students accumulate at least half of the recommended MVPA during the school day (IOM, 2013). These are: high-quality physical education, physical activity during the school day, physical activity before and after school, staff involvement, and family and community involvement. High-quality PE taught by qualified instructors includes standardsbased instruction, where students spend at least 50\% of their time engaged in MVPA (IOM, 2013; Pate, Davis, Robins, Stone, McKenzie, \& Young, 2006). Quality PE is considered the heart of CSPAP. A twoyear study involving 9 elementary school teachers, fourth graders, and fifth graders found that students who received quality PE were significantly more active than those that did not, through the use of videotaped lessons and 7 day PA logs (Chen, Mason, Hypnar, Zalmout, \& Hammond-Benett, 2014). Quality was assessed using the Assessing Quality Teaching rubric. Task design, task presentation, class 
management, and instructional were all found to contribute to student PA levels, more so for girls, especially instructional response.

Physical activity can also be accumulated outside of PE through recess and activity breaks in the regular classroom. Active transport, intramural sports, interscholastic sports, and sports clubs are all ways that physical activity can be provided both before and after school (Pate et al., 2006). The next component, staff involvement, pertains to student and staff programming, so that they, the staff, may serve as physical activity role models alongside physical educators (American Alliance for Health, Physical Education, Recreation, and Dance, 2013).

These components set the foundation for school-based policies and changes on PA energy expenditure in youth (Bassett et al., 2013). In order to achieve these changes, there needs to be mandatory PE, classroom activity breaks, active commuting, renovated parks, after school PA programs, standardized PE curriculum, modified playgrounds and recess, and increased access to parks. There is strong evidence base for PE and classroom breaks that suggests that they increase student activity levels. In the suggested needs for school-based policies and changes, there is no mention of family and community involvement, the final component of a CSPAP. Erwin, Beets, Centeio, and Morrow (2014) suggest collaboration with Physical Education Teacher Education programs, Early Childhood Education programs, Public Health, Exercise Science, Agriculture, Wellness, Health, and Nutrition for a successful CSPAP, but note that parental support is needed in the form of physical activity nights and other activities that focus on the community as a whole.

\section{Family and Community Involvement}

Although arguably the most important component, family and community involvement is the least implemented of all components in a CSPAP. This is surprising as it is supported by many diverse organizations including the National Physical Activity Plan, Let's Move, and Healthy People 2020 (Cipriani et al., 2012), No Child Left Behind, the National Council for Accreditation of Teacher Education, Interstate Teacher Assessment and Support Consortium, Interstate School Leaders Licensure Consortium (Epstein \& Sanders, 2006), the National Coalition for Parental Involvement in Education, 
Coalition for Community Schools, National Parent Teacher Association, National Board for Professional Teaching Standards, and the National Association for Elementary School Principals (Michael, Dittus, \& Epstein, 2007). Furthermore, national teaching exams include questions on family and community involvement skills (Epstein \& Sanders, 2006). Family and community involvement is composed of parents, siblings, and community members to help establish and maintain what's being promoted at school, as well as organize, supervise, and participate in these opportunities (Erwin et al., 2013).

\section{The Neglect of Family and Community Involvement}

According to AAHPERD, the American Alliance for Health, Physical Education, Recreation, and Dance (2008), the success of this component is necessary in order to reach families and collaborate with community members. Furthermore, most teachers have very little undergraduate training in the area (Epstein \& Sanders, 2006; Virgilio, 1990). In a survey of 161 schools, colleges, and state departments of education, $4 \%$ of teachers had taken a whole course; $15 \%$ did some coursework; and $37 \%$ had just one class period on the topic (Epstein \& Sanders, 2006). Over 70\% of respondents believe that coursework in family and community involvement should be required (Epstein \& Sanders, 2006). Student attitudes are fairly positive, but they feel ill-prepared (Epstein \& Sanders, 2006). Full courses allow students to have more confidence and a better understanding and appreciation of partnerships (Epstein \& Sanders, 2006), therefore programs need to build more skill in this area by providing model programs, teaching interpersonal skills, counseling techniques, instructional materials, and by providing clinical experiences (Sanders, 2003; Virgilio, 1990). Current formats of the content include readings, practical activities, and discussions ranging from 30-45 minute sessions (Epstein \& Sanders, 2006).

The same survey examined coursework, content in teacher education programs, and leaders in schools (Epstein \& Sanders, 2006). Leaders believe partnership skills are important, required for accreditation, and are a preferred skill among new hires. Limitations reported included faculty attitudes, university procedures, and state restrictions on graduation requirements, therefore leaders must be active to bring about change and serve as team builders to guide staff. Much of the reported coursework was in the Special Education and Early Childhood Education fields. No states required complete classes on 
family and community involvement; 11 states require some for early childhood education majors; and 15 states require it for special education majors. Half of the respondents require it as a component in elementary education, but not for secondary, which may be a factor in the drop off of family and community involvement after elementary school. Family involvement is generally not expected as much in middle or high school, and is not a high priority in many state departments of education. The study concluded that $30 \%$ of respondents were in the change process, but more research needs to be conducted. Considering that $97 \%$ of teachers say that working with parents is one of their biggest challenges (Epstein, 2008), these programmatic changes in teacher preparation are critical.

Even with programmatic changes in teacher preparation, there may still be barriers to its successful implementation. Some barriers to the implementation of family and community involvement in schools include limited time and resources, cultural differences, and lack of staff and training (Cardon et al., 2012; Michael et al., 2007). Schools also fear public scrutiny, staff burnout, territorialism, and overcoming the attitudes and the perceptions of staff (Sanders, 2001). For families, barriers include lack of time, lack of desire, lack of commitment to the school, (Virgilio, 1990), limited knowledge of opportunities to participate, perception that the school doesn't want their participation, the belief that their child would be embarrassed, and the belief that the subject matter doesn't allow for parental involvement (Michael et al., 2007). Hence, there is a need to have strategies in place to help facilitate parental involvement (Virgilio, 1990).

By building relationships with parents, it is likely that their attitudes will positively change (California State Department of Education, 1973) and they will be more open to participating (Castrechini et al., 2012). Strategies to overcome the barriers include providing transportation to and from events, providing childcare, making schools welcoming (CDC, 2012; Elliott, 2005), taking suggestions for improvement, careful planning (Elliott, 2005), purposeful communication, linking activities to school improvement goals (Epstein, 2008; Epstein \& Sanders, 2006; Sanders, 2003), assisting all families in identifying programs and services to meet their needs, and communicating directly (Castrechini, London, $\&$ the Center for American Progress, 2012). 
Although little study has been conducted on the outcomes of such involvement (Castrechini et al., 2012) and research in the field is not prevalent, the results currently available are promising (Erwin et al., 2013). Some research has shown that for academic subjects, family and community involvement is linked to better grades, better attendance, better behavior, program quality (Castrechini et al., 2012; IOM, 2013), and enhanced student attitudes toward subject matter (Sanders, 2001). Therefore, the same effects are likely to occur regarding health behaviors (Erwin et al., 2013). It is also known that families influence attitudes, and knowledge as well as impact behavior (Erwin et al., 2013). Families that support learning at home have been linked to higher achievement and continuous family involvement results in positive school experiences as children progress through school, and increased support results in increased success for the child (Appalachia, 2005). Families are critical in the lives of children and must be a part of the process (Association for Supervision and Curriculum Development, 2011). With this is mind, one must also remember that a child observes, learns, and develops in the community, as well (Elliott, 2005). Both families and communities teach norms (Harris et al., 1997) that influence and shape a child's behavior (Cipriani et al., 2012).

A longitudinal exploratory study, based on the socioecological model, spent eight months evaluating a CSPAP program in 20 urban elementary schools (Centeio, McCaughtry, Gutuskey, Garn, Somers, Shen, \& Kulik, 2014). Data included pre and post accelerometer data for $4^{\text {th }}$ graders, International Physical Activity Questionnaire data for parents and educators. While no gender differences were found, children increased MVPA by 58\% along with significant parental change. Parent engagement strategies included presentations at parent/teacher conferences and school board meetings, hosting family fitness nights, sending regular correspondence to parents, healthy living education, and healthy living homework to be completed as a family. CSPAP try to encompass all influences on a child's PA behaviors. 


\section{Influences on Child Physical Activity Behaviors}

One way to view the influence of both families and communities is through the socioecological model. This model posits that there are multiple levels of influence on student PA levels (Welk, Wood, \& Morss, 2003): the interpersonal, intrapersonal, organized or structural, community, and policy levels (Van Acker et al., 2011). For the example the intrapersonal level would refer to a child's knowledge, skills, and attitudes towards PA, nutrition, and other healthy behaviors, while the organized or structural level includes schools and a child's access to PA opportunities and meals during the school day. The community level may include access to sidewalks, parks, and fresh fruits and vegetables, while the policy level may refer to state, national, or federal level such as the school lunch program and the national guidelines for physical activity.

The interpersonal domain is very important for children, in that it includes peers, parents, and teachers (Welk et al., 2003). It is known that PA levels can be influenced by biology, psychology, society, culture, and environment (Vidoni \& Ignico, 2011). Family members, especially parents, are powerful, significant influences (CDC, 2012) on the PA levels of children and family members act as role models for one another (Sallis et al., 1992). Parents influence children's behavior across the board, regardless of culture, education, or income (AAHPERD, 2008; Michael et al., 2007). Epstein (1995) describes overlapping spheres of influence to refer to schools, families, and communities. Externally, students grow, learn, and develop at home, in school, and in the community. These three entities can either be drawn closer together or pushed further apart in terms of practices being conducted together or separately in order to influence students. When viewed internally, it demonstrates where and how complex and essential interpersonal relationships and patterns occur between the three settings. This can occur at the institutional level as schools invite all families to an event, or individual, such as a one-onone meeting between a teacher and parent. Regardless, the student is always at the center. The family ecological model describes how parent behaviors affect child physical activity levels in terms of modeling (Bellows et al., 2011; Erwin et al., 2013; Moore et al., 1991; Sallis, Patterson, McKenzie, \& Nader, 1998), accessibility of PA options (Sallis et al., 1992), knowledge, and shaping (Welk et al., 2003), which 
in retrospect have effects on family demographics, child characteristics, organizational/community characteristics, and policy/media influence (Van Acker et. al, 2011). Family support is critical in increasing PA levels (Nader et al., 1996), in addition to parent encouragement (Sallis et al., 1992) and teacher encouragement. In adolescents, it was found that parents play modest, significant roles in PA, but the role of the PE teachers was equally important (McDavid, Cox, \& Amorose, 2012).

These roles are important because discontinued PA is often a result of a lack of social support (Ransdell, Eastep, Taylor, Oakland, Schmidt, Moyer-Mileur, \& Shultz, 2003) and families are a great source of social support for healthy behaviors, despite being overlooked. The self-determination theory states that others, including parents and teachers, encourage self-determined motivation through various social supports, such as providing autonomy support for PA (McDavid et al., 2012). Another theory, the social cognitive theory, explains the relationship between cognitive, behavioral, and environmental factors, which include role modeling, social influence, and social support processes (Nader et al., 1996). Self-regulation requires broader social and institutional support (Welk et al., 2003). Simple encouragement to increase family involvement is no longer enough in the fight on obesity due to the complex nature of families and their lifestyles (Richardson et al., 2006). One has to consider family structure, socioeconomic status (SES), and culture (Sallis et al., 1992), as family demographics and student diversity continue to change (Sanders, 2003). For example, in home situations, parental absence may restrict PA opportunities for some, but for others reduced supervision may increase it (Sallis et al., 1992). Therefore, intervention may be necessary at times.

Many interventions have not only focused on the child, but their families, as well with positive results (Ford, McDonald, Owens, \& Robinson, 2002; Robinson, 1999). Ford et al. (2002), conducted a randomized controlled pilot and feasibility trial with twenty-eight African-American low-income families and their school-age children using counseling and behavioral intervention. Parents chose weekly screen time budget and helped their child stick to that budget. Post-survey data showed decreases in screen time and greater participation in physical activity. Robinson (1999) also wanted to reduce screen time in 
elementary school students by providing 18 lessons in a 6-month period and elicited parental involvement through newsletters and time budgeting devices with similar success.

Support and participation together in PA can enhance relationships in addition to increasing PA levels (Moore et al., 2001; Ransdell et al. 2003). Ransdell et al. (2003), randomly assigned 34 mothers and daughters to a 12-week university or home-based intervention. The home-based group received packets for exercising in or around the home, while the university-based group met three times a week for fitness and recreational activity. Not only did physical activity levels improve, but mother-daughter relationships were strengthened, as well. Positive relationships increase PA from parent facilitation, encouragement, spectatorship, competence beliefs, and participation with child (McDavid et al., 2012; Ornelas, Perreira, \& Ayala, 2007). Unfortunately, many families do not participate in PA even 20 minutes a week (Virgilio, 1990). Parental involvement supports self-determination, and has been found to be one of the three most important forms of parent support for PA (McDavid et al., 2012). Sallis et al. (1992), showed that verbal encouragement alone had no association with PA levels when examining one hundred forty-eight fourth grade girls and 149 fourth grade boys and their parents, thus suggesting modeling may be more effective in increasing PA levels. This was particularly true for boys, where higher levels of PA were associated with transportation and parent participation. However, Welk et al. (2003), in a study of 995 elementary school students and 536 parents, suggests that role modeling has been met with mixed results, and is not a major source of influence, considering children spend lots of time away from their parents.

Despite Welk's finding, others have stated that students are more inclined to be active if they see their parents as active role models (Subramaniam, 2011). Home is the most influential environment for youth, as parents are part of a child's support unit (Bellows et al., 2011; Virgilio, 1990) and serve as gatekeepers to PA, controlling what activities a child has access to, participates in, in addition to having the power to provide or withhold the resources to do so (Sallis et al., 1992; Welk et al., 2003). Parental encouragement and parental facilitation are significant predictors of child interest and involvement in PA (Erwin et al., 2013). 
Several studies have shown how parents influence the PA levels of their children (Freedson \& Evenson, 1991). The studies have used many different research designs, different instruments, and measured several different items including children's perceptions of competence, parent role modeling, parent encouragement, and parent PA levels. However, there is a lack of valid, reliable PA assessment tools, therefore the existing ones need to be improved and standardized. In a survey completed by children and self-reported PA levels by parents, children of active parents had higher scores on parental influence measures and psychosocial correlates (Welk et al., 2003).

To demonstrate the influence that parents have on the activity levels of their children, one study used accelerometers in children ages 5-9 and their parents (Freedson \& Evenson, 1991). There was a $67 \%$ resemblance in father-child accelerometer data and a $73 \%$ resemblance for mother-child. In activity records, the resemblance was $70 \%$ for fathers, and $66 \%$ for mothers. Thus, children exhibited PA patterns similar to that of their parents, but were more active than their parents. It was also suggested that physical inactivity may have more role modeling influence than physical activity. The influence of both parents was more influential than just one, therefore promoting PA to parents can increase PA in their children.

Another study conducted nationally over time involving adolescent health used interviews to collect data on family cohesion, parent-child communication, and parental engagement. All of the aforementioned factors positively predicted MVPA for both genders, while parental monitoring did not (Ornelas et al., 2007). Furthermore, self-esteem served as a mediator for the relationship between parental influence and PA. The study also found that children have higher activity levels when they come from homes that are run in an authoritative manner, have educated parents, and households that are warm and supportive with high autonomy levels. Such households most likely engage in several types of involvement, as described by Joyce Epstein.

\section{Six Types of Family Involvement}

Epstein (2008) identified six types of involvement as ways for families and communities to work together and have a presence in the school without necessarily being at the school in person. Family engagement is beyond parents physically coming to the school for programs and events (Castrechini et 
al., 2012). The six types of involvement are parenting, communicating, volunteering, learning at home, decision-making, and community collaboration.

Fitness behaviors are learned and behavioral parent training has been shown to be effective in changing child behavior (Taggart, Taggart, \& Siedentop, 1986), hence the justification of parenting, where schools provide workshops, seminars, and informational sessions (CDC, 2012; Epstein, 2008) to better assist parents in helping their children lead healthy lifestyles.

Communicating involves keeping parents and community members informed, as both have the capacity to promote healthy behaviors (Harris et al., 1997; Springer, Kelder, Ranjit, Hochberg-Garrett, Crow, \& Delk, 2012) and need some guidance. It is important that students and their families are aware of what resources are in their community, therefore providing this information is critical (Subramaniam, 2011).

Communication is the foundation for success, however communication is not valuable unless it is two-way, effective, and frequent (Elliott, 2005). Communication should occur in a variety of ways that are both verbal and non-verbal (Elliott, 2005). Another consideration is that there are many homes where English is spoken as a second language (Larson, Ward, Neelon, Story, \& Robert Wood Johnson Foundation, 2011). One can start by using school websites or newsletters which are already in place (Cipriani et al., 2012; Elliott, 2005). Other effective modes of communication include: flyers, memos, banners, signs, post cards, letters, text messages (Elliott, 2005), electronic mail (e-mail), door hangers, public service announcements, automated phone system calls, radio, television, (CDC, 2012), results of health screenings (Michael et al., 2007), fitness report cards (Virgilio, 1990), home visits (Appalachia, 2005), bulletin boards (Faber, Kulinna, \& Darst, 2007), brochures (Ford et al., 2002), informational packets (Ransdell et al. 2003), workshops/seminars (Sanders, 2001; Virgilio, 1990), parent-teacher conferences (Erwin et al., 2013), PA calendars where organizations and community members can post their events, a message board with open forum discussion to talk about what is currently available in the community, quick facts sheets, and social media (CDC, 2012). 
Topics and strategies may include motivation for PA (CDC, 2011), strategies to decrease sedentary behaviors such as television viewing (Robinson, 1999), benefits/importance of PA (AAHPERD, 2008), the differences between PA and PE (Hall et al., 2011), and how to help children acquire 60 minutes of MVPA each day (AAHPERD, 2008). In these ways, parents are provided with education (Castrechini et al., 2012), reinforcing PE activities, and made aware of their responsibility in being an ally for healthy lifestyles (Virgilio, 1990).

It is also important to communicate to family and community members about special events that the school will be hosting (Castrechini et al., 2012). Examples include inviting them to observe, participate, or be guest speakers in PE class (Hall et al., 2011), demonstration nights (Virgilio, 1990), and Family Fun Nights (Faber et al., 2007; Subramaniam, 2011). The PE teacher can take an active role in community and family involvement by using parents to develop and reinforce PE programs (Nader et al., 1996).

Some ways that this can be accomplished include, but are not limited to the following: involving the Parent Teacher Association (PTA) for promotion of PA (Michael et al., 2007), gathering volunteers/support and money, hosting PA fundraisers (Appalachia, 2005), creating active events (Harris et al., 1997), encouraging parents to walk or bike children to school or work out together (Subramaniam, 2011), assigning active homework (Epstein, 2008; Erwin et al., 2013) to be completed with a family member (Subramaniam, 2011) at home and in the community (Taggart et al., 1986; Virgilio, 1990), providing resources for families (Taggart et al., 1986), and having PE field trips to help students in skill transfer (Cipriani et al., 2012). Furthermore, other staff and subject matters can also be involved in the promotion of PA (Michael et al., 2007).

For example, PA and literacy can be combined through hosting book clubs and Family Literacy Nights or picnics (Richardson et al., 2006). Books can focus on a PA topic, then afterwards the child and family member can participate in the activity. Family picnics can enforce healthy eating, literacy, and PA. School-wide events change the school environment by heightening student morale and spirit (Virgilio, 1998), as well as motivate students and their families to be active for a lifetime (Subramaniam, 2011). 
Volunteering lends itself to family and community members in that they can volunteer time (Castrechini et al., 2012; CDC, 2012; Hall et al., 2011), money, or making other donations (Hall et al., 2011) to active events such as Fitness Field Day, School Health Fairs, and Fit For Life Family Night (Erwin et al., 2013). Other ways for parents to volunteer are through service, such as building or repairing equipment, painting, or landscaping (Sanders, 2003; Virgilio, 1990).

Another type of involvement, learning at home, can be implemented in a variety of ways (CDC, 2012), including active activity logs (Subramaniam, 2011), assignments such as PA calendars, goal setting, family discussions (CDC, 2012), collecting information about PA opportunities for their families in the community, and other community-based PA projects (Michael et al., 2007). It is important that homework builds basic skills instead of duplicating teacher efforts (Virgilio, 1990).

One strategy to get more students to do their active homework is to assign extra points for parent participation or a point system that allows them to redeem active prizes, such as field trips to ski slopes or water parks (Subramaniam, 2011). The Child and Adolescent Trial for Cardiovascular Health (CATCH), implemented in ninety-six elementary schools, assigned activity packets and provided a variety of incentives for completed packets in order to reinforce the classroom curriculum at home (Nader et al., 1996). The packets included recipes, physical activity, and goal setting, in addition to two family nights that were hosted. Taggart et al. (1986) used a twelve-week home-based activity program to help improve the fitness levels of twelve elementary school children and their families. Parents kept track of their child's activity levels and were encouraged to observe and/or take part in the activity with their child using a contingency contract decided upon by the parent and child. Family contracts give an outline, but then allow families to decide what they will do and when and how long in order to get fitness rewards (Nader et al., 1996) including gym passes or frozen yogurt. Local businesses can donate free passes for these items (Sanders, 2001; Sanders, 2003). Providing parents with a resource room where they can meet and network (Castrechini et al., 2012), while also providing access to active video games, workout videos, and other health-related resources (Virgilio, 1990). Furthermore, a homework assignment could require the use of the room. 
School-wide events can benefit from the different types of involvement as they are a great strategy to involve parents and community members (Virgilio, 1998). They are able to assist in supporting, budgeting, advertising, and planning on a committee for the event. Fitness Field Day would emphasize health, participation, PA, and social interaction. Fit for Life Family Night could begin with facts and information about fitness followed by a warm up, fitness activities, and cool down. Special events can last anywhere between $1 \frac{1}{2}-2$ hours with a variety of prizes, games, and activities in fair format occurring in the gym, auditorium, or play area to raise awareness of goals and skills in a fun way (Nader et al., 1996). The paragraphs that follow will provide other examples of school wide events to elicit participation from families and communities.

Geography Run is a school wide walking and jogging program that can occur at school, at home, and in the community. Students report mileage on a trip ticket that must be signed by a teacher or parent, then plot it on a map of the United States posted in a central location of the school. This is a great activity that incorporates other subjects. A school health fair can be conducted in the same manner that schools have science or social studies fairs, only the topic of interest is on health and PA. In the Neighborhood Fitness Trail, parents and children design fitness stations around their neighborhood and calculate mileage. Wake up or Evening's End Workouts are ten minute routines made up by the parent(s) and child to be completed before or after school. The workouts can be tracked on a refrigerator calendar.

A Fall Community Health Fair can be hosted in collaboration with businesses such as physical therapists, gym owners, dance studios, nutritionists, and many others (Sherwood-Puzzello, 2007; Virgilio, 1990). Young at Heart gives senior citizens in the community a child as a workout partner and is another way for children to link PA to the community. This is a feasible idea to provide children with active role models and mentors in the community (Sanders, 2001).

Jogging and Walking Clubs (Subramaniam, 2011) or Wellness Groups (Cardon et al., 2012) that include teachers and family members are another effective way to increase student involvement. The interaction between parent and child through active events (Castrechini et al., 2012) and homework help support new health behaviors at home (Nader et al., 1996). 
One strategy to keep in mind is that higher attendance may be gained when events are planned the same nights as Parent Teacher Conferences (PTC) or PTA meetings, when parents are already on school grounds (Virgilio, 1990). When planning active events, it is important to enlist the help of the community, as well as host some events in the community itself (CDC, 2012). One such way is through the use of partnerships. School-family-community partnerships are one way in which community collaboration, the final type of involvement, can be implemented.

\section{School-Family-Community Partnerships}

School-community-family partnerships empower both family and community members to serve on school wellness councils (Michael et al., 2007), be advocates of PA in the decision making-process (CDC, 2012). Joint use agreements (JUA) have been suggested by many researchers as a way to connect schools, families, and communities and increase participation and PA levels (Evenson, Fang, Lee, Heinrich, \& Eyler, 2010; Sherwood-Puzzello, Miller, Lohrmann, \& Gregory, 2007). Schools can allow community and family members to use facilities before school, after school, and on the weekends. Furthermore, schools can allow community partners to use facilities, as well (Sanders, 2001). In return, these organizations can offer services on school grounds for lower costs. The School Health Policies and Programs Study (SHPPS) found that there were no meaningful changes or progress towards JUA (Evenson et al., 2010). The study measured school PA facilities and community access to school for PA. Two-thirds of schools allowed community-sponsored sports teams to use outside facilities during nonschool hours, but this rate was less for indoor facilities. Availability was also higher after school hours, on evenings, weekends, and school vacations, but not before school. The rates were also higher for public schools, schools with intramurals, and schools with one or more indoor spaces. Adult access is lower than youth access, but JUA are a way to provide adults with additional opportunities. At the time of the study, the United States was not meeting Healthy People 2010 objective 22-12 pertaining to JUA. In West Virginia, community access outside of school hours to indoor facilities was lower in elementary schools, but outdoor access was higher. There are many benefits to JUA that reflect the usefulness of partnerships. 
Partnerships can reduce barriers in regard to access and cost through cost sharing, creating greater community access (CDC, 2011), and lowering costs for students and their families (Cardon et al., 2012). Considering that PE can only do so much with limited time and funding, it is only fitting that community resources are promoted, facilitated, and modeled to support student success (Sanders, 2003) and PA levels outside of school (Faber et al., 2007). Partnerships can enhance a child's quality of life and well-being. Some goals in Healthy People 2010 were intended to achieve a better quality of life, thus the need to promote PA at home and in the community (Subramaniam, 2011). Partnerships with organizations have the potential to provide staff, training, and support to schools and families (Van Acker et. al, 2011). For example, a partnership with the parks and recreation board could supply attendants at parks. In one community, this small change resulted in more children being active outdoors and spending less time engaged in sedentary behaviors (Evenson et al., 2010). These relationships can help alleviate funding and staffing issues that the school may currently face (AAHPERD, 2008).

Ultimately it is up to the school to let parents and community members know that their involvement is both wanted and expected, as schools must connect, engage, and sustain these partnerships (CDC, 2012), as well as produce partnerships that engage, energize, and motivate students to produce their own success (Epstein, 1995). The manner in which schools care about children reflect the way they care for the child's family. In this way, families are seen as partners, and the community is viewed as a partner, also, to help children develop to their fullest potential (Epstein, 1995).

School-community partnerships are critical in helping maximize relevant physical activity opportunities for students both in and out of school (Bassett et al., 2013;;, Kann Brener, \& Wechsler, 2007) as schools and communities work cohesively to benefit families (Subramaniam, 2011), children's well-being (Sanders, 2003), and larger society's health and development (Sanders, 2001). Partnerships improve school programs and climate, provide family support/services, increase parent/skill and leadership, connect families with others in the school and community, as well as help teachers do their jobs in an effective manner (Epstein, 1995). Youth are more active and successful if they come from schools that have a strong partnership with the community that help support lifelong PA and learning 
(Epstein \& Sanders, 2006), therefore collaboration between school, family, and community needs to send consistent messages (CDC, 2011), encouragement, and resources (Harris et al., 1997; Sanders, 2003).

Traditionally family and schools have been deemed the greatest influences, however the community is also important because it has resources beyond that of schools and parents (Harris et al., 1997; Sanders, 2001). There are four approaches that guide school and community relationships: familyschool partnerships, family-like schools that support and encourage children, families active in schools, and support at home (Appalachia, 2005). The four approaches can further categorized as family-like schools, school-like families, and family-like communities. Family-like schools welcome all families and make each child feel special and included. School-like families realize that the child is also a student and reinforce what's going on at school in their home, as well as in the community. Family-like communities help families better support their children, as community-minded families help their neighborhood and other families (Epstein, 1995).

Community partnerships serve two purposes: to support and enhance implementation in schools and serve as catalysts for change (Harris et al., 1997). Partnerships can strengthen relationships and trust, but must be a team effort built upon mutual respect, (CDC, 2012; Erwin et al., 2013) and used as a tool for advocacy and collaboration (Erwin et al., 2013; Harris et al., 1997; Virgilio, 1990). Sanders (2001) suggests the following for building partnerships: identify issues/goals to address, define the focus and scope of the partnerships, identify community assets, select partners, monitor progress (Epstein, 2008), evaluate activities and the nature of the partnership (Harris et al., 1997; Sanders, 2003), and share success stories. Epstein (1995) suggests developing an action team, obtaining funds and other support, identifying starting points, developing a three-year plan, and continuous planning and working. Sustainable partnerships require stakeholders (Silva- Sanigorski et al., 2012), with shared goals (Epstein, 1995) and expertise in order to increase collaboration, create additional opportunities for children, and transfer active lifestyles between home, school, and community (Armour \& Sandford, 2013) because only sustainable programs will make a lasting impact (Epstein, 2008). 
One must also consider the intensity and duration of the partnership, hence it is important to start with simple partnerships before moving on to more complex ones (Sanders, 2003). Schools can start by helping students form connections between the home, school, and community (Van Acker et. al, 2011). One important step in the process of forming such partnerships is the support of a school leader and PA team made up of parents, students, administrators, community members, and teachers (Van Acker et. al, 2011) for different perspectives and reflection (Sanders, 2003). It is important to have members from all three settings (school, home, community) represented because ownership is shared between them (Epstein, 1995; Van Acker et. al, 2011). Some studies have sought to find the extent that school-familycommunity partnerships are being utilized.

The School Health Policies and Proms Study 2006 revealed that family and community involvement, according to Epstein's aforementioned framework, was occurring at all levels, however the fundamentals to increase it were not being implemented (Michael et al., 2007). Mail surveys including all 50 states represented a sample of 461 school districts and phone interviews of representatives from 1,029 elementary, middle, and high schools. The sample also represented 912 health educators, and 1,194 physical educators, respectively. Of those surveyed $55.5 \%$ of health educators and $30.8 \%$ of physical educators required learning at home, and less than $50 \%$ of schools offered any form of parenting. There were high rates of communicating in terms of information being sent home, however less than $50 \%$ of respondents encouraged volunteering or collaboration with the PTA. In the decision-making category, most schools had a diverse wellness council, which included parents and community members, but the lowest numbers were in the category of community collaboration. Despite the high frequency of professional development sessions that promoted family and community involvement, many did not target physical education or health, and these teachers had little interest in the component. Between 2000 and 2006, while there were improvements in community collaboration and communication, there were some decreases in family involvement related to the development and implementation of policies. This is somewhat disheartening in that parents are a valuable source in the community and should be involved in the decision-making process, as it affects their child (Elliott, 2005; Subramaniam, 2011). Other areas that 
improved were the requirement of high school students to participate in a community program (Subramaniam, 2011) where the parent was a role model, staff development focused on family and community involvement in PA, and increased funding for staff development regarding this component. Another study showed low scores in pupil, parent, and community involvement (Cardon et al., 2012). Respondents stated that they required better knowledge of community schools and needed more professional development in order to maximize opportunities for students (Cardon et al., 2012; Virgilio, 1990). Community schools offer an efficient use of resources, but integration and collaboration are necessary in order for the concept to be successful (Castrechini et al., 2012). Professional development can be provided in the form of workshops, mini courses, seminars, videotapes, and summer institutes (Sanders, 2001; Virgilio, 1990). A partnership with a local university can increase collaborative capacity through this type of training and can serve as a catalyst for greater collaboration across the university, including cross-curricular collaborations (Epstein \& Sanders, 2006; Sanders, 2003). Furthermore, more community partnerships were occurring at the elementary level than the secondary level, as there is a drop off in maintenance once students transition to middle school (Castrechini et al., 2012; CDC, 2012; Epstein, 1995). Policies on school-community partners and family involvement are generally not being implemented. It is important to have a liaison between the school and community (CDC, 2012), as schools in this study wanted a coordinator for community partnerships. School administrators have been suggested to fulfill this role (Epstein, 2008; Subramaniam, 2011).

When seeking partners, many times the focus is only on businesses and large organizations, however it is important to remember that connections are not just geographical, but social as well, and potential partners can be individuals or non-business establishments, such as churches (Erwin et al., 2913; Sanders, 2001). A national survey based upon Epstein's six types of involvement was conducted for a better view on community partnerships (Sanders, 2001). Schools were provided with a book as a resource (Harris et al., 1997), used newsletters, and provided support through phone calls, e-mails, website access, and a training workshop. Seventy percent of the 443 schools had at least one partnership. Businesses dominated the number of partnerships, therefore it is likely that schools underuse other community 
partners. There were a variety of community partners reported including universities, government agencies, volunteer organizations, senior citizen organizations, faith based organizations, and many more. A broader definition of community will be necessary to encourage schools to reach out to potential partners who are less visible.

One key challenge for schools in the study was expanding to improve existing school, family, and community partnerships and seek out others, but $75 \%$ of schools were working on this. The barriers of these partnerships that need to be overcome in order to maximize benefits are lack of participation, time, community partners, leadership, funding, communication, and focus. Lack of participation can be overcome by reaching out for volunteers beyond faculty to coordinate the partnerships, use local media (Harris et al., 1997), send newsletters, use reminder phone calls (Harris et al., 1997), encourage people to bring friends, offer incentives, change the time of events by including both weekends and weekdays (CDC, 2012), provide transportation and babysitting (CDC, 2012), and use community settings, instead of only the school (CDC, 2012).

In terms of time, one can use a wider range of volunteers to plan and implement activities, hire facilitators for partnership activities, hold meetings before or after school, or use volunteers to cover classrooms so that teachers may meet during the day. To overcome barriers related to community partners, one must look outside of businesses and corporations for community partnerships, attend both formal and informal community events and meetings to learn more about people and the community (CDC, 2012), and network outside immediate geographic locations. Instead of just gathering information, one can form meaningful relationships and learn about norms, traditions, and values in the community (Appalachia, 2005).

By involving other school groups such as the PTA, it is possible to build a wide, diverse pool of leaders (Bassett et al., 2013; CDC, 200; Epstein, 2008; Epstein \& Sanders, 2006; Harris et al., 1997), through trainings on school-family-community partnerships (Harris et al., 1997). Funds from the PTA, donations from community businesses, fundraisers, grants (CDC, 2012), and goods/services from the 
community can help overcome funding issues. Overcoming such barriers is useless if communication is ineffective.

Open communication is necessary for successful partnerships (CDC, 2011; Elliott, 2005; Sanders, 2003). Open communication strategies include suggestion boxes, surveys, focus groups, and parent blogs (CDC, 2012). Communication barriers can be overcome by having students make reminder phone calls, using interpreters, and incorporating a variety of communication outlets, including newsletters, newspapers, television, and radio. By matching partnership goals to school improvement goals, it is possible to overcome barriers related to focus. Despite these barriers, large urban areas have additional obstacles to overcome, such as finding a partner, since there is more competition and a greater emphasis placed upon businesses. Many of the activities reported in the study supported or enhanced the other five types of involvement. There is a need for research on factors that facilitate and hinder partnerships, connections to inform both policy and practice, and different functions and forms of community involvement. Many studies have looked beyond partnerships to determine the involvement of each entity on its own.

$\mathrm{CATCH}$, which focused on family, showed high involvement from teachers in active programming, high rates of activity packets turned in, and high student involvement rates. In addition, 90\% of activities were implemented for two family nights and one party celebration (Nader et al., 1996). The CDC School Health Index collected data via focus groups that included parents and community members about cost, time, equipment, and feasibility (Sherwood-Puzzello et al., 2007). Module 8 focuses on family and community involvement. Areas of improvement included better collaboration between teachers, parents, and community members, as well as hiring a wellness coordinator to make more programs and increase family and community involvement. Other areas for improvement were increasing advertisements by the community for outside programs, increasing family knowledge of community events, increasing family involvement in school events, program planning, and community-based programs. The parent survey also revealed strong support for healthier schools. 
The SHPPS in 2006 was the largest, most comprehensive of school health program assessments (Kann et al., 2007). Data was collected though computer-assisted telephone interviews or selfadministered mail questionnaires. The eight components assessed were PE/PA, nutrition services, healthy school environment, faculty/staff health promotion, health services, mental health/social services and family and community involvement. In terms of involvement, many schools were not effectively using families and communities. In fact, only $55 \%$ of the $39.5 \%$ of schools with health councils, included families. Furthermore, only $32.8 \%$ met with the PTA; $28.2 \%$ offered health education to families; and $30.8 \%$ required homework or projects to be completed with a family member. Existing policies where family and community members served as role models or mentors were evident in $26.6 \%$ of elementary schools, $25.8 \%$ of middle schools, and $30.8 \%$ of high schools. Communication was increased by providing information and taking suggestions from family and students, however impact and effectiveness were not assessed.

Despite the research findings that teacher preparation programs are providing information on family and community involvement for early childhood educators, one can see there is still a gap in the literature regarding its actual implementation in childcare centers. Furthermore, the idea of a CSPAP has not been applied to a preschool setting, but rather a K-12 setting. As demonstrated in the literature, the younger the child, the more involved the parent. Therefore, early childhood is one of the best times to promote lifelong physical activity.

\section{Physical Activity, Nutrition, and Preschool Children}

Daycare centers are relationship-based facilities that play a key role in a child's future (Elliott, 2005) and preschool age is an influential time to promote a lifetime of healthy behaviors (Bellows et al., 2011; Larson et al., 2011). The majority of children ages 3-5 (60\%) attend preschool (Kirk, Vizcarra, Looney, \& Kirk, 2013) with many of them (41\%) spending 35 hours or more a week in this setting. Another 25\% attend for 15-34 hours; $16 \%$ for 1-14 hours; and 18\% don't attend at all (Story, Kaphingst, \& French, 2006). Many daycares focus on nutrition, but neglect PA (AAHPERD, 2011), despite the risk that if a child is obese in preschool, they are more likely to remain obese in adolescence and adulthood 
(Larson et al., 2011; Vidoni et al., 2011; Story et al., 2006). In one study 45\% of daycares offered nutrition education, while only $30 \%$ offered information on PA through flyers, handouts, brochures, and newsletters. A national study showed that $97 \%$ worked on healthy eating and $78 \%$ on PA, but most programs did more than just disseminate information. There were additional educational workshops or discussions and parent teacher conferences. Eighty-percent of programs let parents help and $40 \%$ of parents were involved in obesity prevention. In a 2008 survey of 1,583 Head Start programs, $60 \%$ offered nutrition workshops for staff; and $84 \%$ for parents; $63 \%$ provided workshops pertaining to gross motor activity for staff, and $43 \%$ for parents. Ninety-seven percent reported at least one community partnership for nutrition and 75\% for PA (Gooze, Hughes, Finkelstein, \& Whitaker, 2010).

Regulations regarding PA and nutrition are limited and vary by state, therefore opportunities for parent education and involvement may also be limited (Larson et al., 2011) due to the neglect of policymakers with regard to childcare centers (Story et al., 2006). For these reasons, there is also a lack of research on parent perceptions on nutrition and PA environments. A survey in NC revealed that parents wanted more fruits and vegetables (FAV), structured provider-led PA, and more outdoor play. Successful strategies to promote PA may include: integrating PA into classroom curriculum, modifying food service practices, classroom based nutrition education, and engaging parents through newsletters or other activities. However, it is not clear what combinations or specific strategies actually work. For example, at Head Start, 94\% of programs don't allow staff to eat or drink in front of children. Head Start regulations include giving parents guidance on nutrition and PA, healthy behaviors and attitudes modeled by staff, opportunities for outdoor/indoor active play, adequate space and equipment, opportunities to develop gross and fine motor skills, 90-120 minutes of PA each day, staff involvement, outdoor play, and screen times 30 minutes or less once a week and only if it is educational.

There is a lack of PA/nutrition programs for preschool children, however the Food Friends: Get Movin' with Mighty Moves program wanted to increase gross motor skill and PA (Bellows et al., 2013). The main focus of the program was to overcome barriers that the child may face in the home. The purpose of the study was to determine what messages and materials both reached and motivated families to be 
more active. Four Colorado Head Start centers were assigned to an experimental group in a randomized trial. Ninety-seven surveys were sent out to the centers with 51 respondents for a $52.5 \%$ response rate. Participants were compensated $\$ 20$ for their time. Of those respondents, 37 agreed to participate in a phone interview; 20 of which were contacted. The mixed-methods approach found that the program helped children and their families be more active. Barriers at home include less access to outdoor activity, more screen time, weather and safety concerns, and poverty. Because parent education is essential in lowering obesity rates, parents were provided with handouts, an activity planner, music CD, poster, and trading cards. Ninety-four percent of parents knew about the program; $49 \%$ of parents reported that their child was more active at home; $34 \%$ said that the family was more active at home; $76 \%$ of parents believed that the program itself helped children be more active; and 53\% believed it helped their family be more active. Generally parents had positive comments about the materials. The program materials and dissemination were revised in order to enhance program goals. Future research should look at how children influence parent and family behavior change.

Nemours and partners had an intervention to prevent childhood obesity called Taking Steps to Healthy Success (CDC \& Nemours, 2013; Jones, 2011; National Early Care and Education Learning Collaborative, 2013). The intervention originally started in Delaware with a focus on healthy eating, PA, and screen time in early childhood settings and goal of increasing the number of children and programs who met the standards of several initiatives, including Let's Move Child Care. Let's Move Child Care includes access to checklist, customized action plan, ideas/resources, recognition awards, and success stories as a lead up to Let's Move Active Schools. The program uses 5 learning sessions, homework, assessment tools, and implementation action plans and is used in a variety of settings including Head Start, public, private, and faith-based child care centers. During the pilot, there were $100 \%$ significant changes in healthy eating or PA or $81 \%$ in both and $100 \%$ of centers made targeted health policy and practice changes. Since its inception in 2008 it has spread to six other states: Arizona, California, Florida, Indiana, Kansas, Kentucky, Missouri, New Jersey, and Virginia. The program in those six states is a fiveyear project funded by the CDC. Challenges reported have been getting family involved, staff buy-in, 
time cost, and staff turnover. Some of the benefits have been access to healthier foods, nutrition and PA documented in lesson plans, family nights, cooking demonstrations, increased PA/nutrition knowledge for providers, and increases in healthy eating and PA.

Color Me Healthy $(\mathrm{CMH})$, another early childhood PA/nutrition program, was implemented in 2001 in 47 North Carolina counties and a reservation (Dunn, Thomas, Pegram, Ward, \& Schmal, 2004; Dunn, Thomas, Ward, Webber, Cullitan, Pegram, \& Webber, 2006). The program was based upon the Social Cognitive Theory and Socioecological model was designed to increase PA and healthy eating in children ages 4-5 using color, music, and senses. A Teacher's guide includes activities, bulletin board and display suggestions, strategies for teachers to be role models, food and places to be healthy picture cards to be used in circle time, classroom posters, music, hand stamps, and parent newsletters and posters. Using the information-dissemination model, Train the trainer $\mathrm{CMH}$ provided training to county teams made up of public health professionals to go back to the counties and train childcare providers in their areas in December 2001. The training, which lasted either 4 hours, 1 day, or 2 days, involved visual displays, model lessons, training manual, powerpoint, evaluation instruments, sample training agenda, marketing materials, in addition to strategies and materials for local training. Individual teams were in charge of dissemination plans. Childcare providers received training between March and August of 2002. Childcare providers rated teams regarding their own training (53 trainings with 1,338 participants) as 94.4\% excellent or very good training effectiveness and materials $97 \%$ excellent or very good. Follow-up evaluations were given to trained childcare providers eight weeks thereafter. Of the 486 evaluations administered, 92\% used CMH and increased PA; 91.8\% said knowledge of movement increased; and $93 \%$ increased nutrition knowledge. Six out of seven components were used by $85 \% ; 66.7 \%$ used parent newsletters; 92.3\% said CMH made them realize the importance of teaching PA/nutrition concepts; $73.5 \%$ rated the program excellent or very good (23.6\%); and $99.8 \%$ said they would use it again in the future. Since the program has been implanted in at least ten other states.

Internationally, in Chile, a physical activity and nutrition intervention targeting 530 low SES 4-5 year olds across six daycares was shown to decrease fat intake, increase MVPA in obese children, along 
with less body fat and skinfold thickness in sedentary children (Salazar, Vasquez, Concha, del Pilar Rodriguez, del Rocio Berlanga, Rojas, \& Andrade, 2014). Based on the social cognitive learning model and ecological model, two control groups and two intervention groups were employed along with a multidisciplinary team were used to develop and implement educational material and training. Specifically, there were strategies for parent and family engagement- "Healthy Days" which occurred twice a month and educational leaflets containing growth and nutrition information.

Just as children learn ABCs and how to read and write, they should also learn motor and manipulative skills. Participating in such skills in early childhood helps with confidence and competence in PA. There are a limited number of obesity prevention programs for children (Bellows et al., 2011). The WV Motor Development Center brought preschoolers to campus and parents/grandparents served as play partners. The classes were run by college students and charged modest fees to attend. There was positive feedback from all involved. At Ball State, students provided children with quality physical education on campus, as well, and at Ohio State, it was a similar concept where students provided quality physical education, the only difference being that the university students went to the childcare center.

\section{Physical Activity Levels in Preschool Children}

A study of low-income preschool students presented evidence that children were sedentary $58 \%$ of the time, while engaging in vigorous activity only $11 \%$ of the time (Sallis et al., 1998). The National Association for Sport and Physical Education (NASPE) recommends that preschoolers engage in 120 minutes of PA each day, sixty minutes of which should be structured, and the other sixty unstructured (Kirk et al., 2013). The study used direct observation, Body Mass Index (BMI) measures, self-reported data of parent PA levels and CVD risk, as well as a measurement for Type A behavior, which is linked to CVD. The researchers concluded that children who believed that their parents wanted them to be active had higher PA levels. Another study monitored PA levels with accelerometers in 4-7 year olds and their parents. It was proven that children with active parents were more likely to be active, and parent PA levels were the strongest determinants of child PA levels (Moore et al., 1996). Children of active mothers were two times more likely to be active; and children with active fathers were 3.5 times more likely to be 
active. This effect was increased if both parents were active ( $68 \%$ of children) and decreased if both parents were inactive (27\%). If only one parent was active, the child was still 3.5 times more likely to be active than their less active counterparts, suggesting that if parents value PA, more than likely the child will, too (Moore et al, 1996). It is interesting to point out that in young children, direct encouragement increased PA levels. However, for adolescents parent PA levels increase adolescent PA levels. Regardless, it is evident that a child's family has an influence on their PA levels, even when they are away from them.

There have been many initiatives over the years to prevent childhood obesity (Dersceid et al., 2010). Head Start Body Start was an initiative of AAHPERD with a goal of increasing outdoor play by educating staff, children, and families (2011). The initiative began in 2008 and provided onsite PE and game and activity suggestions from PA consultants and play space grants. Seventy-five percent of staff and parents reported increased outdoor time for children, resulting in a 17\% increase of PA while at daycare. With play space upgrades, children were more active both indoors and outdoors, and had higher levels of MVPA, including more vigorous time. Ninety-four percent of stakeholders agreed on the positive impact on outdoor play and $90 \%$ also agreed that the grant impacted how staff promoted PA.

Considering that nutrition knowledge and practice increased after one intervention, it is likely that knowledge is an issue, highlighting the need for professional development and resources for teachers. A mixed-methods descriptive study on teacher knowledge and perception of healthy habits in their program using a questionnaire and focus groups highlighted that staff believed parents didn't do a good job of PA at home since children were more active at school. Even though teachers with higher education had higher knowledge, they did not believe that it was their job to engage children in PA, as they believed PA should be child-directed.

The year 2008 marked the first federal guidelines for physical activity, solidifying that the promotion of PA had become a public health priority (Pate \& O'Neill, 2012). Unfortunately, the recommendations were for children ages 6-17, excluding children under the age of six. Despite being excluded in the guidelines, children in this age group have not been exempt from increases in obesity 
rates, much like those in school-age children and adults who were included in the guidelines. The statistics show that $10.1 \%$ of children ages $2-5$ are overweight and another $10.7 \%$ are at risk (Pate, Pfeiffer, Trost, Ziegler, \& Dowda, 2004). Obesity in 2-5 year olds went up from 28\% in 1999-2000 to 34\% in 2003-2004 (Pfeiffer, Dowda, McIver, \& Pate, 2009). Internationally, only three countries have guidelines for young children Obesity in children between the ages of two and five has been steadily increasing since the 1970 's with $26.7 \%$ of them being obese or overweight. In 2002, NASPE stated that children between three and five needed at least 60 minutes of structured and 60 minutes of unstructured physical activity. Many preschoolers do not meet this guideline (Pate, Pfeiffer, Trost, Ziegler, \& Dowda, 2004). This may be in part attributed to the fact that there is no clear definition of the guideline, making it difficult to tell the guideline is being met (Beets, Bornstein, Dowda, \& Pate, 2011). Caring for Our Children National Health and Safety Performance Standards stated that children should receive 90-120 minutes of MVPA per every eight hours. This guideline was based on accelerometer findings that PA in young children is often sporadic and light.

Three new guidelines have been recommended. The Commonwealth of Australia Department of Health and Ageing states that toddlers and preschoolers should be active at least three hours spread out throughout the day. The IOM states that childcare providers should provide opportunities for light, moderate, and vigorous PA for at least 15 minutes per hour, which is equivalent to 3 hours over a 12-hour period. Four Chief Medical Officers in the United Kingdom suggest at least 180 minutes ( 3 hours) be accumulated throughout the day. All of the new guidelines are similar as the focus has moved away from MVPA. However, there still remains a need for data to be linked to health outcomes, such as that of older children and adults, to make appropriate guidelines. The lack of research focused on the validation of field measures of PA in preschool children has attributed to public health agency initiatives excluding this age group (Pate, 2001). PA and sedentary behavior must be viewed independently of one another (Pate, 2001). While it is known that the two are closely related, a direct correlation has not yet been proven, hence the need to find a relationship between PA and health outcomes and motor development and PA. Furthermore, little is known about the PA behaviors of preschool children or the influence of preschool 
attendance on PA levels. Policies should be based upon this type of research (Pate, Pfeiffer, Trost, Ziegler, \& Dowda, 2004). Furthermore, little is known about the PA behaviors of preschool children or the influence of preschool attendance on PA levels. Policies should be based upon this type of research (Pate, Pfeiffer, Trost, Ziegler, \& Dowda, 2004). The following are examples of research that adds to this body of literature.

The Children's Activity and Movement in Preschool Study (CHAMPS), conducted in 22 schools in Columbia, South Carolina, 4 of which were Head Start, used surveys and accelerometer data, and direct observation in children ages 3-5 over a 28-month period (Pate, Dowda, Brown, Mitchell, \& Addy, 2013; Pfeiffer et al., 2009) to gather information on parents, support, type of equipment at home, screen time, park visitation, and athletic competence (Trost, Sirard, Dowda, Pfeiffer, \& Pate, 2003). The data has been the basis for many peer-reviewed journal articles as will be discussed in the paragraphs that follow.

In line with other research findings, overweight boys were less active than their non-overweight peers during the preschool day. There was no observance in girls and no significant difference in parent influence on PA. Parent obesity was linked to child fatness (Trost, Sirard, Dowda, Pfeiffer, \& Pate, 2003). It was also found that preschool was in fact a significant predictor of vigorous PA and MVPA through accelerometer data from 4.4 hours a day for 6 days. Children engaged in $\sim 7$ minutes of MVPA per hour, with a range of 4.4-10.2 minutes/hour. Boys were more active than girls as proven in other studies, in part due to the nature of male play. Boys tend to play more in groups, open settings, and more roughly than girls. Girls may also receive less encouragement to be active. Interesting to note, black children engaged in more vigorous activity than whites. This study proved that preschool policies and practices do have an important influence on the overall activity levels of the children they serve. That is to say, school characteristics have greater influence than a child's background.

In seeking to determine predictors of daily PA in children ages 2-5, Pfeiffer, Dowda, McIver, and Pate (2007), measured height and weight, in addition to the use of accelerometers. Children wore the devices 8-10 days, including one weekend. The data were analyzed for 5 weekdays and 2 weekend days. Parents self-reported their age, education, height, weight, race, activity levels, family support for PA, PA 
equipment at home, distance and usage of the nearest park, child's athletic coordination, and child's birth weight from a survey. Regarding MVPA, significant predictors were sex, age, race, distance to the nearest park, and athletic coordination. Age was a significant predictor for boys, however age, BMI, and athletic coordination were significant predictors for girls. Total PA was associated with athletic coordination and PA equipment at home for boys, but for girls it was BMI and athletic coordination, as well. Models only accounted for $27-37 \%$ of the variance in PA. Non-sedentary activity was associated with age, parent perception of athletic competence, PA equipment at home, family support, and child's birth weight (Pfeiffer, 2009). Predictors of non-sedentary activity were athletic competence, BMI, gender, and PA equipment at home. It was concluded that intrapersonal (Pfeiffer et al., 2009), demographic, and environmental factors were predictors of PA and improving athletic coordination may be the most important when increasing PA levels in girls.

A direct observation of outdoor activity in CHAMPS found that activity levels were moderately high at the time of indoor/outdoor transition, but declined over the 20-minute observation period. Different patterns between boys and girls were observed. The PA levels of boys declined in a linear fashion, while those of girls increased slightly before a decline, followed by another increase in activity. PA levels declined the longer play occurred outdoors. The data suggest that brief and more frequent bouts of outdoor play may be more effective, therefore future research should look at the length and frequency of outdoor play (Pate, Dowda, Brown, Mitchell, \& Addy, 2013).

CHAMPS concluded that children were engaged in MVPA 3\% of the time and spent time in sedentary behavior $80 \%$ of the time. Also, three-year-old boys were more active than $4-5$ year old boys (Pate, McIver, Dowda, Brown \& Addy, 2008). The preschool attended was a stronger predictor of PA than other factors. Less time was spent in sedentary behavior and more time spent in MVPA/hour at certain daycares, suggesting that more research is needed on the types of preschools that have more active children. Twenty-one percent of children in the study were in Head Start. Children were completely stationary $55.6 \%$ of the observations and for $31.7 \%$ of the time they were stationary with some limb movements. Of the 30 hours a week that children are at daycare, they are sedentary 25 of these hours and 
spend less than 1 hour in MVPA. Because parents believe that their child is very active while at daycare, they are less likely to provide additional opportunities at home. It is also important to consider space, lack of equipment, and lack of scheduled free/outdoor play. Characteristics of schools where children exhibited less sedentary behavior and more MVPA include higher quality scores, less fixed playground equipment (i.e. jungle gyms), more portable playground equipment (i.e. balls, bikes), less screen time, and larger playgrounds (Dowda, Brown, McIver, Pfeiffer, O’Neill, Addy, \& Pate, 2009).

Other studies independent of the CHAMPS study have also used accelerometer data to gain insight on the PA levels of preschool children (Finn, Johannsen, \& Specker, 2002; Lima, Barros, Cardoso Junior, Silva, Junior, Andersen, \& Barros, 2014; O'Dwyer, Fairclough, Ridgers, Knowles, Foweather, \& Stratton, 2014; Pate, O'Neill, Byun, McIver, Dowda, \& Brown, 2014; Soini, Watt, Tammelin, Soini, Sääkslahti, \& Poskiparta, 2014. Soini et al., (2014) compared 121 three year olds in Finland and Australia. In this study, children wore the accelerometers for five consecutive days (Wednesday-Sunday), collecting data every 5 seconds. The results showed the PA patterns of three year olds, as well as reiterated the fact that boys were more active than girls at daycare and the misconception that children are naturally active on their own. Between countries, there were no significant differences, including overall PA, other than Finnish children spending more time in light PA on daycare days. Most children spent 3 hours or more in light MVPA with children in both countries meeting the daily recommendation for MVPA (average of 48 minutes MVPA meeting the recommendation by $54 \%$ in Finland and 53 minutes in Australia (64\%). The study showed that daycare may be a barrier to PA in disagreement with studies that have shown children to me more active on daycare days. Another international study in Brazil, used random selection to study 180 3-5 year olds (Lima et al., 2014). Children wore the accelerometers for 7 consecutive days measuring at 15 second epochs. In conjunction with accelerometer data, face-to-face interviews, body weight measures, and height measures were obtained. The study faced many methodological limitations and data loss.

Finn et al., (2002) monitored 214 3-5 year olds with accelerometers for two consecutive days between the hours of 9:00 a.m. and 5:00 p.m. in addition to direct observation using the Children's 
Activity Rating Scale (CARS). Accelerometer data was collected every minute with a 1000 count cut off for vigorous activity. There findings included that the childcare center attended was the strongest predictor of activity level, children born pre-term were less active, and highly active children were associated with father with a low BMI. Interestingly, boys were found to be more active than girls except between the aforementioned hours, but were more vigorous and overall active. According to CARS, 75\% of participants had at least one bout of vigorous activity.

Many studies have focused on PA in traditional childcare settings, however little is known about nontraditional settings, such as Montessori schools. The study involved 3014 -year old children across nine Montessori schools and eight traditional daycares (Pate et al., 2014). Accelerometers were worn Monday-Friday, capturing data in 15-second intervals. The cross sectional study showed that children in Montessori school had more light PA, MVPA, and total PA than children who attended traditional daycare. These children also had more MVPA on days that they did not attend school. Children that attended private Montessori schools were also more active than those attended pubic Montessori schools. As with other studies, boys were shown to be more active than girls. Furthermore, high activity levels during the school day carried over into after school hours. The main conclusion of the article is that the school attended does affect PA levels.

In another study, 188 3-5 year olds wore accelerometers for seven days in 12 English preschools (O’Dwyer et al., 2014). Accelerometer data was recorded for 5-second epochs. Again, boys were found to be more active than girls, including MVPA. Boys who attended daycare for a half day had the highest MVPA. Children who attended preschool for a full day had 11 minutes fewer MVPA than those who attended for only half of the day, thus suggesting that the structured nature of preschool may be related to decreased activity. For all students, there was a decrease in afterschool PA. The researchers pointed out that no children had enough PA for health benefits and suggest a need for interventions to focus on preschool and home environments further targeting parents. One limitation stated was the absence of an activity diary.

The Child Health Initiative for Lifelong Eating and Exercise (CHILE) obesity prevention 
intervention targeted 16 low SES rural preschool programs in New Mexico using a socioecological approach (Davis, Sanders, FitzGerald, Keane, Canaca, \& Volker-Rector, 2013). Data was collected across two school years in American Indian and Hispanic communities utilizing 8 intervention groups and 8 control groups. The researchers conducted semi-structured interviews with program directors and staff, grocery store managers, and primary care providers, along with classroom observations; dietary recalls for children, food availability/pricing assessments in community grocery stores, staff orientation, professional development for staff, parent orientation, and family night presentations. After the first year, feedback focus groups were held and improvement were made, such as the development of bilingual materials. Furthermore, the grocery store component had to be modified to be less stressful on the grocery stores. Other improvements included training enhancements such as nutrition modules and PA training and a family component with take-home newsletters, activity cards, and family events. Of importance during development was linking the material to the content via recipes, shopping lists, and family PA recommendations to name a few.

Overall, researchers learned that need continuous professional development is necessary and that not all centers have the ability to make changes in menus. For this particular group lecture format was not as effective as booth $\mathrm{s}$ at family events. The most effective way to communicate and promote events was through the teachers and of all the events, the most highly attended were those focused on PA. This study took place within Head Start program, thus a better understanding of Head Start and how it operates is of critical importance.

\section{Head Start Program}

Head Start, the largest federally funded early childhood program in the U.S. (Whitaker, Gooze, Hughes, \& Finkelstein, 2009), began in 1964 under President Johnson and has been a valuable partner in helping families prepare children for school and lifetime success (Office of Head Start National Center on Parent, Family, and Community Engagement, 2011). Using a holistic approach (Whitaker et al., 2009), its purpose is to serve children ages 3-5 that come from diverse, disadvantaged families. Initially the priority was on math and reading, but gradually PA and other domains have been added (Puma et al., 
2010; Vidoni et al., 2011). PA, like other domains, should be planned, taught, learned, reinforced, and assessed. Workshops are a suggested strategy to help teachers with this transition. There are over 2,000 Head Start programs that serve nearly one million children in the United States (Hughes, Gooze, Finkelstein, \& Whitaker, 2010). Half of children who attend Head Start are overweight or obese. Obesity rates for low-income families have become a larger concern in the United States. In $2010,21.2 \%$ of children were overweight or obese (Vidoni et al., 2011). While the problem is known, there are barriers for obesity prevention programs including lack of time, money, and knowledge. Many staff and parents are under the assumption that heavier is healthier. By law, Head Start must provide health care services, meals, snacks, nutrition education, parent education, outreach activities, and ongoing staff training and development (Puma et al., 2010).

Parent involvement has evolved over the years prompting the Office of Head Start's National Center on Parent, Family, and Community Engagement to develop a research-based framework based upon input from families, programs, experts, and the center itself. The program impact areas and parent and family engagement outcomes coincide with Epstein's six types of involvement. Program impact areas are program environment (communicating), family partnerships (decision-making), teaching and learning (learning at home, volunteering, parenting), and community partnerships (community collaboration). Parent and family engagement outcomes include family as lifelong educators (learning at home, communicating), family as lifelong learners (volunteering, parenting), family connections to peers and community (community collaboration), and families as advocates and leaders (decision-making). Research conducted with staff, family, and community members is one way to inform such a framework.

A survey as part of the study of healthy activity and eating practices and environments in head start (SHAPES) was conducted to locate barriers to healthy activity and eating practices and environments in regard to parents, staff, and programs. Of the 1,583 programs contacted, $87 \%$ responded by both phone and mail survey, 1,283 responded. Half said that they lacked the funding to provide healthier food. Fiftyseven percent of staff don't have a problem encouraging healthy food; $3 \%$ felt that parents also didn't have a problem encouraging healthy eating, although $80 \%$ felt that parents didn't have enough money for 
healthy food and had limited knowledge of healthy foods and beverages. In regard to PA, 1/5 said there were no challenges in increasing gross motor activity, but they lacked indoor spaces, money for equipment, and time in schedules (40\%). Almost half of said that they don't have a problem encouraging gross motor activity; $6 \%$ said parents don't usually have a problem either, but lack time and money and have concerns about safety. One-third stated that lack of money was the biggest barrier at the program level; $30 \%$ said there was a lack of knowledge at the parent level and $22 \%$ for the staff level. In general, both programs and parents lack resources for healthy eating. Furthermore, programs have limited time and money, which are interrelated. Even with the high rates of obesity, $48 \%$ believe that oral health is the most common problem, then asthma (31\%), followed by obesity (21\%). In another study, $47 \%$ believed obesity was an issue for parents; $33 \%$ believed it was an issue for staff; and $20 \%$ believed it was an issue for children (Gooze, Hughes, Finkelstein, \& Whitaker, 2010).

SHAPES also included a two-year randomized multi-component intervention targeting 3-5 year olds (Pfeiffer, Saunders, Brown, Dowda, Addy, \& Pate, 2013). There were 8 control groups and 8 intervention groups. A stratified random sample of schools was utilized and involved 500 4-year old children during the assessment period. Baseline and follow-up data were collected for each school both years. The first part year the intervention lasted 15-25 weeks, while the second year lasted for 31 weeks. One cohort was assessed at baseline and follow-up during the first year of the study, and another cohort at baseline and follow-up the following year. The study was based on the socioecological model (individual, instructional, social, and physical levels) framed around indoor recess, daily lessons, social environment, teacher/administrator trainings/workshops, site support visits, newsletters, and selfmonitoring methods. Classroom level changes included activity resources, teaching practice influences, and the promotion of an adjusted schedule to provide more PA. "Move inside" was to be implemented for ten minutes; "Move outside" was to be implemented in at least two 20-minute sessions, 5 of which were structured; "Move to Learn" was to be two 5 minute sessions. The study was developed based on the idea that formal PE is mainly nonexistent in preschools. It was stressed that teachers physically participate with children and verbally encourage them. In terms of communicating information with 
families, 50\% of programs discussed height/weight with families (Gooze, Hughes, Finkelstein, \& Whitaker, 2012).

Also as part of SHAPES, a survey in 2008 (Whitaker, Gooze, Hughes, \& Finkelstein, 2009) indicated that most Head Start programs reported doing more than what was required federally. Eightynine percent reported having outdoor play areas; $74 \%$ reported adult-led or guided gross motor activity for 30 minutes a day; $73 \%$ reported unstructured gross motor activity for 30 minutes a day; and 56\% had both. Limitations included lack of knowledge by the person answering the survey and the possibility of participants writing responses that they thought were desirable, instead of actual practices.

It is known that childcare teachers and staff are important influences on PA and nutrition. One study surveyed 360 participants, including 32 from Head Start (Derscheid, Umoren, So-Yeun, Henry, \& Zittel, 2010). The study revealed a number of considerations to be aware of when implementing PA and nutrition concepts in a preschool setting. The focus groups found that children liked when their teacher participated in PA with them. Staff members think that parents are the most responsible for providing healthy foods in children's diets but only $1 / 5$ of centers allowed parents to help in menu planning. Of providers, $79 \%$ believed they should promote health and $64 \%$ thought it would have long-term benefits. Interestingly enough, only $1 / 3$ of childcare centers provided FAV at lunchtime.

In 2012, Pennsylvania Head Start teachers were given a web-based survey (Whitaker, Becker, Herman, \& Gooze, 2013). When compared with women of similar demographics, Head Start teachers had poorer mental and physical health, higher fair or poor health status, higher rates of depressive symptoms, and frequent mental/physical unhealthy days. This suggests that children who attend Head Start are not being provided with healthy role models.

\section{I am Moving, I am Learning (IMIL)}

A regional program manager for Head Start was quoted as saying, "Head Start programs can make a major contribution to promoting good health and strong bodies for children by intentionally integrating appropriate PA and wise nutrition choices into their daily routines" (Administration for Children and Families, p. 1, 2006). I am moving, I am learning (IMIL) is a research-based, unobtrusive 
means to infuse quality PA and healthy food choices into already existing preschool curriculum and routines as a means to enhance it that used a variety of activities, music, and props. Props can be purchased, but it is important to note that IMIL can be implemented without any extra costs and some programs elect to make their own props. Many props that can be bought have the face of the character Choosy (Choose Healthy Options Often and Start Young), a friendly green alien. The goals of IMIL are to increase MVPA to meet national guidelines, improve daily healthy food choices, and improve the quality of structured PA. One of the greatest benefits is that it is flexible and customizable to each center's unique needs and is in alignment with Head Start Program Performance Standards. IMIL is currently housed in the Head Start National Center on Health and parts of the program are being used in the Taking Steps to Healthy Success program. Another attractive benefit of IMIL is its ability to meet initiatives of various Head Start national centers. It allows for greater family and community engagement (National Center on Parent, Family, and Community Engagement, as well as meeting the benchmark domains of the Classroom Assessment Scoring System (CLASS) in order to keep their federal funding. CLASS focuses on teacher-child interactions across three domains: emotional support, classroom organization, and instructional support (National Center on Quality Teaching and Learning, 2014). Within each domains are dimensions of the class, such as positive climate, teacher sensitivity, regard for student perspectives, behavior management, productivity, instructional learning formats, concept development, quality of feedback, and language modeling.

Over the course of two years (2004-2005), IMIL was piloted at 10 sites in Virginia and 7 sites in West Virginia. All teachers received training prior to implementation. A variety of strategies for staff, families, and the community were employed including volunteering, food tasting events, pedometers and other incentives, a step tracking program for parents and staff, and the creation of walking trails. Child outcomes at the end of the two year period were increased MVPA, sedentary children had become active, improvements in BMI, and the use of music resulted in more movement. Some family outcomes were that dads became involved in movement, PA and nutrition topics at meetings were met with reception, and PA/nutrition became themes in daily conversations between staff and parents. In addition, there was 
more encouragement to eat healthy and be active, and families only brought in healthy treats for special celebrations. Structured outdoor play in daily lesson plans, MVPA in transitions, revised policies to reflect healthy behaviors, teachers engaging in MVPA with children, and PA/nutrition training were all positive outcomes for staff. In terms of the community, preschool partners were trained on IMIL, wellness groups were formed with community partners, and the partners also funded strategies for more MVPA.

Little study of IMIL has been conducted to date. One study stated that many centers use IMIL to increase active time, make healthy food choices, and improve the quality of teacher-guided PA, however many times it is not fully implemented due to the barriers of time and money. There is a 3-day workshop for IMIL, but no support afterwards for classroom teachers (Hughes et al., 2010). These findings coincide with a 2010 implementation evaluation conducted by the Office of Planning, Research, and Evaluation (ACF, 2010). Programs in Region III decided to target either children, parents, staff, or the larger community in a three stage evaluation period. Stage one included mail surveys to all 53 programs, training, and data collection one year after training. The data from Stage 2 included phone interviews in a purposeful sample of 26 programs that had implemented one or more IMIL strategies and planned to do more in the following year. The final stage comprised of site visits and classroom observation for 13 of the 26 programs from stage 2. Many found the training engaging and tried to implement IMIL in the following year, by focusing on the PA aspects, instead of nutrition. There were many strengths mentioned such as staff enthusiasm and ease of implementation in classes and homes, but barriers included time and support.

Of the targeted areas, 12 programs targeted children and parents; 2 targeted children and staff; 7 targeted children only; and 5 targeted children, parents, and staff. Although, some programs had community partners, no programs chose to target the community. In stage 3, 6/13 programs had decided to add a target group. After choosing a targeted audience, programs then chose to focus on MVPA only (12), MVPA and structured movement (5), MVPA/nutrition (3), or MVPA/structured movement/nutrition (6). $23 / 26$ programs in stage 2 reported using the same nutrition/fitness curriculum that was in place 
before IMIL in the first year, but 6/13 programs in stage 3 added IMIL or changed their existing curriculum to reflect IMIL. Also, in stage 3, 11/13 programs had established or modified policies related to healthy eating and PA.

In terms of training, 15 programs provided training for lead teachers, but only 9 provided training for other staff. In stage 3, most programs reported only providing training for new teachers. With regard to "training of teachers" training, 14/26 thought the training was sufficient, but those that did not desired more examples of IMIL activities, guidance about implementation with certain groups, more resources and materials, and more opportunities to share ideas and network with other teachers. As for community partnerships, in stage 2 18/26 programs reported partnerships with local hospitals, Women, Infants, and Children, and university extension programs to name a few. In stage 3, three programs began partnerships with other Head Start programs and 7/13 reported targeting the community through booths, outreach, workshops, and events to provide training and awareness.

Ways that programs targeted families included a general introduction to IMIL, education and information about healthy eating and PA, examples of PA to do as a family, and education and guidance about healthy food preparation and techniques. The most common strategy was the use of newsletters. At workshops, parents would sing and dance to Choosy songs and some programs provided incentives for participating in IMIL activities.

It is important to note that while the evaluation was revealing about the ways in which IMIL was being implemented, it did not look at the impact on children's weight status. However, classroom observations provided a range of 4-76 minutes of activity, or 1-14 minutes of PA per hour during the school day. As the evaluation only focused on one region, results also may not be generalizable to other Head Start programs in other regions. Because the evaluation did not include the impact on children, families, staff, and the larger community, the next step in evaluating IMIL is to conduct an impact evaluation to see how it is impacting staff, the community, and children and their families. Furthermore, the Early Assessment of Programs and Policies to Prevent Childhood Obesity, a 2-year project collaborative effort by the CDC and Robert Wood Johnson Foundation used an expert panel to assess the 
evaluability of programs. Although, IMIL was found to be clearly conceptualized, strong, research-based, theoretically-sound, well-designed, and well-received and found to have the potential to impact many youth around the country due to the reach of Head Start, it was suggested that further rigorous evaluation was necessary (ACF, 2009).

\section{Future Direction for Research Involving Physical Activity in Preschool Children}

Pate et al. (2013) identified the top ten important research questions related to physical activity for preschool children. The questions were organized into three categories: effects of PA on health, patterns of PA, and interventions and policies to promote PA. The health effects questions are necessary in understanding the significance of PA on the health of young children, while the questions regarding patterns of PA will provide insight on the types and amounts of PA needed, in addition to factors that influence their PA levels. The final category, interventions and policies, will help answer questions on how PA can be increased in an effective and efficient manner. The questions in this category include: What are the most effective strategies for promoting young children's physical activity in the child care, home, and community settings?; How can interventions to increase physical activity among 3-to-5 yearold children be effectively implemented and disseminated?; and how effective are national, state, local, and institutional policies in increasing physical activity of 3-to-5 year-old children?

In order to answer these questions, it is necessary to evaluate existing multi-component (PA and nutrition) programs in preschools in order to identify effective strategies that increase PA and the findings should be disseminated systematically. In addition to sharing effective strategies, challenges should also be shared in order to overcome such barriers in the future. One way to identify efficient strategies and their inherent barriers is through program evaluation.

While all of the questions in each category are important, of particular importance is the final category, that of interventions and policies as affect children's health and PA patterns. As it has been demonstrated in the literature both parents, teachers, and a child's built environment influence PA levels suggesting the importance of the home, community, and school in the promotion and maintenance of PA. Because this may vary by home, community, and daycare center it is important for researchers to study 
each in a variety of geographical locations and share their findings as it may look different and vary by location.

Despite childcares centers using different types of programs and strategies to promote PA and nutrition, there is a lack of their use and effectiveness in the literature, thus creating another deficit in the field. Programs and strategies being used may not be best practice and those that have been evidenced in the literature has been done so minimally with a small amount published work. It is important to collect data from childcare directors, teachers, and families to find out if the programs are working, and barriers to their implementation, in addition to strengths and weaknesses in order to make the programs better.

Finally, a recent study found that overall there were no significant changes in childhood and adult obesity, but for children ages $2-5$ there was a decrease from $14 \%$ in $2003-2004$ to a little over $8 \%$ in 2011-2012 with significant decreases reported for low-income preschool-aged children who participated in federal nutrition programs in at least 18 states (Ogden, Carroll, Kit, \& Flegal, 2014). In addition, another study focused on Head Start programs in Michigan collected data across two school years and compared 43, 748 children receiving Medicaid and those that did not. The participants were $64.9 \%$ white, $10.8 \%$ black, and $14.4 \%$ Hispanic. 83,239 anthropometric measures were taken with $16.8 \%$ of the children being obese and $16.6 \%$ overweight initially. The findings were that if a child entered Head Start as obese they had the greatest decline in BMI in the first year when compared to other groups. Overall, Head Start participants were less obese, overweight, and underweight at follow-up. These changes for children in Head Start were maintained over the second year. There were mentions of Head Start nutrition and health care guidelines, but no mention of IMIL or other types of programs utilized. Further analysis should be conducted in order to look at the types of programs and services children were exposed to that may or may not have contributed to these decreases.

\section{Impact Evaluation and RE-AIM framework}

Program evaluation provides information on the effects of a program and then uses the results to make decisions about the future of the program and ways to improve its effectiveness (Thomas, 1994). There has been a debate on qualitative versus quantitative data when measuring federal programs after 
Head Start was deemed weak (Madey, 1982). Knowing that a program did or didn't work isn't enough, one must also know why (Madey, 1982). Traditionally the evaluator works at a distance as to not be influenced by staff or form a biased opinion with quantitative data being preferred. This method does not work well because it dismisses qualitative data and misses insight.

Another method, utilization-focused evaluation, allows one to see the program both up close and far away using a mixed-methods approach in order to view multiple perspectives on outcomes and information for program modification. Qualitative data can provide leads, identify overlooked respondents, and correct elite bias, while quantitative data can verify the qualitative results. A multileveled, multi-strategy intervention to promote PA that involved media, partners, mega events, and stakeholders in Brazil used a mixed methods approach involving observation, literature reviews, and interviews to evaluate cost-effectiveness, and short-, mid-, and long-term effects (Matsudo, Matsudo, Andrade, Araujo, \& Pratt, 2006). Furthermore, a conceptual framework is needed in order to guide data instrument development and analysis (Madey, 1982). Types of measurements may include program records and statistics, questionnaires, phone surveys, mail surveys, convenience surveys, and interviews. Staff involvement is important in doing the leg work, as they know their needs and the program best. The evaluation of a program can be broken into focusing on the process, impact, or outcome.

Impact evaluations assess the immediate effects of a program, which is critical in measuring strengths and weaknesses to show why a program is successful or unsuccessful and how they might be improved (Matthews, Werch, Michniewicz, \& Bian, 2007). In other words, impact evaluations show program efficacy for long-term outcomes and future program planning. According to Shaul (2001), impact evaluations determine if the program is causing participant outcomes, has the capacity to isolate other factors, and can employ two different designs: experimental or quasi-experimental. Both Head Start and Even Start were evaluated in a 6-year national study with 3-4 year olds who were followed until first grade. Most early childhood impact studies to date have focused only on the child and not their families (Park et al., 1997). 
The RE-AIM program evaluation framework was introduced in 1999 (Glasgow, Vogt, \& Boles). The framework allows the evaluation across five dimensions at multiple levels. The five dimensions are: reach, efficacy, adoption, implementation, and maintenance rated on scales of $0 \%-100 \%$. Reach refers to the percentage of people affected by the program and often includes demographic information. Efficacy can be looked at as either positive and negative outcomes or outcomes to be measured. Adoption is the proportion of settings that adopt the program, while implementation refers to the extent to which a program is delivered as intended to determine effectiveness. Maintenance is the extent to which a program or policy becomes institutionalized or part of the routine organizational practices and policies. While it is suggested that all dimensions are evaluated, the author does have the choice to pick and choose as deemed relevant. RE-AIM can be used to assess a program's overall impact, to compare, and make decisions for program improvement. The paragraphs that follow will provide examples of both RE-AIM evaluations and impact evaluations conducted in a variety of settings.

\section{Sample Studies Using RE-AIM framework}

Many articles have focused on children and nutrition (Winkler, Noller, Waibel, \& Wiest) and/or PA (Austin, Bell, Caperchione,\& Mummery, 2011; Meij, 2010) in school settings (Dunton, Lagloire, \& Robertson, 2009; Dunton, Liao, Grana, Lagloire, Riggs, Chou, \& Robertson, 2012; Nigg, Geller, Adamas, Hamada, Hwang, \& Chung, 2012) in the RE-AIM literature. Others have focused on using the framework with PA in college students (Bartlett \& Zizzi, 2010), an insurance-sponsored weight management program (Abildso, Zizzi, \& Reger-Nash, 2010), health centers (Besculides, Zaverie, Hanson, Earns, Gregroy-Mercado, \& Will, 2008; McKee, Deen, Maher, Fletcher, Fornari, \& Blank, 2010), and a community PA activity program (Van Acker, De Bourdeaudhuij, De Cocker, Klesges, \& Cardon, 2011). Study design has varied using several quantitative, qualitative or mixed-methods approaches. Data has been collected via questionnaires, interviews, surveys, focus groups, site visits, and direct observation. Several literature reviews on the framework have also been conducted. For example, Estabrooks, Dzewaltowski, Glasgow, \& Klesges (2003), conducted a review of school-based interventions focused on promoting healthy behaviors, such as PA and good nutrition. Thirty-two articles from 12 leading journals 
over the years 1996-2000 were evaluated using the RE-AIM framework. Percentages for reach were 59.3\%; efficacy 100\%; adoption $14.8 \%$; implementation 37\%; and maintenance $25.9 \%$. Another review by Gaglio, Shoup, \& Glasgow (2013), looked at 71 articles that used RE-AIM from 1999-2010. The majority focused on PA and obesity. Four articles focused on just one dimension; 44 focused on all five dimensions; 5 with a focus on two dimensions; 7 reported on 3 dimensions; and 11 reported on 4 dimensions. The most reported dimensions in order are reach, implementation, effectiveness, adoption, and maintenance. The researchers noted that there were problems with studies confusing the definition of reach and adoption.

JUMP-in was a multi-level intervention based in 60 schools in Amsterdam (Meij, 2010). RE-AIM was used to improve the program after the pilot to change the content of its components, its organization and management, and its evaluation design. It was determined that for the reach dimension, it was hard to reach inactive children and their parents. Efficacy showed that the program did influence PA levels, while adoption revealed barriers in communication and preparation. Most schools implemented the program but the evaluation revealed time and cost as barriers. As for maintenance, all schools scored the program positively as all planned to continue with the program and add it to their policies. Another instance where RE-AIM was used to evaluate a pilot program was Exercise Your Options, a PA and nutrition curriculum for middle school students (Dunton et al, 2012). The pilot program occurred in California middle schools across the 2006-2007 school year. The design was a nonexperimental pilot evaluation involving 16 classes (668 students and 16 teachers). A convenience sample was taken and 20/86 teachers agreed to participate for a compensation of $\$ 75.00$. Both consent and assent were obtained for the children. Measures included program records, classroom observations, teacher surveys, and student pre- and post-surveys. Statewide the program had reached $50 \%$ of students, as well as increased PA, decreased sedentary behaviors, and improved diet (efficacy). Furthermore, $42 \%$ of classrooms ordered program materials (adoption), $86 \%$ of teachers implemented all lessons (implementation), $52 \%$ of teachers reordered materials for the following school year, and $48 \%$ ordered materials for the first time across a 5 year period (maintenance). Another study conducted in California schools evaluated a nutrition 
curriculum for third graders (Dunton et al., 2009). Two samples were taken: an evaluation sample (938 students and 19 teachers) and a dissemination sample (195,245 students and 7,359 teachers). The study was designed as a randomized controlled trial using the secondary analysis of archival data to describe dissemination and used data from program records, teacher surveys, and student pre-, post-, and 3-month follow-up surveys. The program reached $42 \%$ of elementary schools and was adopted by $39 \%$ of elementary schools. Of those reached, $100 \%$ of teachers implemented the curriculum and $37 \%$ reordered materials for maintenance. Efficacy was shown through changes in knowledge, outcome expectancies, and vegetable intake.

In Australia, a mixed-methods study pertaining to a school-based PA intervention used interviews and questionnaires to determine the effectiveness of the dimensions of RE-AIM (Austin et al, 2011). Schools were contacted to participate via an expression of interest e-mail to all school principals. Each participating school would receive between $\$ 500$ - $\$ 1,000$ for their participation. Telephone interviews were conducted with 16 non-participating schools to determine why they opted out. Eight out of fortynine schools participated (reach). The adoption of certain components of the program varied (student information session 7/8; playground painting workshop 8/8; project launch event 7/8; teacher PA professional development 6/8; project name and logo 8/8; playground plan 7/8; parent brochure 8/8; and working group meetings $8 / 8$ ). As for implementation, $7 / 8$ schools implemented all major intervention components; 7/8 used playground line markings; 6/8 utilized teacher-led playground games; and 4/8 employed peer-led playground games. In terms of maintenance, $7 / 8$ schools maintained the program for twelve months and 6/7 reported positive changes in child behavior.

\section{Sample Impact Evaluation Studies}

A mixed-method, low-cost intervention used PA to potentially impact early literacy skills (Kirk et al., 2013). Academic lessons were taught using PA since preschool teachers were too passive with encouragement and participation in PA outdoors. PA was integrated into other areas, as not to take away from their instructional time. Data was collected using a two-group quasi-experimental design, direct observation, and teacher report. Training was provided for the program that utilized moderate PA for 15 
minutes twice a day. Teachers were free to choose the time and location on their own. In six months, children engaged in $90 \%$ of the recommended levels of PA and greater PA than the control group during free play. At baseline, teachers were not active but this increased. Academic performance increased in alliteration and picture naming. Teachers said that the program was easy to implement and had a positive influence on student learning, and they would have their class participate in it again. Kirk et al. found that limitations included that the study was short and only took place in two schools.

Providing access to Head Start has a positive impact on children's preschool experiences and parenting (Puma et al., 2010). There was also an impact on access to dental care in the health domain in terms of insurance coverage, but not action for PA, nutrition, and dental. Unfortunately, the benefits of Head Start are gone in $1^{\text {st }}$ grade. The Head Start impact study which followed students from pre-k to the end of first grade and collected data from parent interviews, teacher surveys, director interviews, and observation, left many unanswered questions. There were no outcomes for PA, but it basically found that Head Start was good while children were in the program but had no lasting effects once they moved on from the program. In retrospect, Joo (2010) followed Head Start students throughout school (from age 7 to age 17) and found that Head Start participation resulted in higher scores on the Woodcock JohnsonRevised test, less suspensions, less expulsions, and less grade repetitions for girls, but not for boys. It was also suggested that home environment and parent education are both consistent and significant determinants in the long-term outcomes of the program. There was no mention of PA outcomes. It was also found that Early Head Start has positive impacts on child's cognitive development, language development, and social-emotional development, in addition to positive impacts on emotional support and parental support for language and learning (Love et al., 2005). Again, there was no mention of impact on physical or motor development. More recently, Carneiro \& Ginja (2014), used data from Children of the National Longitudinal Survey of Youth of 1979 (CNLSY), a derivative of the National Longitudinal Survey of Youth (NLSY79) looked at data for Head Start children ages 3-5 and concluded that Head Start participation decreased behavioral problems, prevalence of chronic conditions and obesity at ages 12 to 13, decreased depression and obesity at ages 16 and 17, and decreased instances of crime at ages 20-21. 
Another impact evaluation was conducted on a program called Romp and Chomp. Romp and Chomp, a cross sectional and quasi-experimental intervention focused on capacity building and policy implementation related to dietary patterns, active play, and oral health in early childhood, found positive impacts on policy, nutrition, and PA opportunities for staff capacity and practices (Silva-Sanigorski et al., 2012). The daycares involved were government childcare facilities. There were 51 preschools involved in the intervention that were matched up with 508 comparison schools. The intervention was supported by providing resources, linkages to community organizations, collecting evaluation data, phone communication, e-mail, meetings, newsletters, information cards, media coverage, presentations at community forums, and social marketing. Evaluation was cross sectional and quasi-experimental with both baseline and follow-up periods. Measures included anthropometry, weight status, and children's nutrition and activity related behaviors. Outcome and impact measures were weight and nutrition and activity behaviors of 4-year olds. The intervention reduced childhood overweight/obesity by three percentage points. Staff were found to have the biggest impact and PA promotion was increased. An active play policy was in place, as well as resources provided on nutrition, more staff training, fewer food rewards, and written policies. However, students reported more television viewing and less time in free and organized play. There were low levels of communication about healthy eating to parents.

PE2GO was a self-contained PE program for classroom teachers that provided Sport, Play, and Active Recreation for Kids (SPARK) curricula, training, equipment, and workshops (Martin, Martin, \& Rosengard, 2010). Paper-pencil surveys were given pre- and mid-intervention, as well as focus groups mid-intervention, and an electronic post-survey. The researchers evaluated staff comfort level with delivering the curricula, satisfaction with programming, perceived benefits, perceived barriers, and the estimated amount of time students engaged in PA in the day. The pre-survey asked for descriptive information, participant satisfaction and barriers, assessment of previous trainings, and the estimated amount of PA using a Likert scale. Phase two used focus groups of 4-8 people who had implemented and gone to both trainings. The sessions were tape recorded and transcribed using mixed-methods. The focus groups asked questions about strengths, action attitudes of students, how they knew it was effective, how 
it affected the total number of minutes that students were active, any evidence of how well it was perceived with the overall curricula in the school, barriers, one's own attitude, and necessities for sustainability. Phase 3 measured sustainability through a descriptive analysis for the amount of PA, teacher satisfaction, barriers, and administrator and teacher perspectives. Teacher satisfaction and confidence increased. Students asked for the program, were more active, and appeared to be having fun. There was also more cooperation and fewer arguments between students. Barriers reported were shortage of time, being told to go to trainings instead of being asked, logistic issues, and inadequate training. Teachers wanted follow-up for guidance and mentoring, more training for sustainability purposes, more funding, more parental support, and more administrative support. It was noted that a limitation to the study was lack of a control group.

Energize was a multiple component diet and exercise program at three elementary schools in southern Indiana (Herbert, Lohrmann, Seo, Stright, \& Kolbe, 2013). Employing a quasi-experimental design, the study assessed dietary and exercise habits of 104 children in intervention and control groups at each school. There was one 60 minute class a week presented as 15 minutes of nutrition, a 10 minute warm up using the letters that make up the word energize, and 35 minutes of aerobic activity. Participants were teachers who volunteered their classrooms. Longitudinal data was collected through diet and activity logs and post-test questionnaires. The program was shown to make positive changes in diet, but PA levels did not increase.

Matthews et al. (2007), conducted an impact evaluation on an intervention focused on alcohol and PA, because targeting multiple health behaviors is a good strategy considering that many are interrelated and have common determinants. The CD-ROM was presented in multiple formats including one-on-one consultation, self-study, and small group sessions lasting 40 minutes with 10-12 students, a booklet for later perusal, and goal setting afterwards. The intervention utilized parent education materials and flyers. Participants were recruited by classroom visits, and were randomly assigned to groups, before baseline data was obtained. There were no baseline differences. Data was collected using feedback forms about acceptability and outcomes as well as fitness screen questions. The CD-ROM had the biggest 
impact on females and females were more likely than males to pair PA with other healthy behaviors. Of all participants, $87.4 \%$ liked the CD-ROM and $91.4 \%$ would recommend it to others. Of the small groups, $89.2 \%$ liked the small group format and $87.3 \%$ would recommend it to others. The CD-ROM group had a higher commitment to getting exercise, while the small group had a higher commitment to PA and positive images related to PA. One limitation noted is that the study was only conducted in one school.

In another country, six hundred students showed positive benefits for most participants and those that participated in the program for a longer time had more sustainable improvements (Armour \& Sandford, 2013). The focus was on evaluation and outcomes of an outdoor physical activity program using positive youth development. Positive youth development posits that young people are resources that need to be developed and assets can maximize their potential, as well as highlight the relationship of youth and their community. The relationship is reciprocal, in that communities are supportive of youth and contribute positively to their well-being through encouragement and focuses on the resources that help youth make positive choices, experiences, and support. Furthermore, it helps build sustainable relationships with adults in all settings where people are the most valuable asset, based upon the core principles of connection, caring, and compassion. The intervention utilized many partnerships that contributed positively to the community. Activity was school-led, school-based, community-based, and used trained volunteer mentors. Some barriers were that the stories were anecdotal or retrospective which questioned the reliability in regard to outcomes. Baseline data, descriptive surveys, interview transcripts, journal writing, and field notes were all collated and analyzed. The researchers realized that there was no control group and teachers picked participants, both of which limited the study. The majority had positive improvements in their baseline profile and 50\% maintained after leaving the school 36 months after the project. The results of the quantitative and qualitative data backed one another up, but an impact was not made on $1 / 3$ of pupils. Many of the students who showed improvement went on to be involved in other programs. With encouragement from teachers, students increased skills related to teamwork, communication, social interaction, and relationship building. Since positive growth comes from an 
environment that includes caring adults, the relationships with adults were key to the positive impact. Although sustainable positive impact is beyond the scope of the program, the findings will be used to improve the program.

Marathon Kids (MK) was a community-based and school-based walking, running, and healthy eating program for low-income $4^{\text {th }}$ and $5^{\text {th }}$ graders based on partnerships between the school and community, run by classroom teachers, PE teachers, parents, and community members in Texas. The study employed a nonequivalent control group, pretest/posttest evaluation design with multiple measurement periods (baseline, interim, posttest). There were 3 experimental and 3 intervention groups in Houston and 2 intervention groups in Austin. Children were given the Active Kids Project questionnaire and height and weight measures were also obtained. Both teachers and parents helped keep students focused and log their data, in the form of mileage, and both supplied social support and encouragement. Active events such as a kick-off and mile run held at the beginning and end of the program at well-known public places and used local and national celebrities. Students also received a shirt and medal. Participation for students was free, as the project was funded by partnerships and foundations. Promotion occurred in a variety ways including information packets, bumper stickers, and signs. There was a policy in place as a result of the program that allowed built in time for walking and running at various points throughout the school day. In order to determine the impact, survey data was compared with non-MK schools. The results showed that students at MK schools had higher levels of PA, higher FAV consumption, and higher athletic identities than students at non-MK schools. There were no differences in social support for PA, however parental social support for FAV consumption was higher for MK schools. There were no differences in social support for FAV consumption from peers or teachers. Furthermore, MK students had higher PA expectation outcomes and self-efficacy, but there were no significant differences in overweight/obesity.

Semi-structured interviews with adults with intellectual disabilities and their caregivers were used to determine the impact of a physical activity program that occurred 40 weeks out of the year for $60-90$ minutes per class (Lante, Walkley, Gamble, \& Vassos, 2011). Interviews lasted 30 minutes and were 
audio recorded and transcribed. The findings were that the program had short-term impacts, but there's no research on the long term. There were physical and psychosocial benefits, as well as a positive impact on fitness, calorie expenditure, and engagement in exercise. Despite a decrease in light physical activity and an increase in MVPA, participants still did not meet the daily recommendation. Furthermore, activity levels were decreased on days that the class was completed. There was some impact on participants, but this was not sustainable over time. The authors state the following as a limitation: this was a case report and there is a need for validation, multiple intervention groups, control groups, larger sample size, and random allocation.

The Wellingtonne Challenge was a before-after study involving $10 \%$ of the community (Lyle et al., 2008). The intervention lasted 12 weeks and utilized local partnerships and collaboration presented in a variety of formats including informational sessions and exercise circuits. Participants were invited through media advertisements. At baseline, there was a weigh-in and questionnaire. These measurements also occurred at the end of the intervention and 6 months post-intervention using a mixedmethods approach. Participants also provided self-reported data on FAV consumption and PA levels. Participants were asked about their likes and dislikes of the program, factors that encouraged or hindered their involvement, and suggestions for improvement. There were positive changes in diet and PA, despite not meeting the community goal for weight loss. Fifty-nine percent of participants had lost weight with more people walking for exercise and FAV consumption went up. Post-intervention participation was low $(23 \%)$, and there is a need for a more rigorous evaluation. The short-term effects on weight reduction were positive, but the long-term effects are unknown.

In Canada, data on the impact of a public bicycle sharing program were collected in Spring 2009, Fall 2009, and Fall 2010 (Fuller et al., 2013). The cross-sectional study used mixed methods using population-based sample telephone interviews. It was found that there was a greater likelihood of cycling for those exposed to the program after Fall 2010. Those exposed to the program were more likely to cycle than those with no exposure at all. Grim, Hortz, \& Petosa (2011) evaluated a 10-week web-based PA intervention for college students using a quasi-experimental study using three group pretest posttest 
design. The web-based group used social cognitive theory skill building and exercised 3 days a week. The PA group used exercise instruction and three PA labs a week. The comparison group only received health instruction. Data was collected on questionnaires. There were increases in vigorous PA, selfregulation, and outcome expectancy for intervention groups, however there were no significant differences in social support and self-efficacy. Researchers cited a small sample size and lack of randomization as limitations to the study.

Another impact evaluation was conducted on a 2-year community intervention focused on improving the health behaviors of low SES adults in the Netherlands (Kloek, van Lenthe, van Nierop, Koelen, \& Mackenback, 2006). The study was a quasi-experimental longitudinal cohort survey that used postal questionnaires. The focus was on FAV consumption and PA. There was no impact on vegetables or PA and there was a weak effect on fruit. When looking at knowledge and behaviors, knowledge positively increased, but behavior did not except for slightly on fruit consumption. Participants did however have an increased awareness of PA levels.

Heart and Soul was a church-based 12-week program involving African-American women that incorporated scripture, prayer, singing, and dancing (Peterson, 2011). The evaluation occurred though focus groups made up of 7 women who volunteered to do so. The data was audiotaped and transcribed, along with handwritten notes leading to a comparison of all three. The women were asked about experiences with PA as a child and adult, benefits of being physically active, challenges associated with PA, factors facilitating being physically active, support from family and friends, if family and friends supported or inhibited participation, and spiritual beliefs. The results were that they enjoyed PA as a child, but this decreased in their teens. As adults their focus was more on jobs and family. The participants suggested that the program incorporate strategies to help them manage multiple responsibilities, but still be active, and also strategies to help with social support and community resources. 


\section{References}

Abildso, C. G., Zizzi, S. J., \& Reger-Nash, B. (2010). Evaluating an insurance-sponsored weight management program with the RE-AIM model, west virginia, 2004-2008. Preventing Chronic Disease, 7(3), A46-A46.

American Alliance for Health, Physical Education, Recreation and Dance, National Association for Sport, and Physical Education. (2008). Comprehensive school physical activity programs. position statement.

American Alliance for Health, Physical Education, Recreation and Dance. (2011, November 15). Head start body start intervention has increased physical activity levels for more than 28,000 children. [Press Release].

Appalachia Educational Laboratory at Edvantia. (2005). Module 3--school-family-community connections. school improvement specialist training materials: Performance standards, improving schools, and literature review.

Armour, K., \& Sandford, R. (2013). Positive youth development through an outdoor physical activity programme: Evidence from a four-year evaluation. Educational Review, 65(1), 85-108. Retrieved from doi:10.1080/00131911.2011.648169

Association for supervision and curriculum development. (2011, September 20). Families and schools get engaged: A long road to a great marriage? [Web log post] from http://www.wholechildeducation.org/blog/families-and-schools-get-engaged-a-long-road-to-agreat-marriage.

Austin, G., Bell, T., Caperchione, C., \& Mummery, W. K. (2011). Translating research to practice: Using the RE-AIM framework to examine an evidence-based physical activity intervention in primary school settings. Health Promotion Practice, 12(6), 932-941. doi:10.1177/1524839910366101

Bartlett, M. L., \& Zizzi, S. J. (2010). A mixed-method evaluation of a college student fitness program using the RE-AIM framework. Fullerton; USA: Californian Journal of Health Promotion. 
Bassett, D. R., Erwin, P., Fitzhugh, E. C., Frederick, V., Wolff, D. L., Welch, W. A., \& Heath, G. W. (2013). Policies to increase youth physical activity in school and community settings. President's Council on Physical Fitness \& Sports Research Digest, 14(1), 1-10.

Beets, M. W., Bornstein, D., Dowda, M., \& Pate, R. R. (2011). Compliance with national guidelines for physical activity in U.S. preschoolers: Measurement and interpretation. Pediatrics, 127(4), 658664. doi:10.1542/peds.2010-2021

Bellows, L., Silvernail, S., Caldwell, L., Bryant, A., Kennedy, C., Davies, P., \& Anderson, J. (2011). Parental perception on the efficacy of a physical activity program for preschoolers. Journal of Community Health, 36(2), 231-237. doi:10.1007/s10900-010-9302-1

Besculides, M., Zaveri, H., Hanson, C., Earns, R., Gregory-Mercado, K., \& Will, J. (2008). Best practices in implementing lifestyle interventions in the WISEWOMAN program: Adaptable strategies for public health programs. American Journal of Health Promotion, 22(5), 322-328.

Byun, W., Dowda, M., \& Pate, R. R. (2011). Correlates of objectively measured sedentary behavior in US preschool children. Pediatrics, 128(5), 937-945. doi:10.1542/peds.2011-0748

California State Department of Education. (1973). Putting it together with parents: A guide to parent involvement in educational programs.

Cardon, G. M., Van Acker, R., Seghers, J., De Martelaer, K., Haerens, L. L., \& De Bourdeaudhuij, Ilse M. M. (2012). Physical activity promotion in schools: Which strategies do schools (not) implement and which socioecological factors are associated with implementation? Health Education Research, 27(3), 470-483. Retrieved from doi:10.1093/her/cys043

Carneiro, P., \& Ginja, R. (2014). Long-Term Impacts of Compensatory Preschool on Health and Behavior: Evidence from Head Start. American Economic Journal: Economic Policy, 6(4), 135173. doi:http://dx.doi.org.www.libproxy.wvu.edu/10.1257/pol.6.4.135

Castrechini, S., \& London, R. A. (2012). Positive student outcomes in community schools. 
Centeio, E. E., McCaughtry, N., Gutuskey, L., Garn, A. C., Somers, C., Shen, B., ... \& Kulik, N. L. (2014). Physical Activity Change Through Comprehensive School Physical Activity Programs in Urban Elementary Schools. JTPE, 33(4).

Chen, W., Mason, S. A., Hypnar, A. J., Zalmout, S., \& Hammond-Benett, A. (2014). Students' Daily Physical Activity Behaviors: The Role of Quality Physical Education in a Comprehensive School Physical Activity Program. Journal Of Teaching In Physical Education, 33(4), 592-610.

Cipriani, K., Richardson, C., \& Roberts, G. (2012). Family and community involvement in the comprehensive school physical activity program. Journal of Physical Education, Recreation \& Dance, 83(7), 20-26.

Davis, S. M., Sanders, S. G., FitzGerald, C. A., Keane, P. C., Canaca, G. F., \& Volker-Rector, R. (2013). CHILE: An Evidence-Based Preschool Intervention for Obesity Prevention in Head Start. Journal Of School Health, 83(3), 223-229. doi:10.1111/josh.12018

Derscheid, L. E., Umoren, J., Kim, S., Henry, B. W., \& Zittel, L. L. (2010). Early childhood teachers' and staff members' perceptions of nutrition and physical activity practices for preschoolers. Journal of Research in Childhood Education, 24(3), 248-265. doi:10.1080/02568543.2010.487405

Dowda, M., Brown, W. H., Mclver, K. L., Pfeiffer, K. A., O'Neill, J. R., Addy, C. L., \& Pate, R. R. (2009). Policies and characteristics of the preschool environment and physical activity of young children. Pediatrics, 123(2), e261-e266.

Dunn, C., Thomas, C., Pegram, L., Ward, D., \& Schmal, S. (2004). Color me healthy, preschoolers moving and eating healthfully. Journal of nutrition education and behavior, 36(6), 327-328.

Dunn, C., Thomas, C., Ward, D., Webber, K., Cullitan, C., Pegram, L., \& Webber, K. (2006). PEER REVIEWED: Design and Implementation of a Nutrition and Physical Activity Curriculum for Child Care Settings. Preventing chronic disease, 3(2).

Dunton, G. F., Lagloire, R., \& Robertson, T. (2009). Using the RE-AIM framework to evaluate the statewide dissemination of a school-based physical activity and nutrition curriculum: "exercise your options". American Journal of Health Promotion, 23(4), 229-232. 
Dunton, G. F., Liao, Y., Grana, R., Lagloire, R., Riggs, N., Chou, C., \& Robertson, T. (2012). State-wide dissemination of a school-based nutrition education programme: A RE-AIM (reach, efficacy, adoption, implementation, maintenance) analysis. Public Health Nutrition, , 1-9.

Elliott, R. (2005). Engaging families: Building strong communication. Early Childhood Australia, 12(2). Australia: Early Childhood Australia.

Epstein, J. L. (1995). School/family/community partnerships: Caring for the children we share. Phi Delta Kappan, 76(9), 701-712.

Epstein, J. L. (2008). Improving family and community involvement in secondary schools. Education Digest, 73(6), 9-12.

Epstein, J. L. (2001). School, family, and community partnerships: Preparing educators and improving schools. Westview Press, 5500 Central Avenue, Boulder, CO 80301.

Epstein, J. L., \& Sanders, M. G. (2006). Prospects for change: Preparing educators for school, family, and community partnerships. Peabody Journal of Education, 81(2), 81-120. doi:10.1207/S15327930pje8102_5

Erwin, H., Beets, M. W., Centeio, E., \& Morrow, J. J. (2014). Best practices and recommendations for increasing physical activity in youth. Journal Of Physical Education, Recreation \& Dance, 85(7), 27-34. doi:10.1080/07303084.2014.937197

Erwin, H., Beighle, A., Carson, R. L., \& Castelli, D. M. (2013). Comprehensive school-based physical activity promotion: A review. Quest, 65(4), 412-428. doi:10.1080/00336297.2013.791872

Estabrooks, P., Dzewaltowski, D. A., Glasgow, R. E., \& Klesges, L. M. (2003). Reporting of validity from school health promotion studies published in 12 leading journals, 1996-2000. Journal of School Health, 73(1), 21-28. doi:10.1111/j.1746-1561.2003.tb06554.x

Faber, L., Kulinna, P. H., \& Darst, P. (2007). Strategies for physical activity promotion beyond the physical education classroom. Journal of Physical Education, Recreation \& Dance. 78(9), 27-31.

Finn, K., Johannsen, N., \& Specker, B. (2002). Factors associated with physical activity in preschool children. The Journal of pediatrics, 140(1), 81-85. 
Ford, B. S., McDonald, T. E., Owens, A. S., \& Robinson, T. N. (2002). Primary care interventions to reduce television viewing in african-american children. American Journal of Preventive Medicine, 22(2), 106.

Freedson, P. S., \& Evenson, S. (1991). Familial aggregation in physical activity. Research Quarterly for Exercise \& Sport, 62(4), 384-389.

Fuller, D., Gauvin, L., Kestens, Y., Daniel, M., Fournier, M., Morency, P., \& Drouin, L. (2013). Impact evaluation of a public bicycle share program on cycling: A case example of BIXI in montreal, quebec. American Journal of Public Health, 103(3), e85-e92.

Gaglio, B., Shoup, J. A., \& Glasgow, R. E. (2013). The RE-AIM framework: A systematic review of use over time. American Journal of Public Health, 103(6), e38-e46

Glasgow, R. E., Vogt, T. M., \& Boles, S. M. (1999). Evaluating the public health impact of health promotion interventions: The RE-AIM framework. American Journal of Public Health, 89(9), $1322-1327$.

Gooze, R. A., Hughes, C. C., Finkelstein, D. M., \& Whitaker, R. C. (2010). Reaching staff, parents, and community partners to prevent childhood obesity in head start, 2008. Preventing Chronic Disease, 7(3), A54-A54.

Gooze, R. A., Hughes, C. C., Finkelstein, D. M., \& Whitaker, R. C. (2012). Obesity and food insecurity at the same table: How head start programs respond. Preventing Chronic Disease, 9, E132-E132.

Grim, M., Hortz, B., \& Petosa, R. (2011). Impact evaluation of a pilot web-based intervention to increase physical activity. American Journal of Health Promotion, 25(4), 227-230.

Hager, L., \& Beighle, A. (2006). Promoting physical activity through physical education: Increasing parental involvement. Teaching Elementary Physical Education, 17(1), 28-31.

Hall, T. J., Little, S., \& Heidorn, B. D. (2011). Preparing classroom teachers to meet students' physical activity needs. Journal of Physical Education, Recreation \& Dance, 82(3), 40-52. 
Harris, K. J., James, V., Henke, L., Fawcett, S. B., Johnston, J. A., Richter, K. P., . . Lewis, R. K. (1997). Community partnerships: Review of selected models and evaluation of two case studies. Journal of Nutrition Education, 29(4), 189-195.

Herbert, P., C., Lohrmann, D., K., Seo, D., Stright, A., D., \& Kolbe, L., J. (2013). Effectiveness of the energize elementary school program to improve diet and exercise. Journal of School Health, 83(11), 780-786. doi:10.1111/josh.12094

Hicks, L., Hancher-Rauch, H., \& Casselman, K. (2012). Using partnerships to promote health and physical education. JOPERD: The Journal of Physical Education, Recreation \& Dance, 83(7), 3945.

Hughes, C. C., Gooze, R. A., Finkelstein, D. M., \& Whitaker, R. C. (2010). Barriers to obesity prevention in head start. Health Affairs, 29(3), 454-462. doi:10.1377/hlthaff.2009.0499

Institute of Medicine. (2013). Educating the student body: Taking physical activity and physical education to school: Report brief. Washington, DC: The national academies press.

Jones, M.N. (2011, 15 June). Taking steps to healthy success: a childcare learning collaborative (CCLC) to promote healthy eating and physical activity (HEPA). [Powerpoint].

Joo, M. (2010). Long-term effects of head start on academic and school outcomes of children in persistent poverty: Girls vs. boys. Children and Youth Services Review, 32(6), 807-814.

Kann, L., Brener, N. D., \& Wechsler, H. (2007). Overview and summary: School health policies and programs study 2006. Journal of School Health, 77(8), 385-397.

Kirk, S. M., Vizcarra, C. R., Looney, E. C., \& Kirk, E. P. (2013). Using physical activity to teach academic content: A study of the effects on literacy in head start preschoolers. Early Childhood Education Journal, doi:10.1007/s10643-013-0596-3

Kloek, G. C., van Lenthe, F., van Nierop, P., Koelen, M. A., \& Mackenbach, J. P. (2006). Impact evaluation of a dutch community intervention to improve health-related behaviour in deprived neighbourhoods. Health \& Place, 12(4), 665-677. 
Krysiak, B. H. (2001). Full-service community schools: Jane addams meets john dewey. School Business Affairs, 67(8), 4-8.

Lante, K., A., Walkley, J., W., Gamble, M., \& Vassos, M., V. (2011). An initial evaluation of a longterm, sustainable, integrated community-based physical activity program for adults with intellectual disability. Journal of Intellectual \& Developmental Disability, 36(3), 197-206. doi: $10.3109 / 13668250.2011 .593163$

Lima, R. A., Barros, S. S. H., Cardoso Junior, C. G., Silva, G., Junior, F., Andersen, L. B., \& Barros, M. V. G. D. (2014). Influence of number of days and valid hours using accelerometry on the estimates of physical activity level in preschool children from Recife, Pernambuco, Brazil. Revista Brasileira de Cineantropometria \& Desempenho Humano, 16(2), 171-181.

Love, J. M., Kisker, E. E., Ross, C., Raikes, H., Constantine, J., Boller, K., . . Brady-Smith, C. (2005). The effectiveness of early head start for 3-year-old children and their parents: Lessons for policy and programs. Developmental Psychology, 41(6), 885.

Lyle, D., Hobba, J., Lloyd, K., Bennett, D., George, T., Giddings, N., . . Heading, G. (2008). Mobilising a rural community to lose weight: Impact evaluation of the WellingTonne challenge. Australian Journal of Rural Health, 16(2), 80-85.

Madey, D. L. (1982). Some benefits of integrating qualitative and quantitative methods in program evaluation, with illustrations. Educational Evaluation \& Policy Analysis, 4(2), 223-236.

Martin, M. W., Martin, S., \& Rosengard, P. (2010). PE2GO: Program evaluation of a physical activity program in elementary schools. Journal of Physical Activity \& Health, 7(5), 677-684.

Mathews, A. E., Werch, C., Michniewicz, M., \& Bian, H. (2007). An impact evaluation of two versions of a brief intervention targeting alcohol use and physical activity among adolescents. Journal of Drug Education, 37(4), 401-416.

Matsudo, S. M., Matsudo, V. K. R., Andrade, D. R., Araújo, T. L., \& Pratt, M. (2006). Evaluation of a physical activity promotion program: The example of agita são paulo. Evaluation \& Program Planning, 29(3), 301-311. doi:10.1016/j.evalprogplan.2005.12.006 
McDavid, L., Cox, A. E., \& Amorose, A. J. (2012). The relative roles of physical education teachers and parents in adolescents' leisure-time physical activity motivation and behavior. Psychology of Sport \& Exercise, 13(2), 99-107. doi:10.1016/j.psychsport.2011.10.003

McKee, M. D., Deen, D., Maher, S., Fletcher, J., Fornari, A., \& Blank, A. E. (2010). Implementation of a pilot primary care lifestyle change intervention for families of pre-school children: Lessons learned. Patient Education \& Counseling, 79(3), 299-305. doi:10.1016/j.pec.2010.02.025

Meij, J.S.B. (2010). Promoting physical activity in children: The stepwise development of the primary school-based JUMP-in intervention applying the RE-AIM evaluation framework. British Journal of Sports Medicine, 44(12), 879-887.

Michael, S., Dittus, P., \& Epstein, J. (2007). Family and community involvement in schools: Results from the school health policies and programs study 2006. Journal of School Health, 77(8), 567-587. doi:10.1111/j.1746-1561.2007.00236.x

Michael, S., Dittus, P., \& Epstein, J. (2007). Family and community involvement in schools: Results from the school health policies and programs study 2006. Journal of School Health, 77(8), 567-587. doi:10.1111/j.1746-1561.2007.00236.x

Moore, L. L., Lombardi, D. A., White, M. J., Campbell, J. L., Oliveria, S. A., \& Ellison, R. C. (1991). Influence of parents' physical activity levels on activity levels of young children. Journal of Pediatrics, 118, 215-219.

Nader, P. R., Sellers, D. E., Johnson, C. C., Perry, C. L., Stone, E. J., Cook, K. C., . . Luepker, R. V. (1996). The effect of adult participation in a school-based family intervention to improve children's diet and physical activity: The child and adolescent trial for cardiovascular health. Preventive Medicine, 25(4), 455-464.

National Center on Quality Teaching and Learning. (2014). Use of Classroom Assessment Scoring System (CLASS) in Head Start. Retrieved from http://eclkc.ohs.acf.hhs.gov/hslc/sr/quality/class 
National Early Care and Education Learning Collaborative. About the National ECELC Project [Webpage]. Retrieved from http://www.healthykidshealthyfuture.org/home/collaborate/ecelcproject/about.html

National Early Care and Education Learning Collaborative. Learning session one: why should we change? Taking steps to Healthy Success: ECELC [Powerpoint]. Retrieved from National Early Care and Education Learning Collaborative

Nigg, C., Geller, K., Adams, P., Hamada, M., Hwang, P., \& Chung, R. (2012). Successful dissemination of fun 5 - a physical activity and nutrition program for children. Translational Behavioral Medicine, 2(3), 276-285. doi:10.1007/s13142-012-0120-0

Ogden, C. L., Carroll, M. D., Kit, B. K., \& Flegal, K. M. (2014). Prevalence of Childhood and Adult Obesity in the United States, 2011-2012. JAMA, 311(8), 806-814.

O’Connor, T. M., Jago, R., \& Baranowski, T. (2009). Engaging parents to increase youth physical activity: A systematic review. American Journal of Preventive Medicine, 37(2), 141-149. doi:10.1016/j.amepre.2009.04.020

O'Dwyer, M., Fairclough, S. J., Ridgers, N. D., Knowles, Z. R., Foweather, L., \& Stratton, G. (2014). Patterns of Objectively Measured Moderate-to-Vigorous Physical Activity in Preschool Children. Journal Of Physical Activity \& Health, 11(6), 1233-1238.

Ornelas, I. J., Perreira, K. M., \& Ayala, G. X. (2007). Parental influences on adolescent physical activity: A longitudinal study. International Journal of Behavioral Nutrition \& Physical Activity, 4, 3-10. doi:10.1186/1479-5868-4-3

Parker, F. L., Piotrkowski, C. S., Kessler-Sklar, S., Baker, A. J., Peay, L., \& Clark, B. (1997). The Impact of Parent Involvement in Head Start on Parents and Children. Final Report [and] Executive Summary.

Pate, R. (2001). Assessment of physical activity and sedentary behavior in preschool children: Priorities for research. Pediatric Exercise Science, 13(2), 129-130. 
Pate, R. R., Dowda, M., Brown, W. H., Mitchell, J., \& Addy, C. (2013). Physical activity in preschool children with the transition to outdoors. Journal of Physical Activity \& Health, 10(2), 170-175.

Pate, R. R., McIver, K., Dowda, M., Brown, W. H., \& Addy, C. (2008). Directly observed physical activity levels in preschool children. Journal of School Health, 78(8), 438-444.

Pate, R. R., O'Neill, J. R., Brown, W. H., McIver, K. L., Howie, E. K., \& Dowda, M. (2013). Top 10 Research Questions Related to Physical Activity in Preschool Children. Research Quarterly for Exercise and Sport, 84(4), 448-455.

Pate, R. R., O'Neill, J. R., Byun, W., McIver, K. L., Dowda, M., \& Brown, W. H. (2014). Physical Activity in Preschool Children: Comparison Between Montessori and Traditional Preschools. Journal of School Health, 84(11), 716-721.

Pate, R. R., O'Neill, J. R., \& Mitchell, J. (2010). Measurement of physical activity in preschool children. Medicine \& Science in Sports \& Exercise, 42(3), 508-512

Pate, R. R., \& O'Neill, J.,R. (2012). Physical activity guidelines for young children: An emerging consensus. Archives of Pediatrics \& Adolescent Medicine, 166(12), 1095-1096. doi:10.1001/archpediatrics.2012.1458

Pate, R. R., Pfeiffer, K. A., Trost, S. G., Ziegler, P., \& Dowda, M. (2004). Physical activity among children attending preschools. Pediatrics, 114(5), 1258-1263. doi:10.1542/peds.2003-1088-L

Peterson, J., A. (2011). Evaluation of the heart and soul physical activity program by african american women. ABNF Journal, 22(3), 64-72

Pfeiffer, K. A., Dowda, M., McIver, K. L., \& Pate, R. R. (2007). Factors related to daily physical activity in preschool children. Acta Kinesiologiae Universitatis Tartuensis, 12, 152-153.

Pfeiffer, K. A., Dowda, M., McIver, K. L., \& Pate, R. R. (2009). Factors related to objectively measured physical activity in preschool children. Pediatric Exercise Science, 21(2), 196-208.

Pfeiffer, K. A., Saunders, R. P., Brown, W. H., Dowda, M., Addy, C. L., \& Pate, R. R. (2013). Study of health and activity in preschool environments (SHAPES): Study protocol for a randomized trial 
evaluating a multi-component physical activity intervention in preschool children. BMC Public Health, 13, 728-728. doi:10.1186/1471-2458-13-728

Puma, M., Bell, S., Cook, R., Heid, C., Shapiro, G., Broene, P., ... \& Spier, E. (2010). Head Start Impact Study. Final Report. Administration for Children \& Families.

Ransdell, L. B., Eastep, E., Taylor, A., Oakland, D., Schmidt, J., Moyer-Mileur, L., \& Shultz, B. (2003). Daughters and mothers exercising together (DAMET): Effects of home- and university-based interventions on physical activity behavior and family relations. American Journal of Health Education, 34(1), 19-29.

Richardson, J. A., Richardson, M. V., \& Sacks, M. K. (2006). Families and school personnel involved in a literacy and physical activity partnership. Reading Improvement, 43(3), 129-135.

Robert Wood Johnson Foundation. (2011). Preventing obesity among preschool children: How can childcare settings promote healthy eating and physical activity? research synthesis.

Robinson, T. N. (1999). Reducing children's television viewing to prevent obesity. JAMA: Journal of the American Medical Association, 282(16), 1561.

Salazar, G., Vasquez, F., Concha, F., del Pilar Rodriguez, M., del Rocio Berlanga, M., Rojas, J., \& ... Andrade, M. (2014). Pilot nutrition and physical activity intervention for preschool children attending daycare centres (JUNJ); primary and secondary outcomes. Nutricion Hospitalaria, 29(5), 1004-1012. doi:10.3305/nh.2014.29.5.7316

Sallis, J. F., Alcaraz, J. E., McKenzie, T. L., Hovell, M. F., Kolody, B., \& Nader, P. R. (1992). Parental behavior in relation to physical activity and fitness in 9-year-old children. American Journal of Diseases of Children, 146(4), 1383-1388.

Sallis, J. F., Patterson, T. L., McKenzie, T. L., \& Nader, P. R. (1988). Family variables and physical activity in preschool children. Journal of Developmental \& Behavioral Pediatrics, 9(2), 57-61.

Sanders, M. G. (2001). The role of 'community' in comprehensive school, family, and community partnership programs. Elementary School Journal, 102(1). 
Sanders, M. G. (2003). Community involvement in schools: From concept to practice. Education and Urban Society, 35(2), 161-80.

Shaul, M. S. (2001). Early Childhood Programs: The Use of Impact Evaluations To Assess Program Effects. Report to the Chairman, Subcommittee on Oversight of Government Management, Restructuring and the District of Columbia, Committee on Governmental Affairs, US Senate.

Sherwood-Puzzello, C., Miller, M., Lohrmann, D., \& Gregory, P. (2007). Implementation of CDC's school health index in 3 midwest middle schools: Motivation for change. Journal of School Health, 77(6), 285-293.

Silva-Sanigorski, A., Bell, A. C., Kremer, P., Park, J., Demajo, L., Smith, M., . . S Swinburn, B. (2012). Process and impact evaluation of the romp \& chomp obesity prevention intervention in early childhood settings: Lessons learned from implementation in preschools and long day care settings. Childhood Obesity, 8(3), 205-215.

Soini, A., Watt, A., Tammelin, T., Soini, M., Sääkslahti, A., \& Poskiparta, M. (2014). Comparing the physical activity patterns of 3-year-old Finnish and Australian children during childcare and homecare days. Baltic Journal of Health and Physical Activity, 6(3), 171-182.

Springer, A. E., Kelder, S. H., Ranjit, N., Hochberg-Garrett, H., Crow, S., \& Delk, J. (2012). Promoting physical activity and fruit and vegetable consumption through a community-school partnership: The effects of marathon kids on low-income elementary school children in texas. Journal of Physical Activity \& Health, 9(5), 739-753.

Story, M., Kaphingst, K. M., \& French, S. (2006). The role of child care settings in obesity prevention. Future of Children, 16(1), 143-168.

Subramaniam, P. R. (2011). A holistic approach to promoting physical activity among school-age children. Strategies: A Journal for Physical and Sport Educators, 25(1), 23-25.

Taggart, A. C., Taggart, J., \& Siedentop, D. (1986). Effects of a home-based activity program. A study with low fitness elementary school children. Behavior Modification, 10(4), 487-507. 
Thomas, J. C. (1994). Program evaluation and program development. Herman, R. The Jossey-Bass Handbook of Nonprofit Leadership and Management, San Francisco: Jossey-Bass Publishers, $342-366$.

Trost, S. G., Sirard, J. R., Dowda, M., Pfeiffer, K. A., \& Pate, R. R. (2003). Physical activity in overweight and nonoverweight preschool children. International Journal of Obesity \& Related Metabolic Disorders, 27(7), 834.

U.S. Department of Health and Human Services, Administration for Children and Families. (2006). I am moving, I am learning: a proactive approach for addressing childhood obesity in Head Start Children

U.S. Department of Health and Human Services, Administration for Children and Families (2010). Efforts to meet children's physical activity and nutritional needs: findings for the I am moving, I am learning implementation evaluation.

U.S. Department of Health and Human Services, Administration for Children and Families (2009). Report to congress on head start efforts to prevent and reduce obesity in children.

U.S. Department of Health and Human Services, Centers for Disease Control and Prevention. (2000). School health index for physical activity and healthy eating: A self-assessment and planning guide. middle School/High school.

U.S. Department of Health and Human Services, Centers for Disease Control and Prevention. (2011). School health guidelines to promote healthy eating and physical activity: Executive summary.

U.S. Department of Health and Human Services, Centers for Disease Control and Prevention. (2012). Parent engagement: Strategies for involving parents in school health. Atlanta, GA.

U.S. Department of Health and Human Services. (2008). Physical activity guidelines for Americans. Washington DC.

Van Acker, R., De Bourdeaudhuij, I., De Cocker, K., Klesges, L. M., \& Cardon, G. (2011). The impact of disseminating the whole-community project '10,000 steps': A RE-AIM analysis. BMC Public Health, 11(1), 1-11. doi:10.1186/1471-2458-11-3 
Vidoni, C., \& Ignico, A. (2011). Promoting physical activity during early childhood. Early Child Development \& Care, 181(9), 1261-1269. doi:10.1080/03004430.2010.523786

Virgilio, S. J. (1990). A model for parental involvement in physical education. Journal of Physical Education, Recreation and Dance, 61(8), 66-70.

Virgilio, S. J. (1998). Promoting healthy lifestyles with schoolwide events. Teaching Elementary Physical Education, 9(1), 5-8.

Welk, G. J., Wood, K., \& Morss, G. (2003). Parental influences on physical activity in children: An exploration of potential mechanisms. Pediatric Exercise Science, 15(1), 19-33.

Whitaker, R. C., Becker, B. D., Herman, A. N., \& Gooze, R. A. (2013). The physical and mental health of head start staff: The pennsylvania head start staff wellness survey, 2012. Preventing Chronic Disease, 10, E181-E181. doi:10.5888/pcd10.130171

Whitaker, R. C., Gooze, R. A., Hughes, C. C., \& Finkelstein, D. M. (2009). A national survey of obesity prevention practices in head start. Archives of Pediatrics \& Adolescent Medicine, 163(12), 11441150. doi:10.1001/archpediatrics.2009.209

Winkler, G., Noller, B., Waibel, S., \& Wiest, M. (2005). BeKi--an initiative for nutrition education in childrenin the federal state of baden-württemberg: Description, experiences, and considerations for an evaluation framework. Sozial- Und Präventivmedizin, 50(3), 151-160. 


\section{Appendix B}

\section{Agency Administrator Survey Cover Letter}

[WVU CPASS Letterhead]

Dear

You are invited to participate in a research study being conducted to determine how I am Moving, I am Learning (IMIL), also known as Choosy, has made an impact on families and the surrounding community and how centers are using IMIL to make an impact. The study has been reviewed and acknowledged by the Institutional Review Board at West Virginia University. This project is being conducted by doctoral candidate, Ishonté Allar, with supervision of Dr. Sean Bulger, associate professor in the College of Physical Activity and Sport Sciences in partial fulfillment of the requirements for a degree of Doctor of Philosophy in Kinesiology.

The enclosed survey will be used to determine how many centers are using IMIL and how they are using it in the state of Illinois. Your participation in this project is greatly appreciated and it will take approximately 5-10 minutes to fill out the attached survey.

Your participation in this research is completely voluntary. There are no known risks to participation. You may skip any question that you do not wish to answer and you may discontinue at any time. Your responses will be confidential and data from the research will only be reported as combined totals. No one other than the researcher will know your individual answers.

If you agree to participate in the questionnaire, you will be entered in a drawing for one of three $\$ 25$ Lakeshore gift cards. Please complete survey at your earliest convenience but by August 1 to be entered in the drawing. The drawing will take place early August and winners will be notified by mid-August.

Online: Please go to the following link to complete the survey: http://wvu.qualtrics.com/SE/?SID=SV_2hs39iBV1zuo4zH

Mail: Please return the survey as soon as possible in the enclosed prepaid envelope that has been provided.

If you have any questions about this project, please feel free to contact Ishonte' Allar at 304-266-1331 or ijohnso1@mix.wvu.edu. A summary of the findings will be sent at the conclusion of the study.

Thank you in advance for your assistance in this important endeavor,

Ishonte' Allar

Ph.D. Candidate 


\title{
Appendix C
}

\section{Classroom Teacher Survey Cover Letter}

\author{
[WVU CPASS Letterhead]
}

Dear

You are invited to participate in a research study being conducted to determine how I am Moving, I am Learning (IMIL), also known as Choosy, has made an impact on families and the surrounding community and how centers are using IMIL to make an impact. The study has been reviewed and acknowledged by the Institutional Review Board at West Virginia University. This project is being conducted by doctoral candidate, Ishonté Allar, with supervision of Dr. Sean Bulger, associate professor in the College of Physical Activity and Sport Sciences in partial fulfillment of the requirements for a degree of Doctor of Philosophy in Kinesiology.

Your participation in this research is completely voluntary. There are no known risks to participation. You may skip any question that you do not wish to answer and you may discontinue at any time. Your responses will be confidential and data from the research will only be reported as combined totals. No one other than the researcher will know your individual answers. The questionnaire takes approximately 10-15 minutes to complete.

If you agree to participate in the questionnaire, you will be entered in a drawing for one of three $\$ 25$ Lakeshore gift cards.

Online: Please go to the following link to complete the questionnaire: http://wvu.qualtrics.com/SE/?SID=SV_d43qZt6YzT6YaUt

Mail: Please return the questionnaire as soon as possible in the enclosed prepaid envelope that has been provided.

If you have any questions about this project, please feel free to contact Ishonte' Allar at 304-266-1331 or ijohnso1@mix.wvu.edu. A summary of the findings will be sent at the conclusion of the study.

Thank you in advance for your assistance in this important endeavor,

Ishonte' Allar

Ph.D. Candidate 


\title{
Appendix D
}

\section{Parent Survey Cover Letter}

\author{
[WVU CPASS Letterhead]
}

Dear Parents,

You are invited to participate in a research study being conducted to determine how I am Moving, I am Learning (IMIL), also known as Choosy, has made an impact on families and the surrounding community and how centers are using IMIL to make an impact. The study has been reviewed and acknowledged by the Institutional Review Board at West Virginia University. This project is being conducted by doctoral candidate, Ishonté Allar, with supervision of Dr. Sean Bulger, associate professor in the College of Physical Activity and Sport Sciences in partial fulfillment of the requirements for a degree of Doctor of Philosophy in Kinesiology.

Your participation in the survey is completely voluntary. There are no known risks to participation. You may skip any question that you do not wish to answer and you may discontinue at any time. Your responses will be confidential. No one other than the researcher will know your individual answers. The survey takes approximately 10-15 minutes to complete.

If you agree to participate in the survey and complete it by Thursday, May 29, you will be entered in a drawing for one of sixteen $\$ 25$ Target gift cards.

Please go to the following link to complete the survey by Thursday, May 29:

http://wvu.qualtrics.com/SE/?SID=SV 5B8UmObZLgiF3gN

If you do not have access to the internet, please fill out the paper version and return to your child's teacher in this sealed envelope by Thursday, May 29.

If you have any questions about this project, please feel free to contact Ishonte' Allar at 304-266-1331 or ijohnso1@mix.wvu.edu. A summary of the findings will be sent at the conclusion of the study.

Thank you in advance for your assistance in this important matter,

Ishonte' Allar

Ph.D. Candidate 


\section{Appendix E}

\section{Focus Group Protocol}

Hi, my name is Ishonte' Allar. Thank you so much for taking the time to participate in this interview. I'm a Doctoral student in the College of Physical Activity and Sport Sciences at West Virginia University. As part of my dissertation, I am studying the impact that I am Moving, I am Learning has had on families and communities. I cannot do this without the perspective of the teachers themselves. By participating in this research you will help me capture and understand this impact. Your participation is completely voluntary and no personal information will be collected. In gratitude for your time, you will be compensated with Choosy classroom resources. Do you have any questions before we begin?

1. Please describe the strategies you use to educate parents about nutrition and physical activity. (Adoption)

a. Do you use IMIL to educate parents? If so, please describe which IMIL resources are most helpful? Least helpful?

b. If you do not use IMIL, please describe why not.

2. What strategies do you use to communicate with parents? For instance, do you use newsletters, e-email, workshops, etc.? If so, please describe (or others). (Adoption)

a. Do you use the IMIL (Choosy) resources to help you communicate with parents? If so, what resources have been most helpful? Least helpful?

3. Describe the level of involvement of your parents and community volunteers in using IMIL (Choosy)? Is there anything you would like to change about their level of involvement? (Effectiveness, Maintenance)

a. What about their involvement in your classrooms? Is there anything you would like to change about their level of involvement?

b. What about their involvement at events? Is there anything you would like to change about their level of involvement?

4. What strategies have you found effective in supporting the children's learning at home? Do you use any of the following strategies? If so, how effective do you believe they are?

(Adoption, Implementation)

a. Do you use IMIL (Choosy)?

b. PA topics?

c. Nutrition topics?

d. learning activities

e. "Homework"

5. In what ways are parents involved in decision making and advocacy regarding their child's health? For instance, is there a parent advisory board at your school?

a. Have you / Do you use the IMIL (Choosy) resources to help with this? (Implementation)

6. Are you aware of any positive changes that families have made related to physical activity or nutrition as a result of your program? (Maintenance)

7. Are there existing partnerships or collaborations with the community regarding:

a. IMIL (Choosy)? 
b. Physical activity?

c. Nutrition?

d. i.e. events like health fairs, etc. (Implementation)

8. Have you used any strategies aimed at impacting the health behaviors of community members? If so, please describe. (Adoption)

a. Have you used any of the IMIL (Choosy) resources to accomplish this?

9. What have been the biggest barriers of getting families and communities involved within in the center and at events? (Maintenance)

10. What have been the biggest barriers or challenges using IMIL (Choosy)? (Maintenance)

11. In what ways, if any, has IMIL (Choosy) helped you meet class dimensions in emotional support? Please describe.

12. In what ways, if any, has IMIL (Choosy) helped you to meet class dimensions in classroom organization? Please describe.

13. In what ways, if any, has IMIL (Choosy) helped you meet class dimensions in instructional support?

14. Do you have anything additional positive or negative experiences you have had using IMIL (Choosy)? 


\section{Appendix F}

\section{Rock Island/Milan Public Schools - Early Childhood Programs \\ Head Start, Preschool for All, SKIP, \& EDR \\ Superintendent, Michael Oberhaus, Ed.D}

Nicole Berry

Director - Early Childhood Programs
Excellence Every Day $353038^{\text {th }}$ Avenue

Rock Island, IL 61201

(309) 793-5928

March 25, 2014

Dear Sir or Madam:

It is with great pleasure that I am writing this letter in support of Ishonte' Allar to conduct her dissertation research with the Rock Island, Illinois Head Start program.

Childhood obesity has become a concern nationally. Head Start is dedicated to help in the fight to prevent childhood obesity. Rock Island Head Start has been using I am Moving, I am Learning (IMIL), a program that focuses on teaching children healthy behaviors, such as healthy eating and physical activity for nearly ten years. Our teaching staff intentionally plan movement and nutrition activities on a daily basis in an effort to educate both children and families on the benefits of living a healthier lifestyle.

I would welcome the opportunity to collaborate with Mrs. Allar. She would be visiting our classrooms to observe firsthand how Rock Island Head Start has incorporated IMIL throughout their day. She will have the opportunity to meet with focus groups consisting of teaching staff. She will also be able to conduct phone interviews with parents to collect information and assess the impact IMIL has made.

I believe that Mrs. Allar's research will be beneficial in providing insight on how IMIL can be used by programs to meet Head Start goals and also how it can make an impact on the healthy behaviors of both children and their families.

\footnotetext{
Sincerely,

Marilyo arp

Marilyn Arp

Education Manager

Rock Island Head Start

$353038^{\text {th }}$ Avenue

Rock Island, IL 61265

(309)793-5928 X7573
} 
Choosy Kids, LLC

3160 Collins Ferry Road

Morgantown, WV 26505

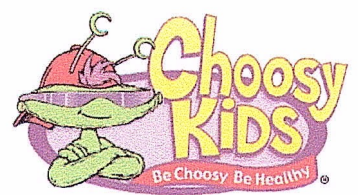

Phone: 304-777-4541

Fax: $\quad 304-777-4543$

Web: choosykids.com

April 21, 2014

Ishonte Allar

530 Wisconsin Avenue

Westover, WV 26501

Dear Ishonte,

On behalf of Choosy Kids LLC, I am pleased to support your research project which will study how I Am Moving I Am Learning (IMIL) is being used by Head Start programs to engage families and communities. I am particularly pleased that you have selected the Rock Island/Milan program in Illinois as your research site. We, at Choosy Kids are well aware of the exemplary dedication and commitment of the staff at Rock Island. They are a fine example of how Head Start programs effectively serve children and their families. You have made a wise choice for your project and a new set of professional colleagues in Illinois.

Because Choosy Kids provided initial training for IMIL not only in Illinois, but in all states, we will commit to supporting your project in two ways:

1. Choosy Kids will provide you with consultation about IMIL and Head Start

2. Choosy Kids will provide you with a $\$ 250$ Choosy gift card for Choosy products and resources to be selected by your project participants in the 18 classrooms in Rock Island/Milan Head Start program.

We wish you the best of luck with this research project. Choosy Kids is proud to continue its support of new knowledge regarding family engagement in healthrelated efforts designed to enhance the well-being of young children and the entire family.

Sincerely,

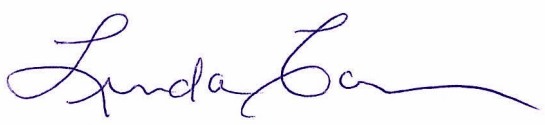

Linda Carson, Ed D

CEO, Choosy Kids

Ware Distinguished Professor Emerita, WVU 


\section{Appendix G}

\section{Biographical Sketch}

May 2015

Name: Ishonté Allar

Title: Doctoral Candidate, Kinesiology-PETE, CPASS-WVU

\begin{tabular}{|c|c|c|c|}
\hline Institution \& Location & Degree & Year Conferred & Field of Study \\
\hline West Virginia University, Morgantown, WV & B.S. & 2007 & $\begin{array}{l}\text { Major: Physical Education } \\
\text { Teacher Education } \\
\text { Concentration: Physical } \\
\text { Education Pre-K-adult, Health } \\
5-12 \\
\text { Minor: Sport and Exercise } \\
\text { Psychology } \\
\text { Certificate: Athletic Coaching } \\
\text { Education }\end{array}$ \\
\hline West Virginia University, Morgantown, WV & B.A. & 2008 & Spanish 5-12 \\
\hline West Virginia University, Morgantown, WV & M.A. & 2009 & $\begin{array}{l}\text { Secondary Education } \\
\text { Concentration: Spanish }\end{array}$ \\
\hline West Virginia University, Morgantown, WV & $\mathrm{MPH}$ & 2013 & Public Health-Generalist \\
\hline West Virginia University, Morgantown, WV & Ph.D. & $\begin{array}{l}\text { Anticipated graduation } \\
2015\end{array}$ & $\begin{array}{l}\text { Kinesiology-Physical } \\
\text { Education Teacher Education }\end{array}$ \\
\hline
\end{tabular}

Personal Statement: As a doctoral student in the College of Physical Activity and Sport Sciences at West Virginia University, I have assisted with county initiatives to improve physical activity participation and healthy living in children, adolescents, and families. My long-term goal is to change the negative status of West Virginia's health. Being a native of the state, I am invested in making our state healthier as a whole. This includes community-based research and community programs that increase physical activity for whole families.

\section{Professional Membership:}

Certified ASEP Coach- lifetime

NASPE Physical Best Certified- Spring 2007- present

Phi Epsilon Kappa- Physical Education Honor Fraternity Fall 2006-Spring 2008

Sigma Delta Pi- Spanish Honor Fraternity, Fall 2006-Fall 2008

WVAHPERD 2013-present 


\section{Honors/Awards:}

WVAHPERD Ethnic Minority Graduate Fellowship Award, 2013

W.E.B. DuBois Fellowship, West Virginia University 2013-present

Patricia K. Fehl Scholarship, West Virginia University 2013-present

Roger Alford Memorial Scholarship, West Virginia University 2006-2007

Big East Academic All-Star 2004-2007, graduated Magna Cum Laude 2008, athletic scholarship 2004-2007, Dean's List, 2003-2008

Athletic Director's Honor Roll 2004-2008

\section{Select Peer-reviewed Publications:}

- Allar, I., Baek, J. H., \& Taliaferro, A. (2014). Addressing Inclusion in Higher Education Physical Activity Programs. Journal of Physical Education, Recreation and Dance, 85(9), 36-41.

- Jones, E. M., Taliaferro, A. R., Elliott, E., Bulger, S. M., Kristjansson, A. L., Neal, W., \& Allar, I. (2014). Feasibility Study of Comprehensive School Physical Activity Programs in Appalachian Communities: The McDowell CHOICES Project. JTPE, 33(4).

\section{Ongoing Research Support:}

- Elliott, E, Bulger, S., Jones, E., Neal, W. Kristjansson, A., Taliaferro, A., Allar, I. Highmark Foundation. McDowell CHOICES. Planning Grant, \$75,000. Implementation Grant, \$204,000 (2012-2014)

- Allar, I., Elliott, E., Acosta, N. BOKS Activation Grant, \$6,000 (\$1,000 per school) McDowell County Schools-Fall River Elementary School, Sandy River Middle School, Southside K-8 School, Bradshaw Elementary School, Iaeger Elementary School, Anawalt Elementary School

\section{Selected Presentations:}

- Mapping Physical Activity Assets in McDowell County, West Virginia- Presenter

West Virginia University School of Public Health Public Health Practicum, August 6, 2013

Meeting with High Mark Foundation regarding funding for the McDowell CHOICES project, August 14, 2013

- The Colloquium for Aspiring Minority Doctoral Candidates Discussion Panel Member October 11,2013

- Asset Mapping in Rural Appalachia: Connecting Schools, Families, and Communities to Promote Physical Activity- Co-presenter, Poster session Appalachian Studies Association Annual Conference, Huntington, WV, Friday, March 28

- Feasibility Study of Comprehensive School Physical Activity in Appalachian Communities. American Alliance for Health, Physical Education, Recreation, and Dance. St. Louis, MO April 4, 2014

- Effective Supervision and Feedback Provision. Slippery Rock University. National Student Teaching and Supervision Conference Co-presenter, lecture April 14, 2014 